\title{
Proposal for the revision of the Background Questionnaire on education and training for the 2nd cycle of PIAAC
}

Citation for published version (APA):

Allen, J., Massing, N., Schneider, S., \& van der Velden, R. (2017). Proposal for the revision of the Background Questionnaire on education and training for the 2nd cycle of PIAAC. ROA. ROA Technical Reports No. 001 https://doi.org/10.26481/umarot.2017001

Document status and date:

Published: 01/01/2017

DOI:

10.26481/umarot.2017001

Document Version:

Publisher's PDF, also known as Version of record

Please check the document version of this publication:

- A submitted manuscript is the version of the article upon submission and before peer-review. There can be important differences between the submitted version and the official published version of record.

People interested in the research are advised to contact the author for the final version of the publication, or visit the DOI to the publisher's website.

- The final author version and the galley proof are versions of the publication after peer review.

- The final published version features the final layout of the paper including the volume, issue and page numbers.

Link to publication

\footnotetext{
General rights rights.

- You may freely distribute the URL identifying the publication in the public portal. please follow below link for the End User Agreement:

www.umlib.nl/taverne-license

Take down policy

If you believe that this document breaches copyright please contact us at:

repository@maastrichtuniversity.nl

providing details and we will investigate your claim.
}

Copyright and moral rights for the publications made accessible in the public portal are retained by the authors and/or other copyright owners and it is a condition of accessing publications that users recognise and abide by the legal requirements associated with these

- Users may download and print one copy of any publication from the public portal for the purpose of private study or research.

- You may not further distribute the material or use it for any profit-making activity or commercial gain

If the publication is distributed under the terms of Article 25fa of the Dutch Copyright Act, indicated by the "Taverne" license above, 


\title{
Proposal for the revision of the Background Questionnaire on education and training for the 2nd cycle of PIAAC
}

\author{
Jim Allen (ROA) \\ Natascha Massing (GESIS) \\ Silke Schneider (GESIS) \\ Rolf van der Velden (ROA)
}

\section{ROA Technical Report}

ROA-TR-2017/1

Researchcentrum voor Onderwijs en Arbeidsmarkt | ROA

Research Centre for Education and the Labour Market | ROA 


\title{
Proposal for the revision of the Background Questionnaire on education and training for the 2nd cycle of PIAAC
}

\author{
Jim Allen (ROA) \\ Natascha Massing (GESIS) \\ Silke Schneider (GESIS) \\ Rolf van der Velden (ROA)
}

ROA-TR-2017/1

April 2017

Research Centre for Education and the Labour Market Maastricht University

P.O. Box 616, 6200 MD Maastricht, The Netherlands

$\mathrm{T}+31433883647 \mathrm{~F}+31433884914$

secretary-roa-sbe@maastrichtuniversity.nl www.roa.nl 


\section{Content}

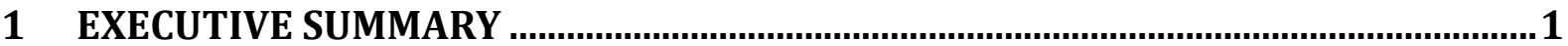

2 CONCEPTUAL BACKGROUND AND RATIONALE FOR OPERATIONALIZATION .....5

$2.1 \quad$ Educational attainment

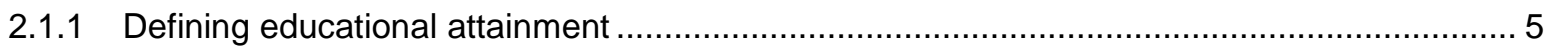

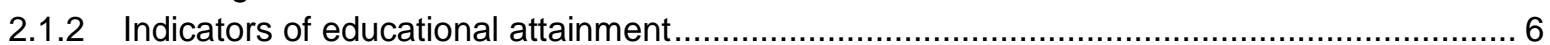

2.1.3 Theoretical framework and implications for measurement.............................................. 7

2.1.4 Challenges in the cross-national survey measurement of educational attainment ................ 9

2.1.5 Methodological developments in education measurement during/since PIAAC Cycle 1 $\ldots . . .11$

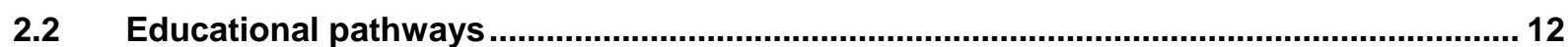

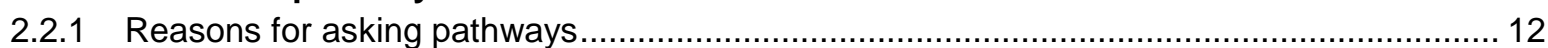

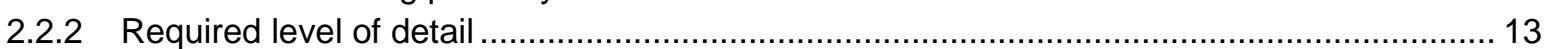

2.3 Measuring non-formal and informal learning opportunities .......................................... 15

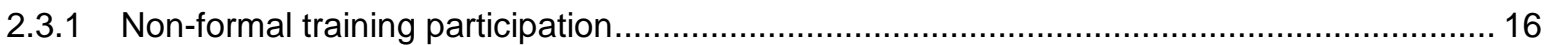

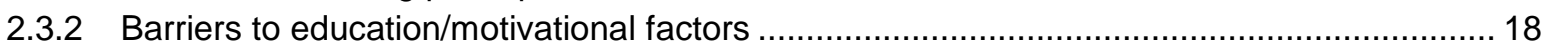

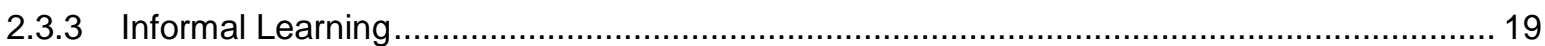

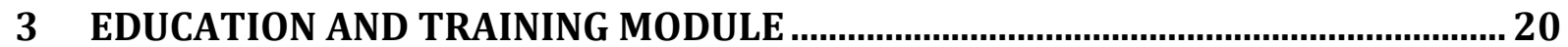

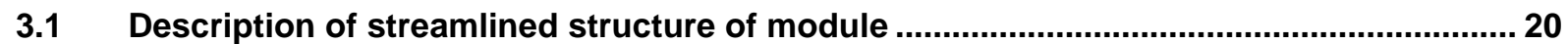

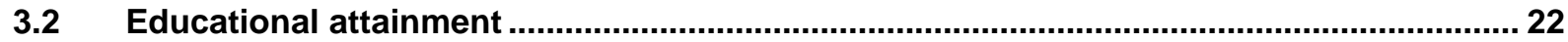

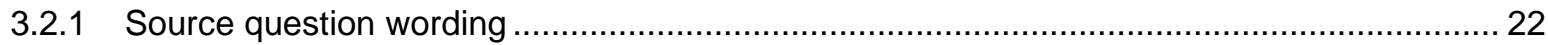

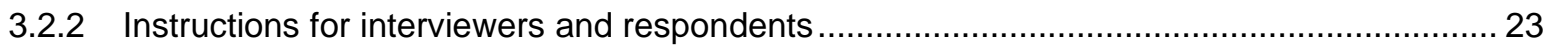

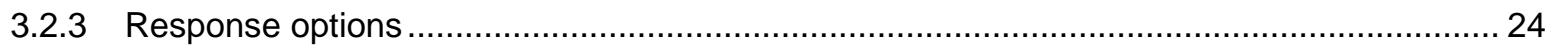

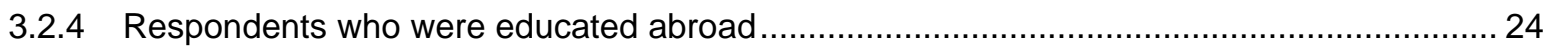

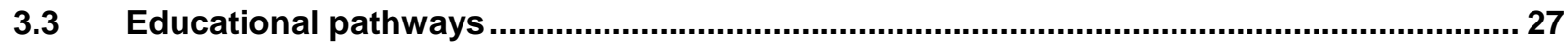

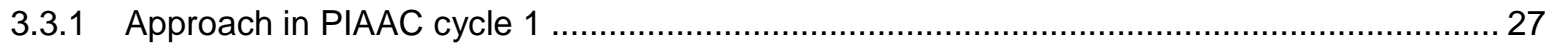

3.3.2 Proposed approach for measuring educational pathways in PIAAC cycle 2 ....................... 28

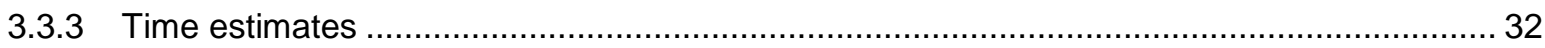

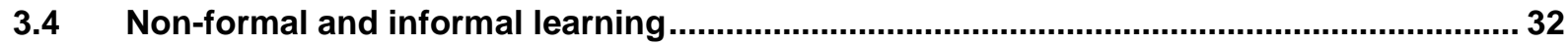

\section{IMPLEMENTATION AND GUIDELINES FOR ADAPTATIONS AND}

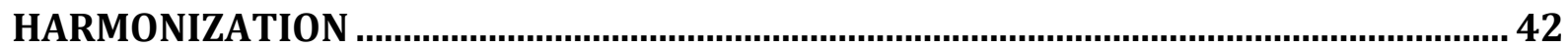

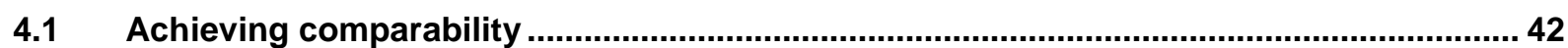

4.2 Educational attainment

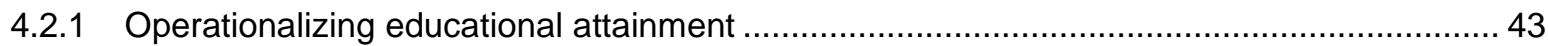

4.2.2 Choice of ISCED coding scheme and other target variables ........................................... 43

4.2.3 Guideline for development of country-specific educational attainment question(s) ..............46

4.2.4 Guideline for development of mapping to detailed ISCED variable ................................... 47 


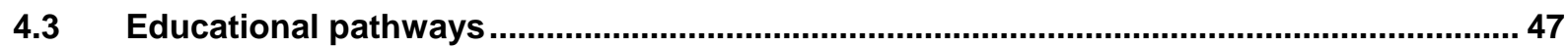

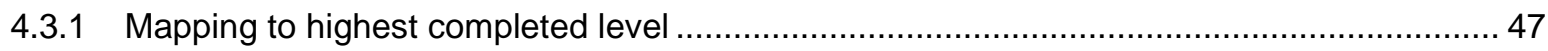

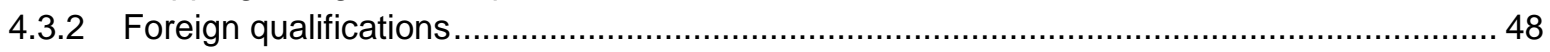

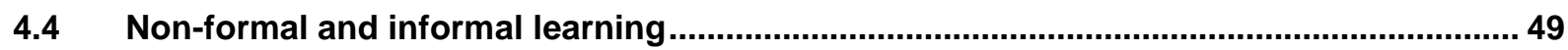

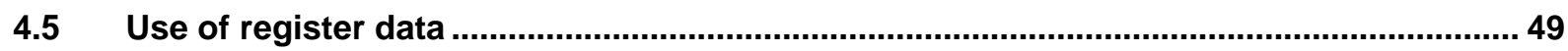

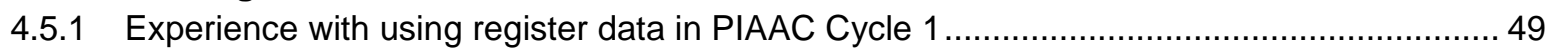

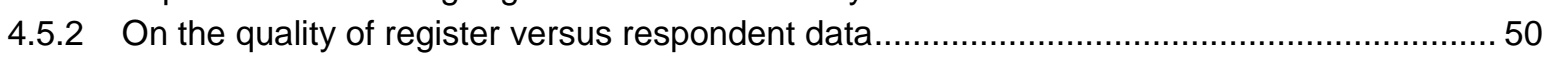

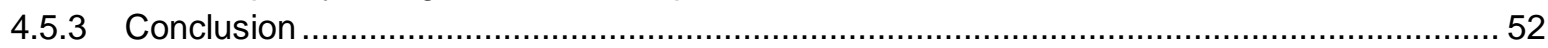

5 CONCLUSIONS AND REMAINING GAPS, SUMMARY RECOMMENDATIONS.......... 55

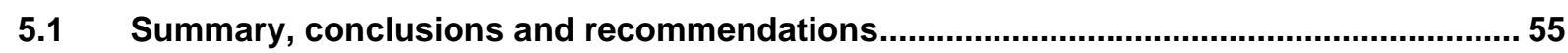

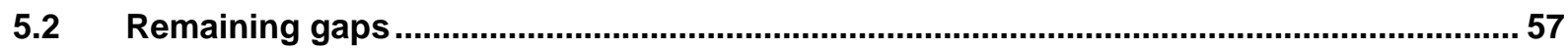

6 REFERENCES

7 APPENDIX

7.1 Detailed analyses of educational attainment variables in PIAAC Cycle 1.......................62

7.1.1 Inconsistencies in measurement instruments and harmonization in PIAAC Cycle 1 ............62

7.1.2 Empirical evaluation of the comparative validity of the PIAAC Cycle 1 ISCED-based coding scheme

7.2 Descriptive results on training participation based on PIAAC, PIAAC Germany, PIAAC-

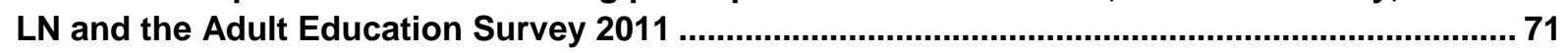

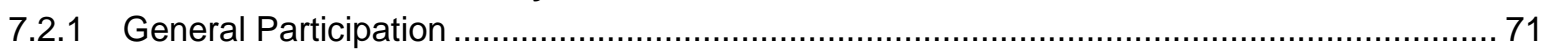

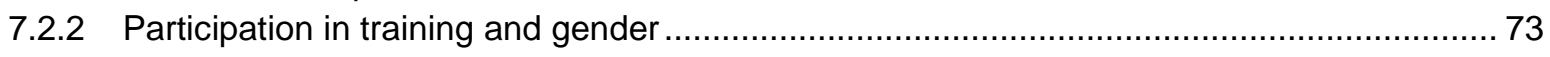

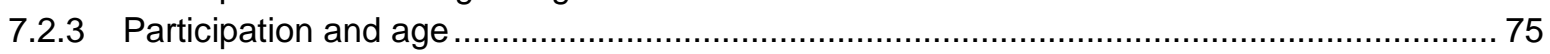

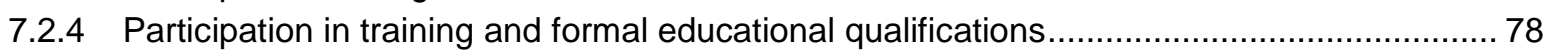

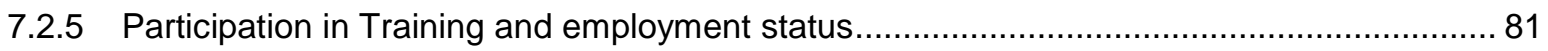

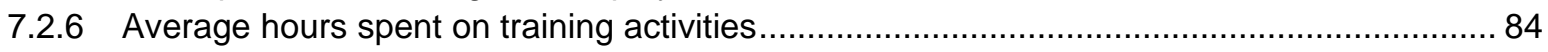

7.2.7 Participation in work-related, employer-sponsored and non-job-related training .................. 86

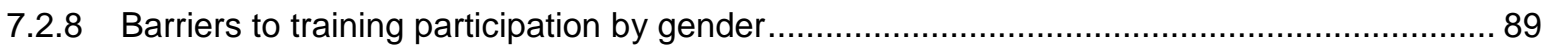

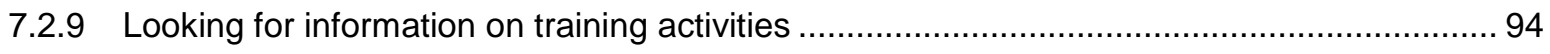

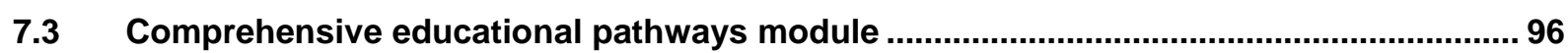




\section{Executive Summary}

Education and training are the most important predictors of key information-processingkey skills. Constructing unbiased, reliable, and valid measures of education and training is therefore crucial to the success of PIAAC. In the first cycle of PIAAC, the questionnaire focussed primarily on establishing educational attainment (the highest degree) and current participation in formal education. Little information about pathways through education was collected. Information on non-formal training was gathered with a quite extensive set of questions on participation in different training activities. However, despite their extensiveness, the informative content of these questions was again quite limited.

In this report, we provide suggestions for improving the way in which education is surveyed in PIAAC. We critically assess how the concepts of educational attainment, educational pathways and non-formal training were measured in the first cycle, and suggest improvements in how these can be measured in the second cycle of PIAAC. We also provide a detailed reasoning of the way in which educational attainment, educational pathways, and non-formal education can be surveyed, and provide concrete suggestions for the implementation and harmonisation of these measurements in the secondycle of PIAAC.

\section{Measuring educational attainment}

The respondent's educational attainment is probably the single most important variable in the PIAAC BQ, used as a predictor of adult skills and labour market outcomes, and as a control variable. Its reliability, validity and comparability across subpopulations are thus of crucial importance. A close look at the country-specific educational attainment measures used in PIAAC Cycle 1 reveals a lack of measurement quality of the source items in many countries, as well as inconsistencies in the way they have been harmonized into the international standard ISCED-based coding scheme as specified in the PIAAC Master BQ (B_Q01a). Furthermore, even though comparative construct validation analyses show that the mapping to B_Q01a predicts adult skills almost as well as the country-specific variables, this is partly due to the fact that many countries only measured education in the exact level of detail required by B_Q01a, rather than at the level of detail that would have been most suitable for the respective national education system. For example, some countries used measurement instruments that failed to distinguish between vocational and general upper secondary education, a distinction which is highly important for both skill development and the labour market in many countries. Finally, the validation analyses show that ISCED 2011 categories perform substantially better in multivariate analysis of adult skills than years of education, ISCED 1997 categories levels or 'broad' ISCED levels (low, medium, high). This indicates that detailed educational categories contain information lost in mappings to more simplified measures, and highlights the importance of a more precise and policy-relevant measurement of highest attained level.

The report draws practical conclusions for PIAAC Cycle 2 and sets out ways to improve both the quality of education measurement within countries as well as the harmonization of 
educational attainment across countries, both in terms of an improved target variable, better guidelines for countries and a consultation processes supporting countries in realizing optimized instruments. The report also summarizes options for PIAAC to better identify and potentially directly measure foreign qualifications.

\section{Measuring non-formal and informal education}

Although formal education is the most important indicator for key skills, the relationship is not perfect and also varies between countries. Therefore, there are also other mechanisms that affect the acquisition of key skills. One of them is the participation in non-formal and informal learning activities. Individuals who engage in training activities are expected to also engage in learning opportunities which have an impact not only on specific but also on key skills. In the first PIAAC cycle, several items on non-formal training were part of the background questionnaire. However, the analyses of these variables showed that some of the items did not collect the information in a manner that was most useful. Therefore, we suggest items that should be changed. The extensive set of questions designed to capture different types of non-formal learning has been replaced by more concise measures of incidence, frequency and volume of training in the last 12 months. Respondents are also asked to report on whether the training was related to and/or useful for work and whether they received support and/or encouragement for their training participation. They are also asked to reflect on their current and future training perspectives, such as whether they experience barriers to training, what their motivation to engage in training is, and how likely they think it is that they will participate in training in the future. We also propose several items on informal learning opportunities: what the source and purpose of this learning is, how much time was spent, and whether it was useful at work or in private life.

\section{Measuring pathways}

Information on educational pathways to their highest degree is crucial to understanding how selection effects and learning effects shape individuals' human capital. For example, it should make quite a difference whether someone reached higher education through a general program in secondary education, or through a vocational track. Secondary VET programs are usually seen as stepping stones to the labour market; general programs are thought to prepare for further education. As a result, VET programmes in secondary education usually aim at transferring occupationally specific skills, whereas general programs more strongly focus on general academic ability. However, in many countries, VET programs can provide access to further education as well, and it is quite possible to finish university after having followed an vocational path through education.

Despite a lengthy and quite complicated set of questions, PIAAC Cycle 1 did not provide comprehensive data on educational pathways. The only indicators other than highest attained level concerned respondents who were in education at the time of the survey, or who had enrolled in a formal education programme at some point but left without completing it. In this report, we provide a detailed description of the opportunities and challenges when measuring pathways. The report discusses the level of detail required for analysing pathway effects. The 
large number of possible permutations, and the low number of cases for most of those permutations, probably render a detailed analysis of every conceivable pathway unrealistic. At a minimum, the coding of pathways should allow for creating a typology. We argue that it is relatively easy to obtain detailed information on the full list of qualifications completed during one's lifetime, by simply using a checkbox item and requesting respondents to report all qualifications completed.

In order to reconstruct pathways, listing completed qualifications is not enough. We should also gain information about the timing of key qualifications. In principle this could be asked for all completed levels, but for those respondents whose path through education has been long and perhaps complex, the resulting time burden may be unacceptably high and recall bias is an issue. We propose a pragmatic compromise, in which the timing is asked for the highest qualification and other programmes at the same broad level (low-medium-high) and the broad level below the highest level. For most respondents this only requires timing data to be provided for two to four qualifications. We also propose questions on respondents' current education, and education started but not completed, both only if applicable. We offer a number of recommendations about how to best approach this.

A key aspect of pathways involves those respondents who completed all or part of their education abroad. The PIAAC Cycle 1 instrument failed to provide good information on this. The current proposal aims to provide a fairly comprehensive overview of pathways that were partially or entirely completed abroad, and offers a way in which at least some foreign-born respondents can report their education in terms of the educational classification of their country of origin.

\section{Improving data collection by using register data}

One of the main ways in which we may improve upon the data collection from the first PIAAC cycle is by making better use of register data. The common arguments in favour of using register data are:

- Lower burden for respondent

- Lower costs of coding

- Increased accuracy of coding and increased quality of data

The first two of these arguments certainly hold true for PIAAC. Questions on education, occupation and sector, usually take up much time in the interview, especially if show cards have to be used (some 1-2 minutes for each question). This can be significantly reduced when using prefilled information from the register.

We also have indications from the countries that the quality of the data can be improved. In general, coding of education, and especially occupation and sector, is difficult and requires highly trained interviewers to extract the relevant information from the respondent as well as highly trained coders to transfer this information into a valid code. We argue that register data can be used to improve the quality of the data in the second cycle of PIAAC, especially with respect to education variables, occupation and sector of employment. However we have to acknowledge that register data are not error-free. We propose that countries that have such register data will use that to prefill the questionnaire, but should always include the possibility 
that respondents can adapt or change the information if it is not correct (as was done in Sweden during PIAAC Cycle 1). Only in this way can we really improve from a situation where we have to rely solely on either survey information or register information. 


\section{Conceptual background and rationale for operationalization}

Education and training are the main policy-relevant determinants of general key skills. Their adequate measurement is thus crucial for PIAAC, in order to both analyse antecedents of skills as well as factors to control for when analysing the (net) effects of skills on labour market outcomes. In PIAAC Cycle 1, education was measured in a fairly minimal fashion, focusing on highest educational qualification obtained (educational attainment) and current participation in formal education. No information was collected on the individual pathway to the highest level of education completed. Non-formal training was collected through several questions on participation in different training activities. Analyses of the results, showed however that some of the questions were not mutually exclusive and thus a correct estimation of training participation was not possible. This chapter presents in more detail the concepts of educational attainment, educational pathways and non-formal training and the rationale for their operationalization. These three concepts together can be regarded as providing a snapshot picture of individuals' educational opportunities and investments over their life course up to PIAAC data collection, which will, together with information on social and migration background collected in the PIAAC BQ, be the most important antecedents of general key skills.

\subsection{Educational attainment}

Educational attainment is one of the most important control variables in survey micro data analysis generally, but, especially in a study like PIAAC, it is also one of the most important variables captured in the background questionnaire for theoretical reasons. This section firstly presents how educational attainment is defined and operationalized. Secondly, it provides theoretical background to the relationship between educational attainment and other variables of relevance to PIAAC, especially general key skills and labour market outcomes, and reflects on the implications of this theoretical background for measurement of educational attainment in PIAAC.

\subsubsection{Defining educational attainment}

Educational attainment refers to the highest level of formal education successfully completed by an individual.

Formal education comprises both general or academic as well as recognized vocational or professional education and training offered in a country's educational system, i.e.

"provided in the system of schools, colleges, universities and other formal educational institutions that normally constitutes a continuous "ladder" of full-time education for children and young people, generally beginning at age 5 to 7 and continuing up to 20 or 25 years old. In some countries, the upper parts of this "ladder" are constituted by organised programs of joint part-time employment and part-time participation in the regular school and university system: such programs have come to be known as the "dual system" or equivalent terms in these countries" (OECD, 2011, p. 25).

While the PIAAC Cycle 1 Conceptual Framework of the Background Questionnaire (OECD, 2011) states that whether these latter programs are to be considered as formal education or not 
should be up to national conventions, it is argued here that as long as these programs lead to qualifications generally recognized in the labour market in these countries, i.e. having market value, they should always be considered as formal education. Otherwise there is a risk that equivalent qualifications are considered as formal in one country and as non-formal in another country, leading to incomparable measures of educational attainment. Following OECD (2011), in case of doubt, all programs that have a distinctive place in the ISCED classification should be regarded as formal education.

Given its heterogeneity and lack of regulation and general recognition, non-formal education is usually not within the scope of educational attainment. For the concept and measurement of non-formal training in PIAAC, see section 2.3.

Formal education is however also quite heterogeneous in terms of educational content and demand. Depending on their specific goals, different types of educational programs can be expected to lead to different levels of general key skills and labour market outcomes. In order to distinguish between attainment of such different types of education, educational attainment can be differentiated by programme orientation (usually general/academic vs.

vocational/professional) and whether a qualification gives access to a higher education level or not.

\subsubsection{Indicators of educational attainment}

The successful completion of a formal educational program is usually certified in some way. Educational attainment is thus typically indicated by the highest formal educational qualification (i.e. credential, diploma, certificate or degree) obtained. As in OECD (2011), in some cases (namely when a program does not award any qualification upon successful completion), "it is sufficient to have completed all the required classes, tutorials, etc." In countries where grade repetition is practiced, it should be added that success implies the possibility to move on to the next higher school grade or level of education. In the case of primary schooling not ending with a primary school certificate, this means, for example, having completed the final grade of primary school with the right to continue formal education (rather than having to repeat the final grade of primary education).

There are two alternative indicators of educational attainment worth mentioning: actual years of education and hypothetical years of education. The former directly asks respondents to calculate how long they have been in education (where the scope is defined inconsistently across surveys, e.g. some surveys exclude vocational training that is not entirely school-based, or even ask for years of schooling up to the end of secondary education only). Such measures are affected by a high degree of measurement error, which is partly related to respondents' numeracy skills. Furthermore, such a measure does not reflect qualitative differences between different types of educational programs and qualifications. Thus, it is not recommended to use this as the sole indicator of educational attainment. It is very useful though as an additional indicator for respondents without any formal educational qualifications, which is quite common in some countries.

Hypothetical years of education are derived from measures of the highest educational qualification obtained by assigning modal actual or theoretically/nominally required years of education to educational qualifications. The purpose of this is to obtain a linear variable, when 
qualitative differences between different types of educational programs and qualifications are assumed not to matter. If such a variable is to be derived in future PIAAC Cycles like in PIAAC Cycle 1, it is therefore to be decided whether all respondents should be asked about their actual years of education (rather unlikely), or whether information on the theoretically required years are to be collected during the design of measurement instruments on educational qualifications again. The latter seems to have been difficult at times though, partly because the education categories employed by countries often contain a collection of qualifications that do not have the same nominal cumulative duration.

\subsubsection{Theoretical framework and implications for measurement}

Educational attainment is one of the most important control variables in survey micro data analysis generally, but, especially in a study like PIAAC, it is also one of the most important variables captured in the background questionnaire for theoretical reasons.

Typical research questions regarding educational attainment in PIAAC are:

- How do general key skills relate to educational attainment (across countries)?

- How and why do general key skills vary between individuals with equivalent educational attainment? What does this look like across countries?

- How do general key skills impact labour market outcomes at any given level of educational attainment (across countries)?

- How do general key skills mediate the relationship between educational attainment and labour market outcomes (across countries)?

- How does social and migration background impact educational attainment and general key skills (across countries)?

- How does educational attainment mediate the relationship between social and migration background and general key skills (across countries)?

From a theoretical point of view, education and skills are closely related. Firstly, formal education is the main policy-relevant driver of general skill development. Examinations in formal education aim to validate the successful acquisition of knowledge, skills and competences. Secondly, both educational attainment and general key skill have common causes beyond formal education, especially primary socialization, which largely happens in the family context, and cognitive ability. Thirdly, educational attainment and general key skills also have common consequences, like unemployment risks or earnings. Consequently, in general surveys, educational attainment is often used to proxy the individuals' level of knowledge, skills and competences.

However, the relationship also cannot be perfect: for example, educational opportunities and attainment are known to differ across countries and social groups even when prior skills are the same, and skills still change after the completion of formal education. Educational qualifications and certificates are important selection devices within the educational system, and thus structure later opportunities independently of the actual skills of the individual. Subsequently, they serve as signals of the individuals' success in education, which is an important piece of information in e.g. the marriage and labour markets. Differences in skills by education level cannot be interpreted causally as being due to differences in skill acquisition in the highest educational program completed: Skills build up through the lifecourse, the ground being laid before birth and then continuing to grow in both primary and 
secondary socialization. In complex educational systems like those in most developed countries, educational systems provide alternative programs within education levels, and different pathways to the same highest qualification. Not only the content and quality of educational programs, but also selectivity of programs by prior skills shape the skills observed for different educational groups in the adult population.

At the simplest level, we can distinguish antecedents and consequences of education and skills at the individual level (which is the level of measurement of any survey of individuals). In the micro-sociological literature, this is well captured in the "OED triangle" (Erikson and Goldthorpe, 1992) comprising $\boldsymbol{O}$ rigins such as social and migration background, Education, and $\boldsymbol{D}$ estinations, such as earnings, unemployment, social class/status, or health. All three elements as well as the relationships between them are in influenced by specific factors at the meso and macro level, such as the educational system, labour market conditions, and welfare state characteristics. Figure 1 adopts the OED triangle but adds, for the purposes of PIAAC, general key skills:

\section{Figure 1: OED triangle, extended by skills}

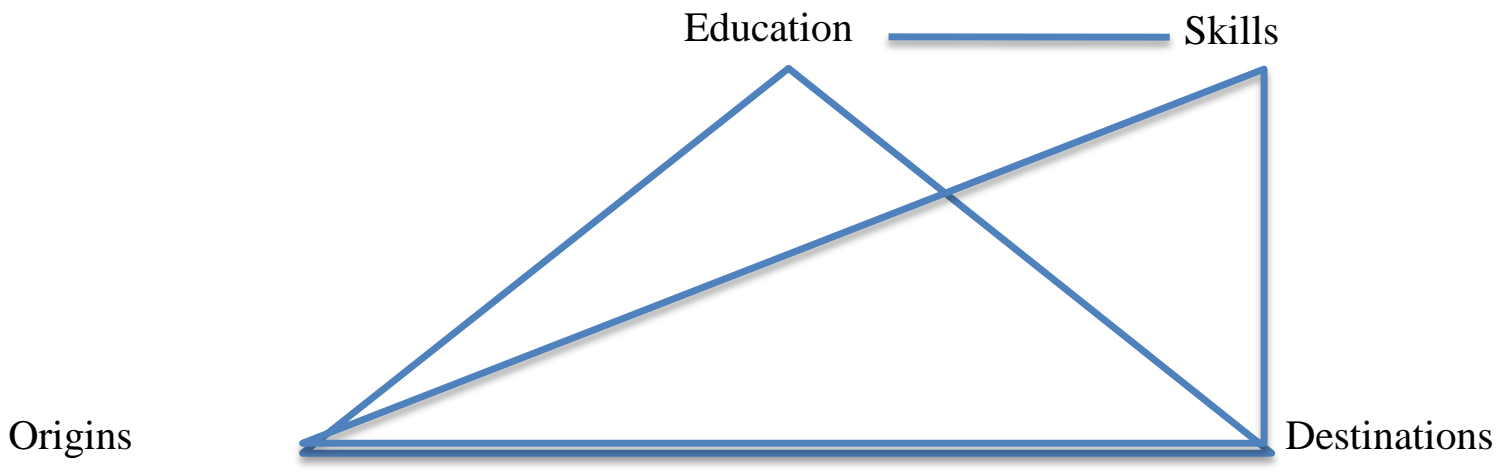

When analysing antecedents of skills, educational attainment is typically the main control variable because analysts want to distinguish between the direct effects of some variable (e.g. social background) on skills and effects that are mediated by formal education. Only when analysing the total effect of some variable on skills, the gross relationship is useful to look at. When analysing the outcomes of skills, educational attainment is typically also the main control variable because analysts often want to distinguish between the effects of formal education (on top of general key skills) and general key skills (on top of formal education). Only when analysing the total effect of skills, the gross relationship is useful to look at.

Because of the close relationship between educational attainment and skills, if one of the concepts is not well measured, unmeasured heterogeneity in this concept may be picked up by the measure of the respective other concept. It is thus of great importance in a survey of adult skills that both educational attainment and adult skills are measured with a high degree of reliability and validity. In a cross-national study, such as PIAAC, comparability across countries is another core data quality requirement. In order to achieve this, two points require further reflection because there are, within education levels, different types of education which may relate differently to general key skills. 
Firstly, general/academic and vocational/professional education (as defined by the dimension 'programme orientation' in ISCED, UNESCO Institute for Statistics, 2012, p. 14 § 53-55) have different aims. In vocational and professional education, students spend some of their time learning vocational and practical skills that are often directly relevant to the labour market. In contrast, in general education, most learning time is dedicated to content and methods that foster general key skills. Books and writing tasks for example play a more prominent role in general than in vocational education. Therefore, we expect general education to produce higher general key skills than vocational education at the same level of education. ${ }^{1}$ (We can also expect variation across countries in how strongly the skills of generally and vocationally educated people differ, because the specific character of vocational education strongly differs across countries.) For PIAAC, it is thus highly important that general and vocational educational qualifications can be clearly distinguished and classified. This was not realised in an optimal way in PIAAC Cycle 1, where measurement instruments in many countries did not differentiate between general and vocational qualifications although the ISCED mappings clearly point at such distinctions in the respective countries.

Secondly, in countries offering different educational programs at one level of education, these programs may differ with respect to their skill selectivity, independently of the kinds of skills that they aim to develop. For example, many countries have different types of vocational upper secondary education programs. Some of them give access to higher education, while others do not. Typically, those providing access to higher education are more selective, resulting in higher skills of their graduates, which were however already evident when entering the program and are thus not or only partially caused by the program. Thus, even beyond the distinction of general and vocational educational programs, for PIAAC it is important to differentiate types of educational programs in terms of their skill selectivity and skill productivity.

Unfortunately, ISCED 1997 and even more so ISCED 2011 is ill suited to draw such distinctions: ISCED 2011 only differentiates whether an educational qualification gives access to the next higher ISCED level, without differentiating which types of programs at this higher level, although this is where skill selectivity is expressed most clearly. Most educational systems have moved away from offering "dead end" educational programs altogether anyway. ISCED 1997 draws the distinction in principle by offering destination categories A, B and C, but the distinction between A and B programs was not implemented in PIAAC Cycle 1.

Some of the distinctions suggested here can thus unfortunately not be checked empirically using PIAAC Cycle 1 data.

\subsubsection{Challenges in the cross-national survey measurement of educational attainment}

\subsubsection{Ex-ante output harmonization}

Given cross-national educational attainment categories such as ISCED levels are incomprehensible for respondents, cross-national surveys use country-specific questionnaire items to collect information on respondents' educational attainment. The resulting country-

1. ISCED levels do not measure skill levels but rather reflect the duration of the educational career. 
specific education variables are then recoded into a cross-national variable such as ISCED after data collection. In order to achieve a good representation of country-specific education categories in the cross-national variable and in order to be able to effectively code it, it is important to anticipate the cross-national target variables when designing the country-specific data collection instruments for educational attainment. This approach to rendering measures comparable across countries is called ex-ante output harmonization. It consists in three steps: 1) decide on cross-national coding scheme (ISCED codes to be used, see 2.1.4.2 below), 2) develop country-specific measurement instruments that can be mapped to this scheme and 3) recode the categories resulting from step 2 to the scheme determined in step 1 after data collection.

It is often difficult for country teams to implement steps 2 and 3 consistently. Without central support, this may result in inconsistent solutions across countries, leading to less comparable education data. In PIAAC Cycle 1, not all countries implemented the coding scheme as specified beforehand, and some issues were insufficiently specified to achieve consistent coding (see section 7.1 in the appendix).

\subsubsection{Which ISCED?}

Looking at survey practice, different cross-national surveys use different coding schemes, even if they refer to ISCED. In PIAAC Cycle 1, a coding scheme closely related to the one used in the European Union Labor Force Survey (EU-LFS) until 2013 was used. The only difference is that in PIAAC, the Bachelor and Master levels (levels 6 and 7 in ISCED 2011) are systematically distinguished, anticipating an important improvement that came about with the switch from ISCED 1997 to ISCED 2011. In terms of information content and thus validity, this scheme is definitely an advantage compared to using ISCED 1997 main levels only, as is e.g. done in the European Union Survey of Income and Living Conditions (EUSILC). ISCED main levels are known to be highly heterogeneous and thus of limited predictive power also for general skills, and the kind and degree of heterogeneity depends on the educational system. This in turn leads to low comparability (Schneider, 2010). Empirical analyses show that, compared to the country-specific education measures used in PIAAC Cycle 1, the detailed variable b_q01a comes about with an average loss of information across countries of 3\% (ranging from 17 to 0\%), ISCED 2011 main levels with an average loss of $7 \%$ (ranging from 22 to 0\%), and ISCED 1997 main levels with an average loss of $12 \%$ (ranging from 25 to $2 \%$, see section 7.1.2 in the appendix for details). While the most detailed variable in PIAAC fares relatively well, we need to note however that due to the mixed quality of country-specific measures, these are conservative estimates - many countries just implemented the level of detail minimally required for coding of b_q01a (and some did not even manage that). Beyond information losses, after the theoretical discussion above, it is also clear that the way that ISCED is implemented in cross-national surveys, including PIAAC, does often not allow studying the antecedents and consequences of educational attainment with references to program orientation and program destination or even selectivity, even though these are important elements when studying skill acquisition and labor market outcomes. 


\subsubsection{Vocational education and training}

In PIAAC Cycle 1, it seems to have been difficult for some countries to distinguish vocational and general education in their educational attainment measures. Due to the fact that national experts had to indicate whether a qualification was vocational or academic, rather than taking this information from ISCED mappings by default, some diversity in definitions may have arisen. In principle the country experts were expected to consult the ISCED mappings and deviate from them only when appropriate, but it was difficult for the consortium to control the extern to which they complied with this requirement. The variable "VET" coded ex-post is not very clear and contains a large amount of 'unspecified' and missing data even for countries where the educational system quite visibly distinguishes between vocational and general education. Moreover, the distinction was only made for ISCED 3 and 4 and not for other levels, such as higher education.

\subsubsection{Education of first generation migrants}

First generation migrants who arrived after completing their formal education have foreign educational qualifications. Using the country-specific education question of the survey country for measuring their educational attainment means that they (possibly 'supported' by the interviewer) need to indicate which educational qualification in the survey country they consider to be equivalent with the educational qualification they actually hold. This is firstly a difficult task, since it potentially requires a lot of extra thinking and knowledge on the side of the affected respondents (and interviewers), and secondly it is error prone: what the respondent (and/or interviewer) may consider to be equivalent qualifications may not be equivalent qualifications in terms of ISCED. Offering a specific response option "foreign qualification" at the end of the country-specific education question and thus being able to separate those with foreign qualifications from others as practiced in PIAAC Cycle 1 seems not to have been equally successful across countries.

\subsubsection{Parental education}

Proxy information on parental education as an indicator of social background: In PIAAC Cycle 1, social background was measured by only one indicator, parental education. Given that people often know more about their parents' occupation than education, it is a risky strategy in terms of data quality to only ask about parental education but not occupation.

\subsubsection{Methodological developments in education measurement during/since PIAAC Cycle 1}

- Revision of education measures and harmonization in European Social Survey Round 5 (European Social Survey, 2010, 2012) and in the European Values Study (2017 - details to be clarified). Implementation of a coding scheme anticipating ISCED 2011 but also implementing distinctions not made in ISCED.

- Adoption and implementation of ISCED 2011 (UNESCO Institute for Statistics, 2012) for educational attainment (ISCED-A), including updates of ISCED mappings (http://uis.unesco.org/en/isced-mappings) and new operational manual (UNESCO et al., 2015).

- Eurostat and OECD have agreed on joint guidelines for the measurement of educational attainment in household surveys (OECD and Eurostat, 2014).

- Computer-assisted measurement of education in multicultural surveys (CAMCES) project at GESIS, 2013-2017 (http://www.gesis.org/en/research/external-funding- 
projects/overview-external-funding-projects/camces/). The CAMCES tool provides questionnaire items, software interfaces (for CAWI and CAPI) and an international database of educational qualifications to collect educational attainment data in an adaptive way, i.e. asking respondents about their highest qualification relative to the country in which they were educated. Especially useful for capturing the specific foreign qualifications of first generation migrants. The tool could possibly be adapted to support educational pathways (see next section), but this would incur programming costs.

\subsection{Educational pathways}

\subsubsection{Reasons for asking pathways}

The simplest reason for wanting more information on educational pathways is the observation that the returns to a given level and type of education have been shown to be heavily influenced by the route taken to get there (see e.g. Brunello and Rocco 2015). These effects may be due to both selection effects (people who choose direct pathways differ in abilities, motivations, personality traits, etc. from those who achieve the same level through a more convoluted route) and learning effects (accumulated human capital is the sum of all educational experiences en route to the highest attained degree).

One of the key distinctions within educational pathways is that between vocational education and training (VET) programmes on one hand, and general (non-VET) programmes at the same level. VET programmes in secondary education are usually aimed at instilling relatively specific knowledge and skills in preparation for skilled positions in the labour market. Although there are some marked differences between countries in such things as the strength of the links between acquired competence and expected later performance and the selectivity of the programmes, secondary VET education is usually seen as providing qualifications that can be rather directly used in the labour market (Mulder et al, 2007). By contrast, general secondary education is often designed as a stepping stone to more academically oriented postsecondary or tertiary education. Consequently, such education often attracts different types of students than do VET programmes. Especially in cases where there is non-random sorting of students into these different pathways, and where the programmes have a very strong workspecific or practical component, this distinction can be very important, so it is not surprising that in many countries this is reflected in different skill levels and outcomes for individuals who leave the education system with nominally the same level of education, but of a different type (OECD 2013).

It is reasonable to ask what happens to these differences in skill levels when students choose to continue in formal education rather than proceeding directly to the labour market. To what extent do these differences persist, and to what extent are they erased or eroded by the common experience of subsequent education of the same level or type. Although PIAAC Cycle 1 did not provide comprehensive data on educational pathways, we do have partial pathway data for some respondents, namely those currently in education at the time of the survey. For these respondents we also know the level and type of the highest completed qualification prior to the current programme. Due to the relatively small number of respondents currently in education in most countries, this data does not provide a strong basis 
for analysis of pathways in general. However, because of the strong oversampling that took place in Canada in PIAAC cycle 1, we can perform some preliminary analyses on the data from that country. Specifically, we can observe the mean literacy scores of students currently enrolled in ISCED level 4 programmes in Canada, separately for students whose highest prior completed qualification was a VET qualification or a non-VET qualification respectively Especially for students enrolled in level 4A-B programmes (which in Canada are all classified as non-VET) the difference is marked. The average literacy score for students enrolled in these courses with a non-VET background is around 280 points, a full 40 points more than the average level of otherwise comparable students with a VET background. Interestingly, there is no such skill gap in the case of level 4C programmes (in Canada always classified as VET programmes). These results suggest that the pathway from VET to non-VET makes a bigger difference that that from non-VET to VET in this case. Of course, these results do not prove anything in terms of a causal link between pathways and skill or ability levels of students. They do however show that the pathway a respondent has followed into a given level of education can be very important in understanding how education, skills and outcomes are interrelated.

Figure 2: Mean literacy score of Canadians currently enrolled in ISCED 4 programmes, by VET versus non-VET prior education

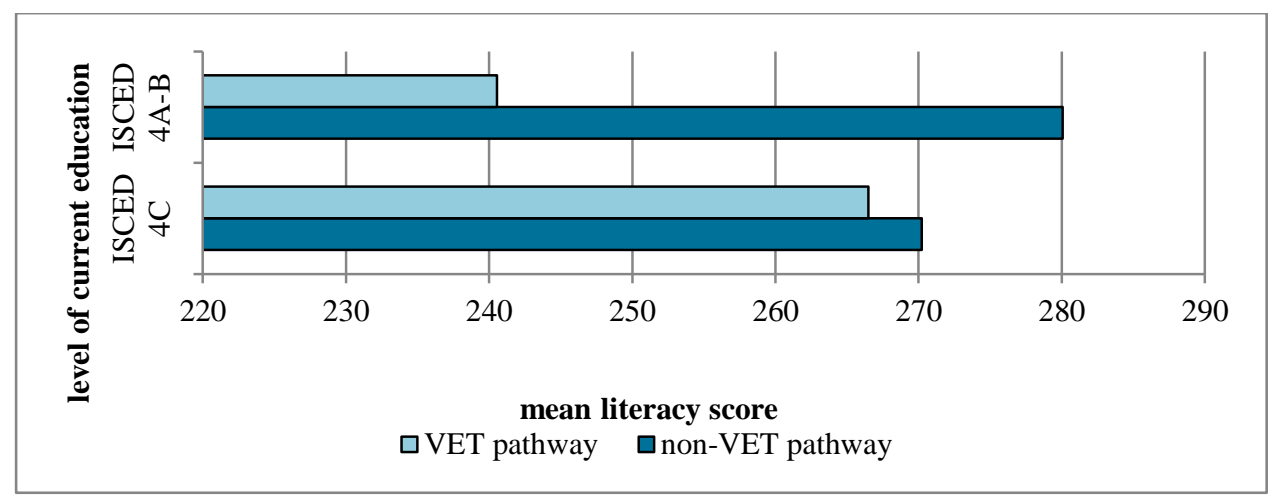

\subsubsection{Required level of detail}

Given that we want data on pathways, it is important to ask what level of detail is needed in order to enable researchers to analyze such effects in a satisfactory manner. At the same time, it should be kept in mind that no level of detail will change the basic fact that the PIAAC survey is cross-sectional in nature, which places strong limitations on the kinds of analysis which are possible, regardless of the precision of information collected on pathways. There are no intermediate outcome variables in PIAAC that would allow the effect of each branching to be analyzed in detail. The large number of permutations, and the low number of cases for most of those permutations, also render a detailed analysis of every conceivable pathway unrealistic. In practice most analyses will be based on some kind of typology of pathways, for example distinguishing straightforward vocational and general pathways on one hand, and the most common hybrid pathways on the other. 
This does not mean that a certain level of detail is unimportant. For one thing typical pathways are likely to differ strongly from country to country, due among other things to strong differences in the nature and extent of vocational education, tracking, etc. It is also desirable to allow researchers using the final data set some leeway to develop their own typologies, reflecting the specific policy questions and research interests guiding their research. Overzealous simplification in the data collection phase can severely limit the flexibility available later, and can therefore detract from the value of the data. From that point of view it is desirable to obtain as much detail as is realistically possible, within the limitations of a strictly time-constrained survey.

Such detail can pertain both to the combination of types of education followed, and to the timing or sequence in which the education has been followed. As will be outlined in section 3.3 , it is relatively easy to obtain detailed information on the full list of qualifications completed during one's lifetime, by simply using a checkbox item and requesting respondents to report all qualifications completed as suggested in Schneider (2008).

An important side note here is that some educational differentiations that are relevant in certain countries were underreported or even ignored in the cycle 1 survey. Although countries were encouraged to make such distinctions when adapting the questionnaire to the national qualification structure, in many cases key distinctions were lumped together when they corresponded to the same broad ISCED levels, e.g. ISCED 2(A), ISCED 3A/B or ISCED $5 \mathrm{~A}$. It is of crucial importance for accurate description of pathways that all such distinctions are made, at least within the constraints on the complexity of the response listings, and the consequent burden for the majority of respondents (see also section 2.1).

In order to reconstruct pathways, listing completed qualifications is not enough; we also need to know when key qualifications were completed. In principle this could be asked for all completed levels, but for those respondents whose path through education has been long and perhaps complex, the resulting time burden may be unacceptably high. In practice this will mainly apply to those tertiary graduates who followed non-standard routes through education, for example going through secondary vocational education before switching to general education, then proceeding on to a master's degree or $\mathrm{PhD}$. As a pragmatic rule, we suggest that all tertiary graduates be absolved of the requirement to report completion dates for primary and lower secondary education. This could if necessary be restricted even further, for example only reporting the date of the highest secondary degree in the case of tertiary graduates, and the highest prior secondary level degree in the case of secondary graduates.

To complete information on pathways, it is necessary to also ask current education, if any, and some information on possible incomplete education. For the latter, we recommend only asking the highest uncompleted qualification, since this is likely to be most informative in terms of the development of educational pathways. We expect the number of respondents with multiple uncompleted qualifications to be too small to be amenable to detailed analysis, so the potential added value seems quite small in relation to the added response burden.

Finally, a key aspect of pathways involves those respondents who completed all or part of their education abroad. The PIAAC cycle 1 instrument failed to provide good information on this, since the design was focused on helping foreign respondents answer the relevant questions rather than on providing a good picture of foreign qualifications obtained. The 
current proposal aims to provide a fairly complete overview, by asking the domestic equivalents of which qualifications were followed abroad, and the country in which the most recent of these was followed. To achieve greater accuracy and minimize the risk of underreporting of foreign qualifications, we aim to provide respondents with the opportunity to report these in terms of the classification of the country of origin. Due to logistical limitations this will not be possible in all cases however, so it is important that interviewers be trained to assist respondents in reporting their foreign qualifications in terms of the classification of the survey country, should this be necessary. By linking the data on foreign qualifications to the abovementioned timing data, it should be possible to gain a fairly accurate picture of the point at which foreign respondents entered the domestic education system (if at all).

\subsection{Measuring non-formal and informal learning opportunities}

In order to actively and successfully participate in today's societies basic competencies, such as reading of texts and evaluating numerical information, are necessary. The aim of PIAACs is to evaluate how these skills are maintained, developed or gained and how individuals can prepare themselves for new changes in society and the labor market, such as digitalization (OECD (2013). Modern societies have evolved into knowledge-based economies, in which lifelong learning has become important to acquire and maintain skills.

Basic competencies are acquired in educational institutions and in everyday life. After initial education, lifelong learning opportunities become increasingly important in acquiring human capital in order to maintain or develop skills and competencies.

Training, together with early ability and initial education, is seen as one of the three main drivers of human capital. Structural and technological changes on the labor market increase the need for specific skills and make it more important to adapt skills regularly (Becker, 1962). Human capital in turn is seen as one of the driving forces of economic development. Furthermore, ageing societies have an impact on lifelong learning as older individuals also need to adapt to new demands; being active and in the labor force may become more important for them and for economic growth (Hanushek \& Woessmann, 2015). Analyses have shown that on an individual level training increases the probability to work and reduces the risk of unemployment (OECD, 2004). Furthermore, participation in educational activities, thus also in training, has a strong impact on individual productivity (OECD, 2004).

The investment in training is thus one of the key measures of policy makers to increase skills and competencies after leaving initial education. It is a key factor both for employment and training policies. Adult education and training are today recognized as essential enablers of economic growth and social development within the rapidly evolving knowledge-based society and economy. Education and training are key to stratification in society, showing the importance of giving access to training opportunities for all individuals. The need to develop skills is especially important in the context of an ageing labor force and internationalization of activities. Furthermore, benefits to the society can be expected from training participation, as more educated and more literate individuals in a society are related to better to social cohesion and participation in democratic institutions for example. 
Lifelong learning is defined as "all learning activity undertaken throughout life, with the aim of improving knowledge, skills and competence, within a personal, civic, social and/or employment-related perspective." (European Commission, 2002).

For the next PIAAC cycle, the aim is to improve the way adult learning opportunities can be measured. Therefore, it is important to measure all forms of participation in educational activities, such as formal, non-formal and informal learning, both in work-related as well as private contexts.

\subsubsection{Non-formal training participation}

\section{What is non-formal training?}

Non-formal education and training is defined as any organized educational activity outside the established formal system (e.g. formal qualifications in secondary schools or universities) (see section 2.2.1 for more information on formal education). Non-formal training can take place within and outside educational institutions and is intended to address individuals of all ages. Generally it does not lead towards a qualification. Non-formal training often takes place in form of courses, workshops and private lessons. The aim of non-formal training can be to improve key skills, such as literacy and numeracy, work-related skills, life-skills or have a positive influence on leisure activities but not to obtain a qualification (as opposed to formal education). Non-formal education is usually shorter than formal education, and often takes place parallel to employment. Non-formal learning is intentional from the learner's perspective (CEDEFOP, 2008).

\section{Why people invest in non-formal training?}

Non-formal training enables individuals to keep up or enhance skills either needed at work or skills individuals want to learn for their private life. The decision to invest in human capital is similar to decisions about other types of investments undertaken by individuals or firms. It involves an initial cost (e.g. tuition) and hopes to gain in the future (earnings, productivity). Individuals take up training because they expect positive outcomes, such as higher chances of being employed, higher wages, more interesting job tasks (e.g. (Hansson, 2008); Büchel and Pannenberg (2004)) or pleasure, from participating in training activities. Much non-formal training takes place at the work place. This is due to the fact that work-related training is not only worthwhile for individuals but also for employers, as both expect positive outcomes, such as higher wages, revenues or more productivity. The assumption is that employers invest in "firm specific skills", while individuals more often are in charge of the costs associated with "general skills". This is due to the fact that employer do not want to invest in skills that their employees can use in a different job. However, Acemoglu and Pischke (1999) show that there are still reasons why employers invest in general training.

Previous research shows that the investment in training has positive effect on individuals in terms of higher employment stability, higher wages and seems to be portable in many cases and positive on the company level in terms of productivity and competitiveness (e.g. Blundell, Dearden, Meghir, and Sianesi (1999); Bartel (1995)) 
Previous research shows that formal education is the most important predictor for literacy skills (e.g. Massing and Schneider (2017)). However, this relationship is far from perfect, leading to the assumption that there are also other factors influencing literacy skills beyond schooling. One of the assumptions is that participation in non-formal training involves literacy-related activities and thus can have an influence on literacy skills (Desjardins, 2003). PIAAC data can be used to better understand why there are differences in participation across countries and different groups. This allows policy makers to better understand where to invest in order to allow individuals to increase their key skills.

Previous research shows that participation in non-formal training varies significantly between countries (Boateng, 2009; Desjardins, Milana, \& Rubenson, 2006; OECD, 2003) and between different socio-economic groups (see also Figures 8-12 in the Appendix).

Previous research also shows that there is a complementarity in human capital investment. Early achievement and acquired qualifications are an important determinant for future investment. This means that individuals with higher education take up training more often than individuals with lower education (Bilger, Gnahs, Hartmann, and Kuper (2013), (Blundell et al., 1999); Maehler et al. (2013) and Figure 11 in the Appendix). Although individuals who participated in training, show higher key skill levels, this does not allow to draw conclusions on the causal mechanisms. Key skills can also be an important factor predicting participation in non-formal training (Desjardins, 2003). Some research still shows small positive effects of adult learning programs on key skills (e.g., Wolf and Evans (2011); Benseman, 2010).

In order to understand the impact of non-formal training, it seems important to distinguish different kind of trainings as returns to different type of trainings differ: Blundell et al. (1999) report that employer-provided training is related to higher returns than other training. Furthermore, returns between men and women vary, often showing higher return from training for working women than for working men (e.g. Booth (1991)). When looking at returns over time it can be seen that acquired skills can depreciate. Blundell et al. (1999) find that employer-provided training does not only have the largest impact on earnings, but its effects are also the most long-lasting. This seems to suggest that depending on different kind of trainings, positive outcomes can vary. Another aspect that is important is the actual use of specific skills after training: in longitudinal studies no significant effects of training on skills proficiency could be found but on skill practices (Reder (2009); Green, Ashton, and Feldstead (2001)).

Why we should include specific measures

As shown above, there are different important aspects of determinants for training participation. Furthermore, beyond specific skill acquisition, it can be assumed that due to key skill engagement in non-formal training, training participation can also be a predictor for skill acquisition. Therefore, it is important to measure training participation. It is not only relevant whether respondents participate in training but it is also important to address policy-relevant factors, such as the intensity or volume of training (see results on average hours spent on training activities in Figure 13a and $13 \mathrm{~b}$ in the appendix), the reasons for training activities (e.g. whether they are job-related), and who is financing the training activities. Furthermore, it 
is important to include measures on the usefulness and portability of training (e.g. usefulness of training for other job, mentioning of training in CV). The portability of training can be seen as another indicator that training is useful and valuable, and thus potentially increases skills.

Training outcomes are probably often only successful if the actual skills are also taken up in daily life. Therefore, questions on the relevance of skills learnt in training are also important.

Although most training takes place in the job context (see Table 9a), it is still very relevant to obtain information on privately motivated training activities because they can also have a positive impact both on key skills, and other relevant factors such as soft skills (Thurow, 1976). Measuring training activities beyond job-related training is especially important to learn more about individuals currently not employed.

\subsubsection{Barriers to education/motivational factors}

\section{What are reasons why individuals do not take up training?}

Although adult training activities have been seen as important factors both on an individual level as well as for society as a whole, not all adults participate in training activities. Some adults are not able to, while others do not see the need or simply do not want to participate. These different reasons can be divided into situational, institutional and dispositional barriers in participation to adult education (Cross (1981). Situational barriers are due to the personal situation or environment (e.g. cost of training, lack of time, no childcare available), institutional barriers are practices and procedures that discourage adults from participating in adult learning (e.g. no suitable courses available/reachable) and dispositional barriers are related to attitudes and self-perceptions (e.g. not confident that one can fulfill the requirements needed).

Previous research shows that cost issues and lack of time are most important situational barriers reported (Desjardins et al., 2006) whereas problems with finding appropriate courses are reported as institutional barriers (Rubenson \& Desjardins, 2009). However, this research cannot link barriers to key skills, and thus does not allow analyzing the relationship between barriers reported and opportunity structures to increase key skills. In our analyses, we see lack of time due to professional reasons, due to family responsibilities and financial reasons as the main barriers reported (see Table $13 \mathrm{~b}$ in appendix)

It is important to understand which barriers to participation exist, in order to address the causes and allow individuals to engage in non-formal training in order to increase their skills. Furthermore, it is necessary to look at the barriers for different groups in order to understand the dynamics of non-participation.

\section{Why we should include specific measures}

Lifelong learning is important and every individual should have access to learning opportunities. Therefore, it is important to understand the reasons preventing training participation. At the same time, it is important to measure how information about training opportunities are accessed in order to assess whether there are gaps that can be filled in order 
to provide opportunities for more individuals (see results from the AES on information search on training activities in Table 11 in the appendix).

\subsubsection{Informal Learning}

What is informal learning?

In addition to non-formal training, it is essential to also measure informal learning practices. The definition of informal learning practices varies. For our purposes, we define it as any form of learning that is intentional and includes learning activities occurring at work, in the family or in daily life. It is not structured in terms of learning objectives, learning time or learning support (CEDEFOP, 2014), and does not lead to certification.

Why is informal learning important and how is it related to skills?

Measuring informal learning is important as adults spend much more time on informal learning activities than on formal learning, and the activities are often interrelated. Another important aspect of informal learning is that the barriers in accessing informal learning are lower. This form of learning is available to individuals in many contexts and often involves lower barriers and opportunity costs. This is supported by the fact that employees in smaller firms engage more often in informal learning than in larger firms where there are more opportunities for non-formal training (Bassanini, Booth, Brunello, De Paola, and Leuven (2005)).

Expectations of informal learning are less systematic than leaning outcomes from non-formal learning, however it is often more problem-oriented, integrated into the natural (work) context and therefore often sustainable. Research with the AES shows that informal learning has become increasingly important (e.g. Kuwan and Seidel (2013)), and that more individuals take up informal learning opportunities in comparison to non-formal training (e.g. (European Commission, 2011). However, as with formal training opportunities, the rate of participation depends on labor market status, education and age and shows considerable country differences (European Commission, 2011). 


\section{Education and training module}

\subsection{Description of streamlined structure of module}

The education and training module had a rather complex structure in the PIAAC Cycle 1 questionnaire. The main source of complexity was located in the submodule on formal education. In this submodule there was a need to avoid repetition in a module structure that aimed to gather information on highest completed education, current education, education left without being completed, and (because it wasn't entirely certain that this would be covered by the former three dimensions), participation in education in the last 12 months. This led to a complex and confusing routing structure that placed a heavy burden on both the consortium and the countries in terms of implementation and adaptation.

In the current proposal we have simplified this structure by dropping the requirement for explicit additional questions on educational participation in the last 12 months. Because we now ask timing data on multiple qualifications during the educational pathway, recent educational participation can be derived with sufficient reliability to remove the need for this additional set of questions. This results in a more coherent and streamlined structure of the module for PIAAC Cycle 2, as shown in Figure 3.

The module is divided into three submodules: educational pathways (formal education), nonformal education (courses, in-house training etc.) and informal learning (learning from everyday tasks at work or in private life). The left hand side of the figure shows the questions that all respondents are required to answer. Everybody is required to report whether they are currently in education, when they were last enrolled in education, whether they completed any education abroad, all the formal qualifications they have obtained in their lives, the field of study of their highest qualification, the end years of their highest qualification and relevant prior qualifications, whether they left any education without completing it, whether they participated in any training (non-formal learning) in the last 12 months, some questions on their perspective for training in the future, if they engaged in any informal learning activities in the last four weeks, and their preferred setting for learning. Depending on the answers to key questions, respondents may be routed to additional questions providing detailed information on current education, foreign qualifications, education started but not completed, training followed in the last 12 months, and informal learning activities in the last four weeks. 
Figure 3: Streamlined structure of module

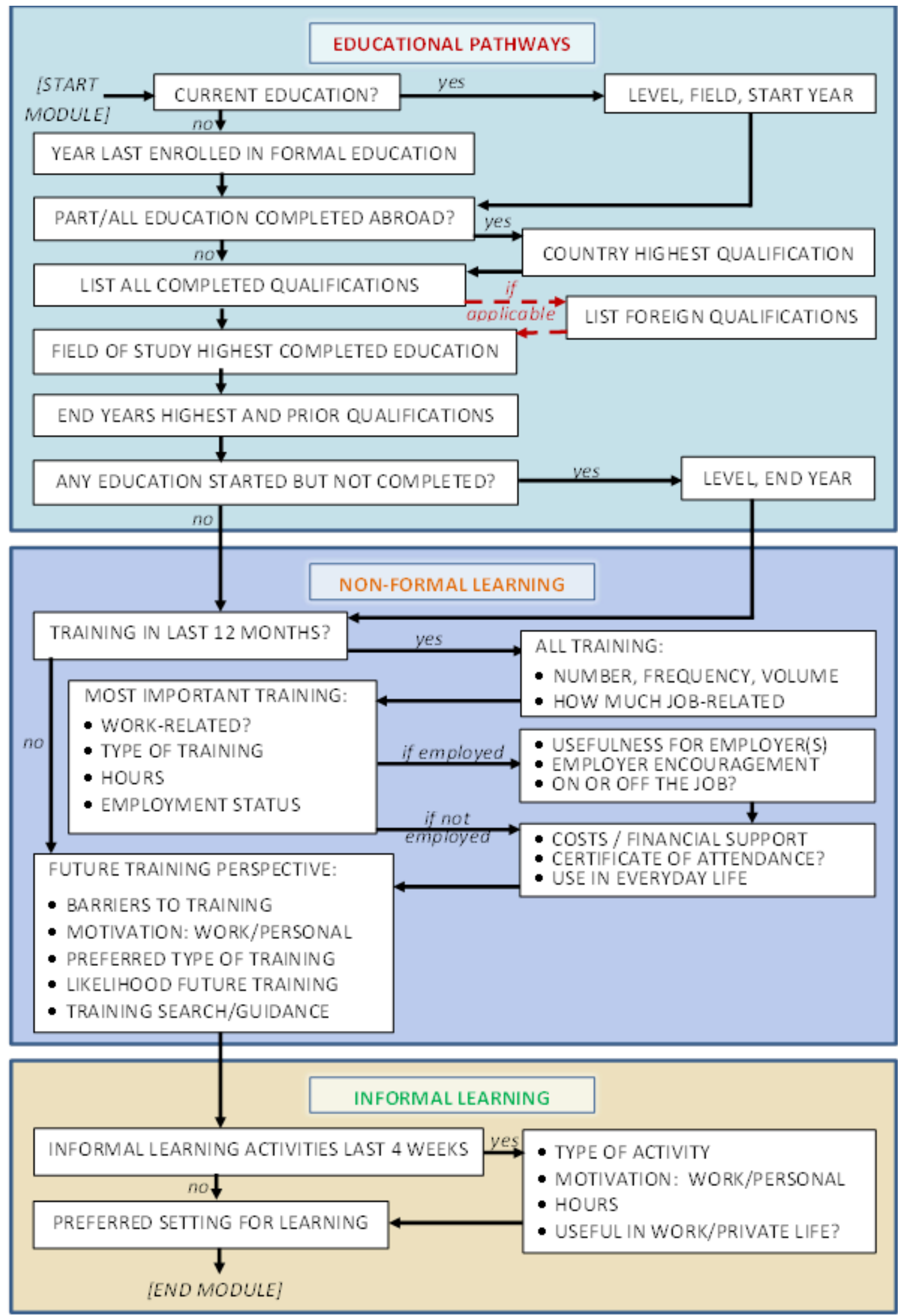




\subsection{Educational attainment}

This section discusses several options for the PIAAC Cycle 2 questionnaire regarding the measurement of educational attainment.

\subsubsection{Source question wording}

As discussed above, the main indicator for educational attainment is the highest educational qualification achieved (see section 2.1.2). In PIAAC Cycle 1, the educational attainment question B_Q01a was worded as follows:

\section{Which of the qualifications on this card is the highest you have obtained?}

As outlined in section 2.2.2, in PIAAC Cycle 2 we propose to ask respondents to report all of their completed educational qualifications in the form of a checkbox item, and have the CAPI system calculate the highest educational qualification. The question then takes a slightly different form (wording option A in our proposal for Cycle 2):

\section{Which of the qualifications on this card have you ever obtained?}

Maybe this question could be simplified further. We would thus like to suggest wording B:

\section{Which educational qualifications have your ever obtained? Please use this card.}

A disadvantage for both wording options A and B is that the term 'educational qualification' is not easily translated in all languages (compared to wording $\mathrm{C}$ below). Also, for educational programs not concluding with any educational qualification or only with a certificate of attendance (e.g. ISCED level 1 - primary education - programs in many countries), successful completion refers to full attendance in the programme, i.e. having followed the programme from its beginning right to the end (allowing temporary periods of absence due to illness etc.). So, for such programs, the response options would not quite fit the question wording. This may however be acceptable because respondents often derive the precise meaning of a survey question from the response options offered rather than the question stem only. Alternatively, a follow-up question could be used, to which all reporting "no qualification" would be routed and then asked which was the highest school grade they completed.

The PIAAC Cycle 1 BQ (OECD, 2010, p. 8) however also mentions another question wording to illustrate how the question wording might be adapted (adaptation here used in the sense of 'good translation'): "What is the highest level of education you have ever successfully completed?" This source question wording is currently used in the European Social Survey (ESS, ESS ERIC, 2016) and seems to work well. This is a more general way of asking for the same theoretical concept, namely without the (not always applicable) focus on the indicator 'educational qualification', taking into account that some response options may refer to completed education levels that do not correspond to formal educational qualifications. This would actually be adequate in a rather large number of countries for primary education, so wording $\mathrm{C}$ could be used as the source question also:

Which levels of education have you ever successfully completed? Please use this card. 
The disadvantage of this question wording is however that in many countries, several different educational qualifications make up one completed level of education (even nationally). PIAAC however is not only interested in the level, but also different types of qualifications within levels. Again, we would need to rely on respondents' inference from the response options offered to the intended meaning of the question. Also, it may be necessary to provide further instructions about the meaning of 'successfully completed', which would have to stress educational qualifications and (if inapplicable) grades completed. Finally, 'level of education' is a more abstract notion than 'educational qualification' and the question slightly more verbose than wording B (13 vs. 11 words), and thus may be more difficult for respondents and result in less precise data.

Therefore, the overall recommendation is to use wording $\mathrm{B}$, and for the consortium to provide guidance to countries for which potential ambiguities could arise.

For parental education, only the highest education is asked, so the options are simpler but otherwise equivalent to those presented above:

A: Which of the qualifications on this card is the highest your father (mother) has obtained?

B: What is your father's (mother's) highest educational qualification? Please use this card.

$\mathrm{C}$ : What is the highest level of education your father (mother) has successfully completed?

Please use this card.

Once again we recommend wording B, with the necessary guidance in case ambiguities exist.

\subsubsection{Instructions for interviewers and respondents}

Regardless of the wording used, it is probably prudent to include an additional instruction in the checkbox item to the effect that all qualifications should be reported. This can probably best be incorporated as a final part of the question, as an explicit instruction to the respondent. The wording for the three alternative versions would be as follows:

A: Please name all qualifications you have ever obtained.

B: Please name all qualifications you have ever obtained.

C: Please name all levels you have ever completed.

For wordings A and B, no additional instruction may be necessary, although one could consider including an interviewer instruction to the effect that respondents without any educational qualifications should still look at the card and check which of the categories not referring to educational qualifications but rather completed grades/schooling levels would apply. This could be somewhat enhanced by visually distinguishing these from the many response options referring to actual educational qualifications.

For wording $\mathrm{C}$, the following interviewer instruction is suggested to be used for clarification if a respondent is unsure whether the level he or she is thinking of has actually been successfully completed:

\section{Successful completion means that}

a) the respondent obtained an educational qualification, or,

b) in the case of an education program not issuing any qualification, the respondent has attended it fully, ideally obtaining a certificate of attendance or completion. 


\subsubsection{Response options}

Given the response options for the question on educational attainment are specific for each survey country, they are not part of the source questionnaire. For how to determine the harmonized target variable and how to develop country-specific response options that can be mapped to this target variable, see section 4.2 below.

\subsubsection{Respondents who were educated abroad}

In the questionnaire, there are several ways of dealing with respondents who have obtained some or all of their educational qualifications abroad. As a minimal requirement, the procedure used should allow us to identify the country in which the highest qualification was obtained. Taking this into account, as well as the proposed approach to measuring educational pathways as opposed to only highest attained level, we can distinguish the following possibilities:

1. Follow the strategy in PIAAC Cycle 1 and add a generic "foreign qualification" response option to the survey country specific response options, and route all respondents selecting this option to an open question requesting the name of this foreign qualification: "What is the name of this qualification?" This solution does not seem to have worked very well, possibly because this extra response option was presented last and thus overlooked by many respondents. This may be further complicated by the checkbox approach, in which respondents are asked to report all qualifications obtained. It may be confusing for respondents as to whether they should report their foreign qualifications directly in terms of the classification provided, separately as an explicitly reported foreign qualification, or both. It may also be quite difficult to ascertain which of these options they have chosen, and for which qualifications. We would therefore strongly advise against using this approach for PIAAC Cycle 2.

2. Follow the Canadian adapted PIAAC Cycle 1 strategy by asking every respondent, right after the actual educational attainment item, whether this highest education qualification was obtained in <survey country>. This extra question likely improves the identification of foreign qualifications compared to the general PIAAC strategy but takes a little extra time. Using a dynamic text rule to insert the local name of their highest reported qualification into a simple yes/no question, it should be very quick though. Respondents saying "no" could then be routed to the open question requesting the specific name: "What is the name of this level of education in the country in which you obtained this qualification?" While this solution would clearly improve upon PIAAC Cycle 1, it would not provide direct measures of foreign qualifications in PIAAC Cycle 2.

3. Employ the adaptive CAMCES cross-cultural education coding tool developed at GESIS - Leibniz Institute for the Social Sciences 2013-2018, which would basically replace the open question regarding the name of the foreign qualification by a closed question adapting to the educational system in which the respondent received his/her education. This requires additional questions in the questionnaire, prior to the checkbox item, to identify in which educational system the respondent has obtained his/her qualifications. The CAPI system can then be supplied with response options for this specific educational system for the actual checkbox item on educational 
pathways. The responses can be classified using the ISCED mappings for the country where the qualification was obtained, which are included in the database underlying the tool. It also allows reporting foreign qualifications in scripts not corresponding to the survey language, such as Kyrillic in Germany or Arabic in France. This solution is technically not trivial but, given that PIAAC will use one central CAPI system, probably not overly inefficient to implement either. Thanks to funding through the SERISS-project (see www.seriss.eu, Work Package 8), by 2019 this will be available for a large number of educational systems (currently around 30, mostly covering countries of origin of migrants in Germany, with the goal to cover 99 countries by 2019). The CAMCES tool has been implemented since 2015 in the IAB/SOEP migrant sample (Brücker et al., 2014). It should however be noted that since 100\% coverage is almost not going to be feasible by the time of data collection for PIAAC Cycle 2, it will be necessary to ask respondents from countries not in the tool to report their foreign qualifications in terms of the classification system of the survey country. Attention should be paid during interviewer training to ensure that respondents from these countries are given sufficient support in doing this. An important requirement is that the lists should contain both old and new qualifications in the case that the education system has changed in the lifetime of the oldest respondents.

4. Employ a low-tech version of the CAMCES approach by first asking whether the highest educational qualification was obtained in the survey country, routing those indicating that they have obtained their highest qualification abroad to a question identifying the relevant educational system, and then asking for the highest qualification obtained using a list of response options relevant for this specific educational system. It may not be feasible to use this approach for more than a limited number of foreign educational systems per survey country (e.g. the top migrant origin countries of the survey country) because interviewers would need to handle one show card per origin country. If a workable system can be devised to provide a greater number of show cards without this becoming too burdensome for the interviewer, the list could in principle be extended to include the full range of countries covered by strategy 3 . The production of these lists could be facilitated by the CAMCES database. For these countries, post-coding would then be hugely simplified by having predefined response options, and pre-defined mappings to the ISCED-based harmonized target education variable. For respondents who have been educated elsewhere, an open question could be asked like in solutions 1 and 2. We are not aware of any large-scale survey having tried this approach.

The main differences between solutions 1 and 2 on the one hand and solutions 3 and 4 on the other hand is whether information is collected on which survey country education qualification the respondent thinks his/her foreign qualification is equivalent with, complemented with an open question on the foreign qualification (solutions 1 and 2), or whether the respondent is asked to directly report their foreign qualification with reference to the respective education system, replacing the open question with a closed question (and thus resulting in valid international education codes without the need to post-code the open responses, which is very difficult in the case of foreign qualifications). While the former approach is pragmatically acceptable according to OECD and Eurostat (2014, p. 11), the latter 
would get the data closer to what is actually intended to be measured. Given the low number of respondents with foreign qualification in the PIAAC samples, average interview duration should not be much affected. That said, the affected group would be conceivably more likely to experience the survey as a burden than respondents who were entirely educated in the survey country.

For immigrants who have completed part of their education in the survey country and part abroad, it may actually be more difficult to place themselves in education categories referring to their country of origin than thinking about survey country equivalents. In their ideal form, options 3 and 4 are likely to work best for respondents whose educational pathways were entirely followed in a single foreign country. Immigrants who completed their educational pathway in the survey country will probably find it easier to place themselves in the destination country educational system.

To conclude, we would recommend going for solution 3 or 4, in the case of respondents who completed all of their studies in a single foreign country. Depending on how far the CAMCES tools are advanced at the time it can be decided which of these options to use. The proposal elaborated here assumes for simplicity's sake that we choose solution 4 . This solution requires that extra resources for developing measurement instruments for educational qualifications in the most common countries of origin of migrants in all PIAAC countries be raised. From our experience and with the help of the CAMCES database, two person days should be calculated per origin country. One advantage of taking a centralized approach here is that many migrant groups are important in several countries participating in PIAAC so that only e.g. the instrument developed for say Moroccan qualifications needs to be developed once and this can be used in all countries with substantial numbers of first generation immigrants from Morocco. For migrant origin countries that are also PIAAC participating countries, the instruments developed for the respective country can be used for foreign qualifications in other countries also. If this approach (or even employing the CAMCES tools) is regarded as too resource intensive, PIAAC should go for solution 2 in Cycle 2. 


\subsection{Educational pathways}

\subsubsection{Approach in PIAAC cycle 1}

In PIAAC cycle 1 the submodule on educational pathways had the following rough structure:

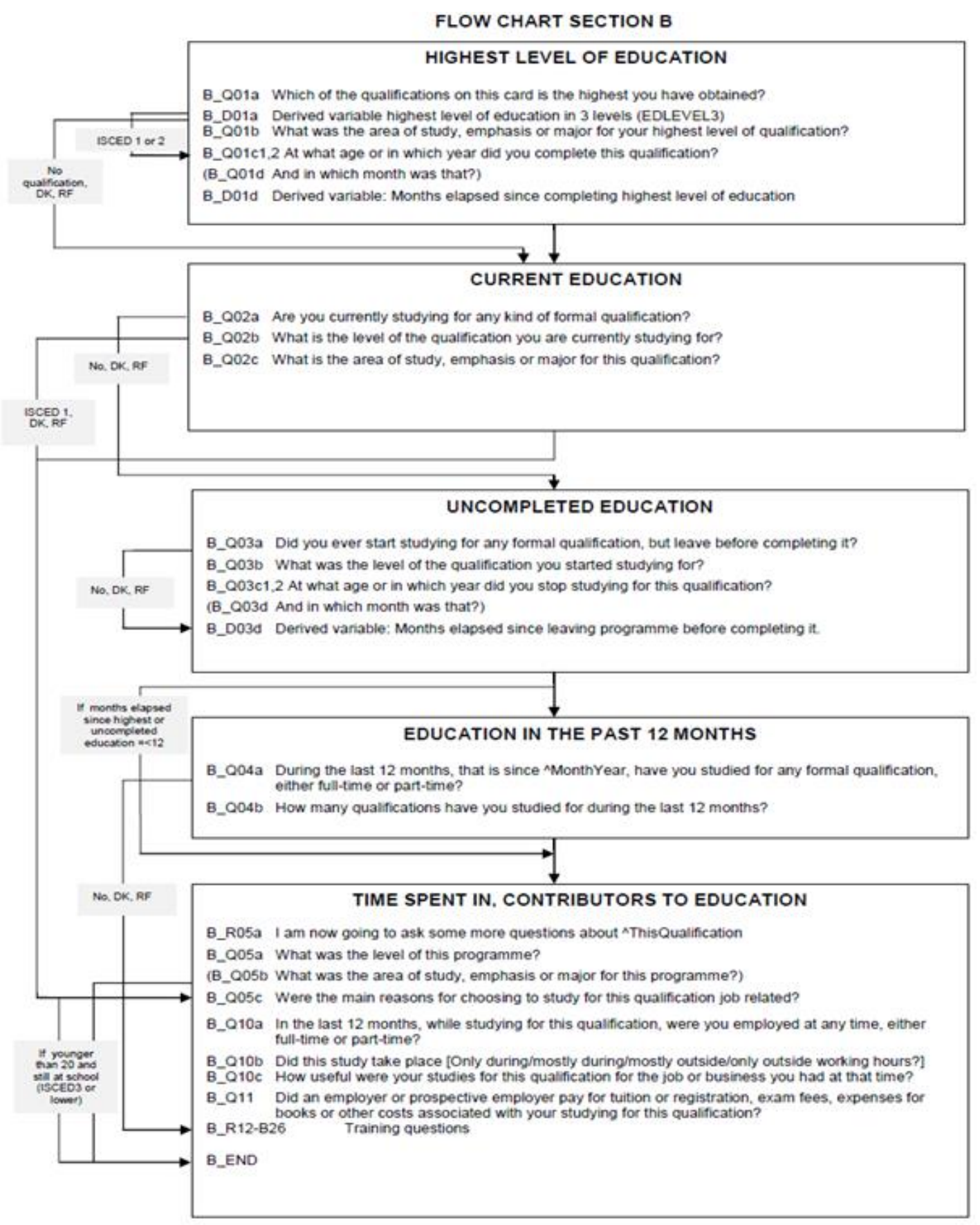

As indicated above in section 3.1, for various reasons this approach was regarded as unsatisfactory. A clear aim of this part of the BQ was to produce multiple indicators, comprising highest completed level of education (B_Q01), current participation in education (B_Q02), education started but not completed (B_Q03), as well as any formal education followed in the past 12 months (B_Q04 and B_Q05). Especially the latter requirement gave rise to a routing structure that was extremely complex and difficult for countries to adapt. A disproportionate amount of resources - both of countries and of the consortium - was invested in adapting and checking this part of the BQ. The complexity was further compounded by 
extensive changes to the structure in some countries, splitting single items into multiple questions and using a different routing, etc. Despite this complexity, the submodule still provided little information on respondents' educational history leading up to their highest qualification.

\subsubsection{Proposed approach for measuring educational pathways in PIAAC cycle 2}

The proposal described below offers improved measurement of educational pathways leading to the currently highest level of education. It makes it possible to distinguish alternative routes through education that may lead to the same level of qualification, including educational programmes currently enrolled in, as well as programmes that were started but not completed. It also provides more detailed information on foreign qualifications than was provided by the PIAAC Cycle $1 \mathrm{BQ}$.

The cornerstone of this approach is a checkbox item in which respondents are asked to report on all completed educational qualifications. In addition, respondents are asked to report the year in which they completed their highest qualifications, as well as the year in which they completed relevant prior qualifications. A possible disadvantage of this approach is that it is potentially rather time-consuming. Given the other topics that must be covered within the module and elsewhere in the BQ, this is a serious consideration. For this reason, the final decision on the number of prior qualifications for which respondents are asked to report the completion year should be made contingent on an assessment of what an acceptable time burden is for this part of the questionnaire. This can be varied without infringing on the basic logic of the module in any meaningful way.

We will return to the question of time burden below, after describing the module in detail. At this point it can be pointed out that there are considerable advantages to be weighed against the potential time disadvantage, in terms of information obtained, relative ease of adaptation, and a clear and logical flow for the respondent. Alternative designs (for example asking the highest completed qualification and, in separate questions, a selection of prior qualifications that would allow different pathways to be distinguished) would necessarily have to incorporate criteria for identifying the qualifications about which we require information. Such criteria are likely to be rather arbitrary and may not correspond to the subjective experience of many respondents, resulting in attention being paid to qualifications that are not at all important to respondents, while neglecting qualifications that are crucial in their eyes.

An additional aspect of the "comprehensive" approach may be an advantage or a disadvantage, depending on how it is viewed. The assessment of "highest completed education" is no longer left up to the respondent, but is derived from the answers provided. It is not expected that this will lead to major change in assigned levels, but strictly speaking it is not perfectly comparable to the measure obtained in the $1^{\text {st }}$ Cycle of PIAAC. It may also require additional support and consultation for countries in determining the ordering in cases when multiple qualifications correspond to the same nominal level.

Figure 4 shows in reduced form a sketch of the revised submodule on educational pathways. A complete version is included in the appendix. 
Figure4: Revised submodule on educational pathways

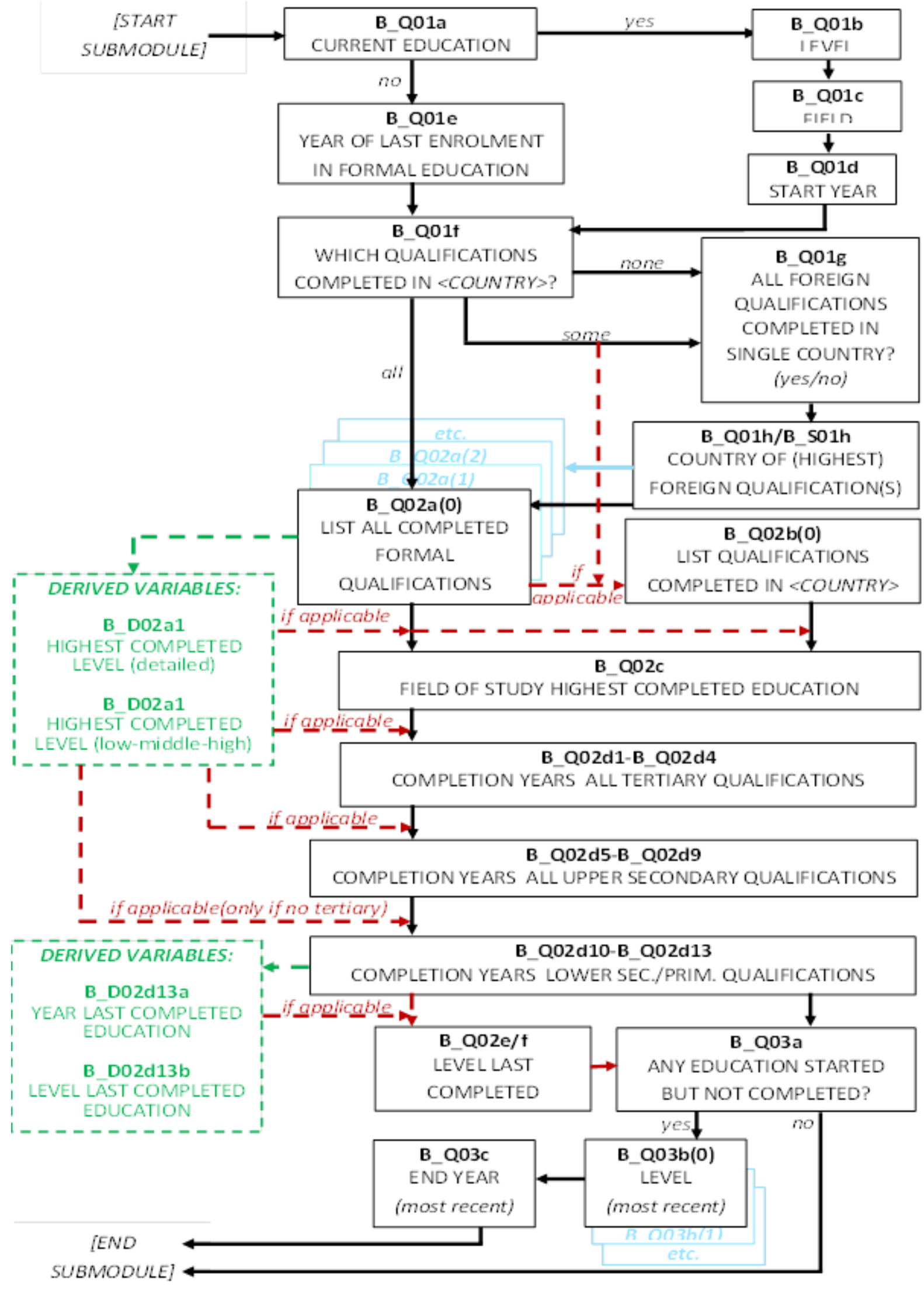


The submodule starts by asking respondents whether they are currently in education (B_Q01a). This could potentially be moved to the end, but for those currently in education it is probably the most important topic in this module, in which case they will probably be happy to start with this. Those who are in education are asked to report the level (B_Q01b) and field (B_Q01c) of this education, and when they first enrolled in their current programme (B_Q01d). This latter question is not strictly necessary, but it could be useful in terms of understanding pathways in general. If time constraints are pressing, it could be dropped .

Those not currently in education are asked to report the year in which they were last enrolled in formal education (B_Q01e). Since we ask timing for individual qualifications, this question may be redundant for many respondents. Given the importance of the transition out of education, it is nonetheless important to have a clear and unambiguous indicator for this.

Following this question all respondents, including those currently in education, are asked whether they followed any or all of their education abroad (B_Q01f). For the majority of respondents the entire education pathway will have been followed in the target country, and they can proceed to the checkbox item on educational pathways (see B_Q02a below). Respondents who followed at least part of their education abroad are asked to indicate whether all their foreign education took place in a single country (B_Q01g), and to indicate the country in which they completed their highest foreign qualification (B_Q01h/B_S01h). It is to be expected that most will report just one foreign country, but respondents who have studied in multiple foreign countries will probably appreciate being able to report this. This question could be dropped if time constraints are too pressing. Using the subsequent timing questions we can determine the point at which most respondents entered the domestic education system.

Respondents will then be asked to report all the qualifications they have completed during their lives (B_Q02a). Depending on the answers to B_Q01f-B_Q01h, some respondents will be assigned to a different version of this question (B_Q02a1-10), in which they are asked to report all qualifications in terms of the classification of their country of origin, using (response items based on) the CAMCES cross-cultural education coding tool. For logistical reasons this is only practicable for those respondents who reported that they received all of their education in a single foreign country for which the consortium possesses an ISCEDmapping derived from the CAMCES tool. For respondents whose educational pathways are divided over multiple countries - whether this comprises multiple foreign countries or a single foreign country in addition to the survey country - it is hazardous to try to second-guess which classification scheme is likely to be easier for them, and allowing them to report in terms of multiple schemes would be too confusing and prone to omissions, double-reporting and other errors. Since the limitations of reporting in terms of the classification of the survey country did not appear to have led to major systematic errors in PIAAC Cycle 1, we recommend that it also be the default option in Cycle 2 (B_Q02a0), with the CAMCES tool only being utilized in cases where the entire pathway was followed abroad.

This single checkbox item provides a snapshot of the complete educational history of all respondents. Two derived variables will be generated by the system at this point: a detailed (BD02a1) and a broad (B_D02a2) indicator of highest completed level. By deriving this from the multiple answer item we remove the respondent's subjective perception from the measure. 
Countries will perhaps require some support in determining the ordering when multiple national qualifications nominally correspond to the same ISCED levels. These will function in subsequent routings.

Respondents who followed part of their education abroad are then asked to list the qualifications they completed in the target country (B_Q02b). Please note that this question is not needed for those respondents who either received all of their education abroad or all of their education in the survey country. Depending on whether we expect those with foreign qualifications to have completed most of their education in their country of origin or in the target country, we also could ask them to list qualifications completed abroad, but since those received in the survey country will generally be more recent, we expect this form to be less of a burden on the respondents' memories.

For the derived highest level of education we then ask the field of study (B_Q02c).

Without timing data the answers to these questions do not strictly speaking describe educational pathways: it could well be that some respondents have deviated from a strict vertical route through education. Using the answers derived from the checkbox item and the associated derived variables on highest completed education, we then ask timing data on the highest completed levels, and on relevant prior qualifications (B_Q02d1-13). Depending on the derived highest level of education, different respondents will be routed past some of these questions. For those in tertiary education we ask for timing data on all qualifications after completion of lower secondary education. This could potentially be restricted further if time constraints demanded, for example asking PhDs to report only prior tertiary education. Such adjustments would require only relatively minor changes to the routing rules. For those with secondary or primary education as highest completed level we ask timing for all completed programmes. In practice the burden should be relatively limited for these respondents, since the pathways are less extensive.

Based on the timing data we derive the completion year (B_D02d13a) and level (B_D02d132) of the last programme completed in formal education. In case the derived year is earlier than that directly reported above, an additional check can be built in to check that the derived degree is in fact the last completed degree (B_Q02e/f).

Finally we ask whether there was any education that respondents started but did not complete (B_Q03a). If not, respondents are routed to the end of the submodule. If so, we then add a question, only asked of those respondents who indicated that they received all of their completed education outside the survey country, to ascertain whether the uncompleted education was also followed outside the survey country. This is necessary because we want to allow those respondents who used the CAMCES tool to report their completed educational pathways to also report the level (B_Q03b) of their uncompleted education using the same classification. This only makes sense however if this education was also followed abroad. If it was followed in the survey country, it makes more sense for them to use the domestic classification to report it. Finally, to complete the information on pathways, we ask the final year (B_Q03c) of the most uncompleted qualification with the highest level.

It should be noted here that we could have incorporated both completed and uncompleted qualifications in the initial checkbox item, adding an additional question to determine which 
ones were actually completed. However, this would have added an unwelcome layer of complexity to this module, which could have created confusion and problems, both for the consortium and countries while developing and adapting the module, and for respondents when providing their answers. Since the information on uncompleted education is regarded as less crucial than completed education (especially highest completed level), we decided not to "muddy" the core questions in this way.

\subsubsection{Time estimates}

The following table provides estimates of the time requirements according to several scenarios.

Table 1: Estimated time required to complete questions on educational pathways according to different scenarios

\begin{tabular}{|c|c|c|}
\hline \multirow[b]{2}{*}{ Scenario } & \multicolumn{2}{|c|}{ Time estimates (minutes) } \\
\hline & full set of questions & $\begin{array}{r}\text { excluding non-essential } \\
\text { questions }\end{array}$ \\
\hline current - foreign - 5 timings - unfinished & 13 & 12.25 \\
\hline current - foreign - 3 timings - unfinished & 12 & 11.25 \\
\hline current - foreign - 4 timings - no unfinished & 11 & 10.25 \\
\hline current - no foreign - 4 timings - unfinished & 10 & 9.5 \\
\hline no current - foreign - 4 timings - unfinished & 10 & 9.75 \\
\hline no current - no foreign - 3 timings - no unfinished & 6.5 & 6.5 \\
\hline \multicolumn{3}{|l|}{ Legend: } \\
\hline \multicolumn{3}{|l|}{ current $=$ currently in education } \\
\hline \multicolumn{3}{|c|}{ foreign $=$ part of educational pathways completed abroad } \\
\hline $3 / 4 / 5$ timings $=$ number of qualifications for which & & \\
\hline
\end{tabular}

The presented scenarios show how much time respondents with different profiles will take to complete the submodule. We show two versions of each scenario, one based only on essential questions, and the other on the full set of questions. As can be seen, for some respondents, namely those who are currently in education, who completed part of their educational pathways abroad, and who have started some education and stopped without completing it, the required time is substantial. However, this is broadly comparable to the equivalent sections in PIAAC Cycle 1, with a much higher information yield, in particular with respect to educational pathways and foreign qualifications. Furthermore, it is to be expected that many of these respondents, in particular those currently in education, will have a lesser time burden in other sections of the questionnaire.

\subsection{Non-formal and informal learning}

In Section 2.4 several reasons are outlined why specific topics should be included in the PIAAC questionnaire on non-formal and informal learning. Furthermore, we analysed data from cycle 1 in order to estimate the relevance of variables related to non-formal training and skills. 
Some items used in the first cycle of PIAAC could be changed and improved in order to better capture some policy-relevant information related to training activities.

B_Q12A: During the last 12 months, have you participated in courses conducted through open or distance education?

B_Q12C: During the last 12 months, have you attended any organized sessions for on-the-job training or training by supervisors or co-workers?

B_Q12E: During the last 12 months, have you participated in seminars or workshops?

B_Q12G: During the last 12 months, have you participated in courses or private lessons, not already reported?

Problem identified: This question is intended to elicit different kinds of training activities that exist in order to draw a full picture of training participation. However, respondents do not necessarily see them as mutually exclusive. Some training activities fit more than one category and could therefore be mentioned more than once. This problem can be assumed looking at the number of training activities mentioned by respondents: while in PIAAC, respondents mention more than 15 activities as a mean, in other surveys this is much lower (e.g. PIAAC-L and AES 2012: about 5 activities). Although non-response is not high, it might be an indication that respondents are confused where to mention their training activities.

Suggestion: include question on total number of trainings (including examples of different type of training activities), then ask about most important activity in more detail. Instead of asking B_Q12D (job-related training) ask about reasons why it was attended, whether it was job-related and whether it was provided by the employer or encouraged by the employer.

Rationale of suggested change: When changing these questions, respondents can answer them more easily. As it is important that respondents mention all of their training activities, the introduction to this question should include a wide array of different training activities. Furthermore, we suggest including more specific measures than just asking about job-related training, such as employer's support. This allows to better estimate expected benefits of training activity.

B_Q15a: Were you employed, either full-time or part-time, at any time while participating in this activity?

Suggestion: include more categories on employment status (e.g. out of the labor market).

Rationale: In PIAAC cycle 1, respondents were asked whether they were employed at the time of taking the training activity. This seems reasonable because a lot of research has shown most training activities are job-related. However, it is also relevant to know more about respondents who were not employed during their training in order to deduct policies. Including more answer categories thus enables us to get more information about the respondent without extending the burden for respondents. 
B_Q16: Did an employer or prospective employer pay for tuition or registration, exam fees, expenses for books or other costs resulting from your participation in this activity? Would that be ...

Suggestion: in PIAAC cycle 1, the information gathered through this item only provides information whether the employer took on expenses for the training activity. Instead of asking if it was paid by the employer, we suggest to ask whether it was paid by the respondent. If the respondent did not pay for it totally, ask who else provided funding.

Rationale: As mentioned above, a lot of training is job-related. From analyses of the items on barriers to education, we know that financial issues are a barrier in some countries but not so much in others. Therefore, it is relevant to know more about who was involved in the financing of the training activity. This question can also provide information about respondents who do not have an employer. Funding by the employer can be an indication of the relevance of training: it can be assumed that employers invest more in training from which they expect positive outcomes.

B_Q17: Now let's look at the total amount of time you have spent in the past 12 months on all types of courses, training, private lessons, seminars or workshops. What is the easiest way to describe the total time you spent on all these activities: would that be in whole weeks, in whole days or in hours? Exclude time spent on homework or travel.

B_Q18A: From ^MonthYear until now, how many whole weeks did you spend in these activities?

B_Q19a: From ${ }^{\wedge}$ MonthYear until now, how many whole days did you spend in these activities?

B_Q20a: From ${ }^{\wedge}$ MonthYear until now, how many hours did you spend in these activities? Exclude hours spent travelling to and from the places at which these activities took place.

Problem identified: The items in PIAAC cycle 1 were asked in a way that was supposed to make the answer process for respondents easier. However, it seems as though these answers are difficult to answer, especially the first item on time frame are difficult to answer. Furthermore, it is difficult to estimate the time spent on education from the different answers. Suggestion: Instead ask about total days of training in the last 12 months, and ask about total hours of training directly for the most important training activity (can be given in hours or weeks).

Rationale of suggested change: Asking to different questions allows to have different indicators on time spent on training activities. Furthermore, asking directly about the hours or weeks of training enables respondents to better answer this question without putting too much burden on them.

B_Q26b: Which of the following reasons prevented you from participating in education and training? Please indicate the most important reason. 
Suggestion: Answer categories for barriers to training should be extended.

Rationale: This may help to get a more comprehensive picture of different kind of barriers that could be addressed by policy. Especially important is the aspect that respondents were not interested in training activities.

Additional information that is relevant but not included in PIAAC cycle 1:

-Looking for and accessing information related to training

Rationale: From a policy perspective it is relevant whether respondents are actually able to find information they need. This enables to know more about respondents who are not taking up training activities and forms one potential barrier to training.

- More information on transferability of training

Rationale: from a theoretical perspective, employers are less willing to fund training if it transferable to other jobs. However, for employees transferability is positive because it increases their career opportunities. It can be used to assess the impact this kind of training has on skill development.

- Questions about potential training in the future

Rationale: information about the likelihood of training in the near future can give an indication of the motivation to learn and to develop.

- More information on informal learning

Rationale: informal learning has become more important and therefore it is important to know more about informal learning and its relationship to skills. Informal learning is a type of learning with lower barriers and especially takes place in smaller firms in which less nonformal training takes place. Having more information about informal learning, gives a better estimate of the total efforts spent on training which impact skill development.

We would like to propose to ask the following topics. Topics listed in grey are less relevant than the other topics and could be omitted due to time constraints or policy decisions:

- Participation in training in the preceding year

- How many trainings

○ Distinction whether job-related or not

- How many days in total

- More information on most important training during previous year

- Job related or not

- Reason for participation

- Total hours, days or weeks

- Training by employment agency

- Occupational status during training (employed, unemployed,...)

- For employed: Usefulness of training for current job

- Usefulness of training in case of job change

- Employer encouraged participation

- Employer offered training 
- Participation during working hours

○ Cost participation (employer, self...)

- Certificate for training used in $\mathrm{CV}$

- Was training content used in work/every-day life (skill use)

- Trainings one would have liked to participate

○ Barriers to training participation (detailed list)

- For non-participants, questions about potential training activities:

○ Participation more likely work-related or private

o Which format most likely

- How likely to participate in training in following 12 months

- Looking for training information in past year

- Find information

- Where looking for information

- Would like information/guidance about training opportunities

- Informal learning

○ In which form/from whom

○ Work-related/non-work related

- Usefulness of learning activity

Suggested wording of items on non-formal and informal learning. Questions listed in grey are not seen as core questions:

In the following questions we will ask you about participation in training activities in the last 12 months. By training activities we mean participation in a course, workshop, seminar, conference or other training activity that aims at improving or acquiring knowledge or skills. It can be job-related or not, the initiative to participate can come from you or your employer, from yourself or someone else. The activity can take up few hours or be spread over several months. Learning outside of courses, for example reading of text books should not be included here.

Q1. Did you participate at least in one training activity in the last 12 months?

1 Yes

2 No

DK

RF

Q2. How many training activities did you attend in the last 12 months?

DK

RF

Q3. How many of these trainings were job-related?

DK

RF 
Q4. How many days in total did you attend training activities?

Please mention every day of training even if the training activity only lasted a few hours.

\section{DK}

RF

R5. If $Q=1$. We will now ask you more detailed information about this training activity. If $Q>1$ : We will now ask you more detailed information about the training activity which you find most important.

Interviewer: "Most important" refers to the subjective impression of the respondent. It can refer to the most useful for the job, the most helpful for private life. If the respondent cannot choose between different activities, they should choose the most recent.

Q5. Was this training activity work-related?

1 Yes

2 No

3 Partially

DK

RF

Q6. What was the main reason why you participated in this training activitiy?

1 To do my job better and/or improve career prospects

2 To be less likely to lose my job

3 To increase my possibilities of getting a job, or changing a job or profession

4 To start my own business

5 I was obliged to participate

6 To increase my knowledge or skills on a subject that interests me

7 To obtain a certificate

DK

RF

Q7. How much time did you spend in the last 12 months as part of your training activity? Please also consider homework. You can tell me in total hours, hours per week including the number of weeks or months that you attended this activity. total hours hours/week in hours/week in weeks

\begin{tabular}{lr}
\hline & hours/week in \\
\hline & hours/week in $\_$weeks \\
\hline $\mathrm{DK}$ &
\end{tabular}

Q8. Was it a training activity offered by the employment agency?

1 Yes
2 No
DK
RF

Q9. When you participated in this training activity, were you...

1 Employed

2 Unemployed

3 Not employed (e.g. retired, student, homemaker)

DK

$\mathrm{RF}$ 
If Q9=1: Q10. How useful was this training for the job or business you had at that time? Would you say it was...

1 Not useful

2 Somewhat useful

3 Quite useful

4 Very useful

DK

RF

If $Q 9=1$. Q11. How useful would this training be if you worked for another employer? The training activity would be...

1 Not useful

2 Somewhat useful

3 Quite useful

4 Very useful

DK

RF

If $Q 9=1$. Q12. Did your employer encourage you to participate in this training activity?

1 Yes, and participation was mandatory

2 Yes, and participation was voluntary

3 No, participation was own initiative

4 Not applicable, I am or was self-employed

DK

RF

If $Q 9=1$. Q13 Did your employer provide this training activity?

1 Yes

2 No

DK

RF

If Q9=1. Q14. Did this activity take place ...

1 Only during working hours

2 Mostly during working hours

3 Mostly outside working hours

4 Only outside working hours

DK

RF

All. Q15. Did you pay for the tuition and fees of this training activity fully or partially yourself?

1 Yes, fully

2 Yes, partially

3 No

4 No such costs

DK

RF 
If $Q 15=2$ or 3. Q16. Who else took up tuition or fees of this training activity?

1 Employer

2 Employment agency

3 Other public funding

4 Others

DK

$\mathrm{RF}$

Q17. Would you mention this training activity in your CV when applying for a job?

1 Yes

2 No

3 Depends on the job

DK

RF

Q18. In the last 12 months, were there ${ }^{\wedge}$ MoreAny learning activities you wanted to participate in but did not?

1 Yes

2 No

DK

RF

If Q1=2, DK or RF. Q19. Which of the following reasons prevented you from participating in training activities? Please indicate the most important reason.

1 No suitable education or training activity offered

2 Training took place at inconvenient time or at inconvenient location

3 No time - due to work-related responsibilities / conflicted with work schedule

4 No time - due to family responsibilities

5 Lack of employer's support

6 Training would not have improved job prospects

7 Training would have entailed costs or salary cut

8 Did not dare participate

9 Did not have prerequisites

10 Training is not worthwhile at my age

11 Did not have a good overview of training possibilities

12 No interest

13 Other reason

DK

RF

If $Q 1=2$, DK or RF. Q20. How likely is it that you will participate in a training activity in the next 12 months?

1 Not at all likely

2 Not very likely

3 Somewhat likely

4 Very likely

DK

RF 
If $Q 1=2$, DK or $R F \& Q 20>1$. Q21. If you take up a training activity in the future, would you rather participate because of job-related or private reasons?

1 Mainly job-related

2 Mainly personal reasons

3 Both

DK

RF

If Q1=2, DK or RF: Q22. Did you look for information about training activities in the last 12 months?

1 Yes

2 No

DK

RF

If Q1=2, DK or RF: Q23. Did you find relevant information you were looking for?

1 Yes

2 No

3 Partially

DK

RF

If Q1=2, DK or RF: Q24. Where did you look for information?

1 Internet

2 Family, friends, neighbors, colleagues

3 Employer

4 Career guidance providers or Federal Employment Agency

5 Providers of continuing education (e.g. adult education centers)

6 Education or training institution (school, university)

7 Professional journals or textbooks

8 Other media (e.g. TV, radio, newspaper)

9 Other

DK

RF

If Q1=2, DK or RF: Q25. Would you like to receive more information or guidance on training activities?

1 Yes, more information

2Yes, more guidance

3 Yes, both

$4 \mathrm{No}$

DK

RF

R26. Skills and knowledge can be acquired or improved by different means. Apart from school, university, courses or further training you can also intentionally learn on your own. By this we mean learning from colleagues, visiting museums, reading textbooks, learning on the computer, or on the internet. This can include learning during work or free time, in groups or alone.

Q26. Please think about the last four weeks. Did you intentionally learn anything about a specific topic on your own during the last four weeks? 
Interviewer Instruction:

- Please mark all applicable answers.

- Training activities mentioned before, should not be repeated.

1 Yes, from family members, friends or colleagues

2 Yes, by reading books or journals

3 Yes, by using learning tools on the computer, the internet or with apps

4 Yes, from programs on TV, Radio, the internet or other media

5 Yes, by doing research on the internet or on other media

6 Yes, by practicing (learning by doing)

7 Yes, by other means

8 No

DK

RF

Q27. Please think about the most important topic that you learned about by one of these means. Did you carry it out mostly because of work-related or because of private reasons?

1 Predominantly work-related reasons

2 Predominantly for private reasons

DK

RF

Q28. How often did you spend time learning on your own in the last four weeks?

1 Never

2 Seldom

3 Sometimes

4 Often

DK

RF

Q29. Do you have the impression that this learning was helpful for you?

1 Yes, it was useful for my job.

2 Yes, it was useful for my private life.

3 Yes, it was useful for my job and for my private life.

$4 \mathrm{No}$, it was not useful.

DK

RF

Q30. To which of these statements do you agree most?

1 I prefer learning by myself.

2 I prefer learning in courses.

3 I prefer learning in groups outside of courses.

4 It depends on what I want to learn.

5 None of the above options.

DK

RF 


\section{Implementation and guidelines for adaptations and harmonization}

\subsection{Achieving comparability}

The survey design literature distinguishes two general approaches for achieving comparability of survey data (see e.g. Wolf et al., 2016): Input harmonization and output harmonization. Input harmonization means that the same instruments can be used across countries, and that comparability is achieved by the translation of instruments. A 'good' translation, in contrast to a naïve literal or word-to-word translation, often involves adaptations to the relevant cultural context in which the instrument is to be applied. Output harmonization in contrast is necessary when translation (including adaptation) does not produce comparable data, or is not possible, which is usually the case when national institutions play a role. This is typically the case when dealing with education-related information. If output harmonization is built into the survey design process, which is recommended for cross-national surveys, it is called ex-ante output harmonization (but for simplicity we will use the term 'harmonization' in the remainder of this text).

In PIAAC Cycle 1, the term adaptation was used in a very broad sense of any changes in questionnaire items required to make the item suitable for a specific national context, i.e. for good translation and output harmonization. This usage is somewhat confusing because 'adaptation' in the sense of 'good translation' and 'harmonization' have quite different practical implications in terms of the specific steps that need to be taken to achieve comparable data (for details see Wolf et al., 2016). To better clarify tasks for national teams in PIAAC Cycle 2, we propose the following differentiation:

- Whenever text elements in the questionnaire need to be 'adapted' to national circumstances without any further design differences between instruments across countries (especially identical number and equivalent content of response options), this is referred to as an adaptation. After data collection, data resulting from adapted items do not require further processing, or rather, the data processing is the same across countries. Such items thus do not require country identifiers in variable names.

- Whenever the number and/or type of response options needs to differ across countries (and it is often even difficult to specify a 'source' version), this is referred to as harmonization. The country-specific response options need to be specified and mapped to internationally harmonized codes for every single country before data collection, and after data collection, they need to be applied in every country individually. Such items require country identifiers in variable names (the harmonized variable will have the same name without the country identifier).

While adaptation can usually be achieved during the translation process according to the translation guidelines, ex-ante output harmonization requires extra work both in terms of central coordination as well as in the country teams. We recommend that in PIAAC Cycle 2, this 'extra work' is identified, planned, executed and quality monitored separately from the translation process. It is recommended to provide harmonization templates for the affected questionnaire items. 


\subsection{Educational attainment}

This section discusses the implementation of educational attainment measures proposed in section 3.2 in PIAAC Cycle 2. It specifically sets out several options for harmonized target variables that could be implemented, and how country-specific response options for the education question can be developed in such a way as to produce comparable data when coded into the harmonized target variable.

\subsubsection{Operationalizing educational attainment}

In PIAAC Cycle 1, the specifications for harmonizing national educational qualifications had gaps leading countries to fill these gaps differently, producing a lower than optimal degree of comparability. Some examples of this are provided in the appendix (section 7.1), such as countries differently classifying respondents without educational qualifications, or some countries equating attendance in a specific educational level with completion of that level.

PIAAC Cycle 2 should follow the internationally agreed definitions of educational attainment as laid down in the International Standard Classification of Education (ISCED, UNESCO Institute for Statistics, 2012, p. 20). OECD and Eurostat have since PIAAC Cycle 1 published further detailed guidelines for measuring educational attainment in surveys (OECD and Eurostat, 2014). These guidelines should be made available and followed by all countries participating in future PIAAC rounds. This should reduce some of the problems reported in the appendix (section 7.1).

Specifically, it is important that educational attainment is measured by the highest level of education successfully completed, which is typically indicated by the highest formal (officially recognized) educational qualification obtained. For education levels that do not conclude with any formal qualification, which is common for ISCED level 1 in many countries, and sometimes also ISCED level 2, the indicator would be access to the next higher level of education. This usually corresponds to the successful completion of the final year of the educational programme in question.

\subsubsection{Choice of ISCED coding scheme and other target variables}

To achieve cross-nationally comparable education variables for PIAAC, the country specific variables need to be output-harmonized into the coding scheme determined for use in PIAAC. For both theoretical and empirical (see section 7.1.2 in the appendix) reasons, the ISCEDbased coding scheme used in PIAAC Cycle 2 should clearly differentiate ISCED 2011 main levels as well as vocational and general education and program destination (OECD and Eurostat, 2014, p. 12). Using main ISCED 1997 levels as suggested in the Core Social Variables (European Commission, 2007) is not recommended because this means that a lot of information on differentiation in tertiary education gets lost to the analyst.

Two options are proposed here to improve both the empirical as well as theoretical qualities of education harmonization in PIAAC Cycle 2:

1. Educational levels and qualifications are classified according to ISCED-A. The variable will become substantially more differentiated, resulting in 32 categories.

2. Educational levels and qualifications are classified according to a coding scheme derived from ISCED-A but not directly corresponding to it. This should basically add the vocational/general distinction to b_q01a and better distinguish destination 
categories A, B and C adopted from ISCED 97. Categories with unspecified information like in PIAAC Cycle 1 ("ISCED 3 (without distinction A-B-C, 2y+)" or "ISCED 4 (without distinction A-B-C)") should be avoided as much as possible - the ISCED mappings usually permit identifying the required piece of information. This coding would result in 21 categories, which can be recoded to ISCED 2011 main levels. Some of them would be empty in some countries, but this is not a problem in general because educational systems are just not equally differentiated. This would basically create a new ISCED-related standard that is specifically geared towards a study focusing on education, while the coding scheme used in PIAAC Cycle 1 was adapted from the labour force survey, which may have different measurement requirements. The ESS has since 2010 successfully implemented an ISCED based coding scheme with 27 categories which is similar but yet a bit more complex than the solution proposed here for PIAAC Cycle 2.

Table shows the relationship of these options to b_q01a. Issues of disclosure/small case numbers in specific categories in specific countries need to be discussed. 
Table 2: Detailed ISCED coding scheme in PIAAC Cycle 1, B_Q01a, and its relationship with ISCED-A (ISCED 2011)

\begin{tabular}{|c|c|c|c|c|}
\hline B_Q01a & Label & ISCED-A & ISCED-As & Label \\
\hline \multirow[t]{2}{*}{1} & \multirow{2}{*}{$\begin{array}{l}\text { No formal qualification or below } \\
\text { ISCED } 1\end{array}$} & 010,020 & 0 & No primary education, never been to school \\
\hline & & 030 & 030 & Some primary education (ISCED 1) \\
\hline 2 & ISCED 1 & 100 & 100 & Primary education (ISCED 1) completed \\
\hline \multirow[t]{2}{*}{3} & \multirow[t]{2}{*}{ ISCED 2} & $\begin{array}{l}200,240,242,243,244,250,252, \\
253,254\end{array}$ & $250^{2}$ & (Pre-)Vocational and lower track general lower secondary education (ISCED 2 low) \\
\hline & & 244 & 244 & General lower secondary education (ISCED 2 high) \\
\hline \multirow[t]{2}{*}{4} & \multirow[t]{2}{*}{ ISCED $3 \mathrm{C}$ shorter than 2 years } & 254 & 259 & Vocational short upper secondary education (ISCED 3Cs voc) \\
\hline & & 244 & 249 & General short upper secondary education (ISCED 3Cs gen) \\
\hline \multirow[t]{2}{*}{5} & \multirow[t]{2}{*}{ ISCED 3C 2 years or more } & \multirow[t]{2}{*}{$352,342,353,343$} & 353 & Vocational upper secondary education, no access to tertiary (ISCED 3C voc) \\
\hline & & & 343 & General upper secondary education, no access to tertiary (ISCED 3C gen) \\
\hline \multirow[t]{2}{*}{6} & \multirow[t]{2}{*}{ ISCED 3A-B } & 354 & 354 & Vocational upper secondary education, access to tertiary (ISCED 3AB voc) \\
\hline & & 344 & 344 & General upper secondary education, access to tertiary (ISCED 3AB gen) \\
\hline 7 & $\begin{array}{l}\text { ISCED } 3 \text { (without distinction A-B- } \\
\mathrm{C}, 2 \mathrm{y}+\text { ) }\end{array}$ & 300 & & N/A \\
\hline 8 & ISCED 4C & 453,443 & 453 & Vocational post-secondary education, no access to tertiary (ISCED 4AB voc) \\
\hline \multirow[t]{2}{*}{9} & \multirow[t]{2}{*}{ ISCED 4A-B } & \multirow[t]{2}{*}{454,444} & 454 & Vocational post-secondary education, access to tertiary (ISCED 4AB voc) \\
\hline & & & 444 & General post-secondary education, access to tertiary (ISCED 4AB gen) \\
\hline 10 & $\begin{array}{l}\text { ISCED } 4 \text { (without distinction A-B- } \\
\text { C) }\end{array}$ & 400 & & N/A \\
\hline \multirow[t]{2}{*}{11} & \multirow[t]{2}{*}{ ISCED 5B } & \multirow[t]{2}{*}{540,550} & $540^{3}$ & Academic sub-degree level education (ISCED 5A int gen) \\
\hline & & & 550 & Applied sub-degree level education (ISCED 5A med voc) \\
\hline \multirow[t]{2}{*}{12} & \multirow[t]{2}{*}{ ISCED 5A, bachelor degree } & \multirow[t]{2}{*}{640,650} & $640^{3}$ & Academic Bachelor's level education (ISCED 5A med gen) \\
\hline & & & 650 & Applied Bachelor's level education (ISCED 5A med voc) \\
\hline \multirow[t]{2}{*}{13} & \multirow[t]{2}{*}{ ISCED 5A, master degree } & \multirow[t]{2}{*}{740,750} & $740^{3}$ & Academic Master's level education (ISCED 5A long gen) \\
\hline & & & 750 & Applied Master's level education (ISCED 5A long voc) \\
\hline 14 & ISCED 6 & 800 & 800 & Doctorate degree \\
\hline
\end{tabular}

2. Qualifications classified as general in ISCED level 2 but not designed to prepare for ISCED 34x programs should be classified here rather than in $24 x$.

3. While there are no internationally accepted international definitions for academic and 'non-academic' tertiary education, we suggest to use national distinctions within tertiary education to distinguish $540 / 550,640 / 650$ and 740/750. While not strictly comparable, the most selective educational qualifications will be coded 640 and 740 across countries. 


\subsubsection{Guideline for development of country-specific educational attainment question(s)}

\subsubsection{Instrument development}

While measurement instruments from PIAAC cycle 1 could generally be used as the starting point for instrument development, these instruments need to be thoroughly reviewed for use in PIAAC cycle 2. Feedback from cycle 1 fieldwork and other lessons learned from PIAAC Cycle 1 (e.g. issues with reliability or validity etc.) should be taken into account, as well as potential results from cognitive pretesting or empirical studies using this data hinting at instrument issues.

For some countries, the country-specific instruments were much more complex than for others in PIAAC Cycle 1. Specifically in light of the new instruments and routing for educational pathways, it is strongly recommended to limit countries' freedom to implement complex multi-item education instruments. Unless countries have strong reasons to do otherwise, we strongly discourage deviations from the proposed basic structure for measuring educational pathways. In the case that such reasons do exist, we recommend limiting the number of questionnaire items to identify the list of educational qualifications followed over the life course to two or, after consultation and sign-off, three. Other questions would need to be regarded as extensions that should not interfere with the flow of questions in the educational pathways module.

\subsubsection{Question wording}

Adaptations to the source question wording (all wording options proposed in section 3.2.1) should usually not be necessary and thus need to be reported and monitored. The translation process should ensure that the wording of the education question is functionally equivalent to the source question. Country teams should not copy question texts from other surveys in the country or from PIAAC Cycle 1 without closely examining whether this text is functionally equivalent with the PIAAC Cycle 2 source question. Most importantly, the question should refer to the same empirical indicator of educational attainment, namely the highest educational qualification obtained, and, for respondents without qualifications, whether they have completed an educational level that does not award any qualifications in the country in question (typically primary education). It should for example not ask for the last educational institution a respondent was enrolled in, or the highest educational programme ever attended.

\subsubsection{Response categories}

The response options offered to respondents in the education question should cover all formal educational qualifications expected to occur in the PIAAC sample. By 'formal' we mean education that is generally recognized by state education providers and/or employers.

Response categories used in PIAAC Cycle 1 should be systematically checked for completeness, especially concerning outdated educational qualifications (for older respondents), formal vocational qualifications, as well as qualifications that were changed or newly introduced since PIAAC Cycle 1. Rather than asking respondents whether their highest educational qualification is vocational or general, the response options should offer distinctive categories for vocational and general educational qualifications whenever possible. It is advisable that instruments use the specific denominations for qualifications that are used by respondents in their day-to-day language rather than official but potentially less familiar 
terms, or even abstract summary descriptions. Response categories need to be differentiated enough to allow coding into the target comparable education scheme (see section 4.2.2), e.g. when there are separate general and vocational programs and qualifications at an education level, they should be presented separately to respondents.

\subsubsection{Guideline for development of mapping to detailed ISCED variable}

In PIAAC Cycle 2, country-specific education categories should be mapped to an ISCEDbased cross-national scheme from the outset. The harmonization needs to be specified during measurement instrument development (i.e. ex ante) so that the target education coding scheme implemented in PIAAC can effectively be derived from the country-specific education question(s).

PIAAC needs to decide whether countries should stick to the same ISCED mappings as used for Cycle 1 (but this does not seem to be documented so may be impossible) and just update to ISCED 2011 codes (maximize consistency with Cycle 1), or whether current ISCED 2011 mappings should be used, which may lead to inconsistencies with Cycle 1 because of the upor downgrading of qualifications. The current ISCED mappings available at http://uis.unesco.org/en/isced-mappings can be used to determine the required codes, including whether an educational qualification is vocational or general. If a country wishes to deviate from the determined mapping for specific reasons, this needs to be discussed with and signed off by the consortium partner/expert responsible for ex-ante output harmonization and coding in PIAAC Cycle 2.

For outdated qualifications not covered in the ISCED mappings, these should not be mapped in the same way as any potential current qualification that is nationally perceived to be its 'successor' or in some other way equivalent, but ISCED criteria should be applied to the outdated qualification itself (i.e. it should be classified independently, UNESCO Institute for Statistics, 2012, p. $20 \S 88$; OECD and Eurostat, 2014, p. 10).

\subsection{Educational pathways}

\subsubsection{Mapping to highest completed level}

In the current proposal there is no explicit question asking respondents to report their highest attained level of education. Instead, the highest completed level of education is derived by the system from the checkbox item asking respondents to report all completed qualifications. Since this derived variable is used directly in routing, dynamic text etc. in the subsequent questionnaire, it is essential that a unique mapping is provided in advance from the answers provided to the highest level. A complicating factor hereby is that in some countries multiple qualifications may map to the same ISCED level. For example, in PIAAC cycle 1, the following Dutch qualifications all mapped to "ISCED 3A-B": bol/mbo 3 of 4 jarig", "havo, mms", and "vwo, gymnasium". To some extent these "ties" may be resolved by a more rigorous application of the detailed ISCED classification (see Table 2 in Section 4.2.1 above), but more or less by design countries are encouraged to draw distinctions that are relevant nationally without necessarily corresponding to different ISCED categories. Although it is unlikely that large numbers of respondents will report having followed more than one such programme, it cannot be ruled out, so the system has to provide a unique mapping which identifies in all cases the highest completed level. 
This mapping exercise can be seen as an extension of the abovementioned mapping from the national classification to the ISCED variable. As far as possible this should be theoretically driven and decided by the consortium, but some consultation with countries may be necessary. In many - perhaps most - cases this regards the question of whether general or vocational qualifications at the same ISCED level should be treated as higher or lower. There is no obvious answer to this. In terms of general key skills, general education may be regarded as higher in many countries, while in terms of labour market preparation vocational education may have a stronger claim. Furthermore, such distinctions may differ from country to country, according to particular features of the national system and the particular status assigned to vocational versus general education in each country. For this reason it is not advisable to strive for a priori "one size fits all" solutions, but rather to develop the rules in consultation with national and international experts. The consortium should however provide some more or less objective guidelines or criteria that can be used as a basis for the specific rankings, such as whether the selectivity of the education system or the value of the qualifications in the labour market should be the decisive factor. Based on such guidelines the country-specific rankings can be developed in consultation with national experts.

\subsubsection{Foreign qualifications}

As outlined above in Section 3.2.4, we propose to use the adaptive CAMCES cross-cultural education coding tool to make it easier for foreign respondents to report their qualifications. Depending on the logistical possibilities afforded by the platform, it is still to be decided whether the tool should be implemented directly into the platform, or whether the CAMCES database should be used as a basis for developing response categories and show cards specific to each education system in the data base. The former case would require more intensive technical collaboration between CAMCES and the PIAAC consortium, while the latter would require considerable preparatory work in terms of developing the response categories and show cards. In both cases there would also be non-trivial demands in terms of developing standard syntax for routing and derived variables related to the country-specific lists.

The current proposal is based on the second option, namely lists and show cards based on the CAMCES database. In this proposal we have assumed that there will be lists for no more than 10 countries of origin per survey country. It is however conceivable that lists could be provided for a much larger number of countries. In this case this would create additional logistical problems in terms of the standardized list of countries of origin (B_Q01h), which would need to be implemented in a different form, such as a drop-down list. There is also the issue of the large number of show cards the interviewer would need to deal with, and the challenging of successfully programming routing, response categories and derived variables for such a large number of countries. Although the syntax for these aspects would be developed in standardized form by the consortium, implementing and checking the functionality of these lists in a large number of survey countries could prove challenging to say the least. Given the likelihood that a large percentage of countries of origin for foreign qualifications can probably be captured by the 8-10 largest migrant groups in each survey country, the added value of expanding the number beyond 10 may be questionable. We 
recommend that this should only be done after a thorough examination of the technical capacity at the consortium's disposal to deal with this.

\subsection{Non-formal and informal learning}

In contrast to formal education, non-formal and informal training does not require ex-post harmonization. It is possible that some questions need to be adapted in order to fully account for national specificities.

For the implementation of the items on non-formal and informal training it is important how many aspects PIAAC wants to include in the final background questionnaire. Depending on the amount of items chosen, it will be possible to carry out different analyses.

\subsection{Use of register data}

\subsubsection{Experience with using register data in PIAAC Cycle 1}

Register data in PIAAC Cycle 1 was used in two different ways: for enriching the data set or to replace certain questions in the background questionnaire (BQ).

The most important use is that several countries used register data to enrich or validate the information obtained in the PIAAC BQ. Of course this use was restricted to countries that a) have register data and $b$ ) had ensured at the time of the data collection that a link could be made between the respondent and the information in the registers. As far as we know, this use of registers was most elaborately practised in the Scandinavian countries and the Netherlands. The Scandinavian countries even had a separate program financed by the Nordic Scientific Council to collect register data in all Nordic counties (Norway, Sweden, Finland, Denmark and Estonia). In this program, Nordic countries agreed to enrich the PIAAC dataset with variables on e.g. employment history, information on the firm or sector etc. Also in the Netherlands, PIAAC data have been enriched by linking it to register data, e.g. on poverty or employment history. A specific use of this enrichment also allowed comparing the data obtained in PIAAC with the data obtained from the register. This will be discussed below.

The other use of register data was to replace certain questions in the BQ. In PIAAC cycle 1, we offered countries the possibility to have some information prefilled in the BQ. Several countries made use of this possibility by importing information from the case management system. This related only to information about age and gender, with one exception: Sweden used information from the registers to prefill answers on the highest qualification obtained (B_Q01a) and sector of employment (D_Q02a). In the pilot, Sweden also used register data for current occupation (D_Q01a), but this was dropped in the main survey, as occupation needed to be coded in 3-digit ISCO08, while the register information was coded in ISCO88. In each of these cases, the information from the registers was prefilled and the respondent was asked whether or not this was correct. The register information was the latest available when the survey was conducted (August 2011 - April 2012), which was spring 2010 for highest completed level of education and autumn 2009 for workplace information. The reason for this is that register data always lag behind. The information about highest completed level of education for spring 2011 was not available until April 2012 and the information about workplace and occupation for November 2011 was not available until spring 2013. 
The standard way of asking this was as follows:

At Statistics Sweden there is a register on the highest level of education and according to the register your highest education is <<Field and Level of Education from the Register $>>$. Is this correct?

If the information was not correct, the respondent was routed to the original question asking about the highest level of qualification obtained or the current sector of employment. Swedish respondents are used to having these types of questions where information from the register is used to prefill the answers. There are no indications that there is a higher non-response due to the use of register data in a survey like this.

\subsubsection{On the quality of register versus respondent data}

The Swedish case provides us with a good opportunity to have a better look at the quality of the register data versus the answers given by respondents. Our colleagues from Statistics Sweden have provides us this information.

In Table 3 we compare the information obtained by the register and the information by the respondent on the highest level of education. Instead of the register information of Spring 2010 which was used during the PIAAC Survey, the register data of Spring 2011 was used for this comparison, so that any outdate due to using older register data was avoided.

Table 3: Distribution of persons by highest completed level of education in PIAAC and register

\begin{tabular}{llll}
\hline \multicolumn{3}{c}{ Estimation of \% of persons (95\% CI) in the register whose information was correct/not correct } \\
& PIAAC survey 2011/2012 & \\
\hline & Low education & Medium education & Higher education \\
Register 2011 & $22 \pm 10$ & $73 \pm 12$ & $5 \pm 6$ \\
Low education & $13 \pm 4$ & $74 \pm 4$ & $13 \pm 4$ \\
Medium education & $1 \pm 2$ & $9 \pm 4$ & $90 \pm 4$ \\
Higher education & &
\end{tabular}

A total of $21 \%$ of the Swedish respondents indicated that they had obtained a different level of education. Especially the lower educated indicate that in fact they had achieved a higher level of education than was indicated in the register, most often medium education (73\%). In the case of the medium educated, one out of four indicated that they had obtained a different level, equally distributed between the higher and the lower level. In the case of the higher educated according to the register, some $10 \%$ of the PIAAC respondents indicated to have obtained a medium level instead. The differences are biggest for those with low education according to the register. This might be due to outdated information in the register (although Statistics Sweden indicates that the percentage of outdated information in the register is estimated to be low). Another explanation might be that young persons who have nearly finalized upper secondary education might overestimate their education in an interview situation. But this certainly does not provide a sufficient explanation for the huge discrepancy for the low educated. Aside from this, for $5 \%$ of the PIAAC respondents the register had no information about the highest completed level of education. Most of these had a low level of education according to the information of the PIAAC respondents themselves. The majority of persons with unknown information about highest completed level of education in the register are persons born abroad. 
To conclude, for some $75 \%$ of the respondents in the PIAAC survey correct information could be obtained in the register, but for some $25 \%$ additional information needs to be obtained from the respondent, either because the information in the register is not correct or because it is missing.

A similar exercise can be done for the information on sector of employment. In the case of sector of employment, $26 \%$ of the respondents indicated to be working for a different employer or at a different place of work. And the proportion of respondents with unknown information about the workplace in the register was $13 \%$. So for sector of employment, register data can provide correct information in some $60 \%$ of the cases.

As indicated before, the register data were not used to obtain information about the occupation as the register uses the ISCO88 classification and the PIAAC survey uses the ISCO08 classification. There is no simple one-to-one crossover between the 3-digit codes in the ISCO88 to the 3-digit codes in ISCO08. However, the one-digit code is the same between the two classifications and we can use that to estimate the extent to which the job level (at ISCO 1-digit) was the same in the register and according to the respondent. To take account of job mobility, we compare the register data from 2011 to the data of the PIAAC survey conducted in 2011/12.

Table 4: Distribution of persons by ISCO 1-digit occupation in PIAAC and register

\begin{tabular}{|c|c|c|c|c|c|c|c|c|c|c|}
\hline \multicolumn{11}{|c|}{ All employed persons in PIAAC $(95 \% \mathrm{CI})$} \\
\hline \multirow[b]{2}{*}{ Register 2011} & \multicolumn{10}{|c|}{ PIAAC survey $2011 / 2012$} \\
\hline & 0 & 1 & 2 & 3 & 4 & 5 & 6 & 7 & 8 & 9 \\
\hline 0 & $75 \pm 21$ & & $6 \pm 12$ & $6 \pm 12$ & $6 \pm 14$ & $7 \pm 10$ & & & & \\
\hline 1 & & $62 \pm 10$ & $12 \pm 6$ & $13 \pm 6$ & $1 \pm 2$ & $3 \pm 4$ & $1 \pm 2$ & $4 \pm 4$ & $1 \pm 2$ & \\
\hline 2 & & $4 \pm 2$ & $80 \pm 4$ & $11 \pm 4$ & $2 \pm 2$ & $1 \pm 2$ & & $1 \pm 2$ & & \\
\hline 3 & & $5 \pm 2$ & $31 \pm 4$ & $51 \pm 4$ & $3 \pm 2$ & $5 \pm 2$ & & $3 \pm 2$ & $1 \pm 2$ & \\
\hline 4 & & $2 \pm 2$ & $7 \pm 4$ & $25 \pm 8$ & $40 \pm 6$ & $12 \pm 4$ & & $3 \pm 4$ & $7 \pm 4$ & $3 \pm 4$ \\
\hline 5 & & $1 \pm 2$ & $4 \pm 2$ & $5 \pm 2$ & $2 \pm 2$ & $81 \pm 4$ & $2 \pm 2$ & $2 \pm 2$ & $1 \pm 2$ & $1 \pm 2$ \\
\hline 6 & & & $4 \pm 6$ & $7 \pm 8$ & & $5 \pm 8$ & $70 \pm 14$ & $7 \pm 8$ & $3 \pm 6$ & $3 \pm 8$ \\
\hline 7 & & $1 \pm 2$ & $3 \pm 2$ & $5 \pm 4$ & $2 \pm 2$ & $12 \pm 6$ & $2 \pm 2$ & $65 \pm 8$ & $6 \pm 4$ & $3 \pm 2$ \\
\hline 8 & & $1 \pm 2$ & $2 \pm 2$ & $8 \pm 2$ & $3 \pm 4$ & $2 \pm 2$ & $2 \pm 2$ & $18 \pm 6$ & $60 \pm 6$ & $4 \pm 4$ \\
\hline 9 & & $1 \pm 2$ & $5 \pm 4$ & $6 \pm 4$ & $4 \pm 4$ & $24 \pm 10$ & $2 \pm 4$ & $6 \pm 4$ & $10 \pm 6$ & $41 \pm 8$ \\
\hline
\end{tabular}

We can note that the information on the job level according to the register data is far from ideal, when we look at the proportions of people indicating themselves that they are working at a different job level. The proportion of workers on the diagonal varies from $40 \%$ of Clerical Support Workers (Major Group 4) to $81 \%$ of Services and Sales Workers (Major Group 5).

Some deviations clearly stand out. For those officially registered as working as Technicians and Associate Professionals (Major group 3), 31\% are classified as Professionals (Major group 2) when using their survey responses on occupation. For those officially registered as working as Clerical Support Workers (Major Group 4), a large proportion (25\%) are classified as Technicians and Associate Professionals (Major group 3). And for those officially registered as working in Elementary Occupations (Major Group 9) a similar large proportion (24\%) are classified as Services and Sales Workers (Major Group 5). 
Register data have also been used to check the quality of the educational level of the parents of the respondents. In Norway, Lundetrae et al. (2016) linked data from PIAAC to the education register to compare the information from both sources.

Table 5: Highest educational level of parents according to PIAAC respondents (16-24-year-olds) and register

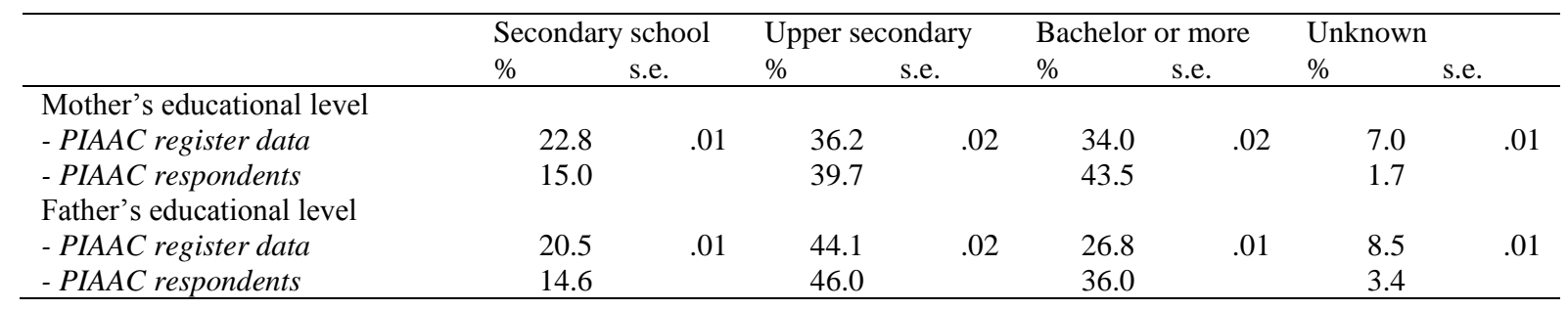

5 provides information on educational background of the parents for the 16-24-year-olds. There are two striking differences between the two data sources. One is that the percentage of 'unknown' is much higher in the register data ( 7 and $8.5 \%$ for mothers and fathers respectively) than from the answers given by the respondents (1.7 and 3.4\%). A second difference is that in the view of the respondents the average level of their parents is much higher than would be deduced from the registers. For mothers, the estimated percentage having a bachelor degree or higher is $43.5 \%$ on the basis of respondent's answers, but only $34 \%$ if based on the register data (or $44.3 \%$ vs $36.5 \%$ when excluding the 'unknown' category). For fathers, the estimate is $36 \%$ on the basis of respondent's answers, and $26.8 \%$ if based on the register data (or $37.3 \%$ vs $29.3 \% \%$ when excluding the 'unknown' category).

Now the difference in the two types of information is not necessarily an indication of bad quality of the answers given by the respondents. As we have seen in the Swedish example, respondents do find that the information from the register is sometimes not correct. Note that in the Swedish case, it is harder for respondents to 'talk up' their own education, as they have to explicitly state that the information from the register is wrong. We expect that the threshold of doing so is much higher than in the case of an open question. Still there are considerable differences and no less than $21 \%$ indicated a different qualification than was retrieved from the register. This is also the case in other countries. In the Netherlands for example, registers have no information on foreign qualifications or qualifications obtained at a private institute. In the latter case this is because these institutes receive no funding from the Ministry, although the diplomas are fully recognized in the national qualification structure. This leads to structural biases in the registers. Another issue with the registers is that these can also contain 'noise' and errors, just like the survey information obtained from the respondents. Although it is hard to get an exact estimate on this, and knowing that this will differ from register to register (see the above example for Sweden where the percentage disagreement varied from $21 \%$ for the education register to $39 \%$ for the employer register), as well as from country to country, we know that there is always some error there.

\subsubsection{Conclusion}

The common arguments in favour of using register data are:

- Lower burden for respondent

- Lower costs of coding 
- Increased accuracy of coding and increased quality of data

The first two of these arguments are certainly true. Questions on education, occupation and sector, usually take up much time in the interview, especially if show cards have to be used (some 1-2 minutes for each question). This can be significantly reduced when using prefilled information from the register. We also have indications from the countries that the quality of the data can be improved. In general, coding of education, and especially occupation and sector, is difficult and requires highly trained interviewers to extract the relevant information from the respondent as well as highly trained coders to transfer this information into a valid code. In PIAAC Cycle 1 we used as a standard that the average coding error should not exceed $10 \%$, which already indicates that even with highly trained coders and a good quality assurance system, some noise and error in the coding process cannot be avoided. We should not underestimate the importance of this part of the data collection and data processing. Education and occupation are the most important predictors for the kind of outcome variables that we tend to measure in PIAAC (be it skills or economic or social outcomes). Improving the quality of the data of these predictors is therefore key in establishing a good and relevant data set that can be used for both scientific and policy questions. The quality of this coding can be improved when using register data.

On the other hand there also some arguments against using register data. Among the arguments mentioned are:

- Respondents might be 'scared off' if it is made explicit that some information is retrieved from the register.

- Registers are not 'error-free' and may contain systematic biases (certain target groups might be overrepresented in the category 'unknown', or certain information might be systematically missing).

- Not all countries have suitable registers. This may limit the comparability across countries.

Although the first point is worth paying attention, this situation is probably different from country to country. In certain countries, people are much more concerned about their privacy and whether or not the government holds information on them than in other countries.

Probably this is also reflected in the rules and regulations of these countries, suggesting that in countries where this is an issue, the possibility of using register data is also probably lower. In the Swedish case, there is no indication that using register-based information leads to higher non-response rates, as most respondents are used to this.

The second point is a serious issue for all countries. Although register data have some connotation of being 'true' and 'valid', this is not always the case. Data in registers are usually not collected with the explicit purpose of conducting research: this means that one always has to be alert on the presence of certain errors or systematic biases. The Swedish case illustrates that in some 25 to $40 \%$ of the cases, the information from the register is different from those of the respondent. Part of this is caused by the fact that there is always a time lag between the information being entered into and retrieved from the register and the time of the survey. But there are also indications that there are systematic biases in the registers. 
The way forward is to combine the best of both worlds as has been done in the Swedish case. This means that countries that have register data, can use this to prefill the questionnaire, but should always include the possibility that respondents can adapt or change the information if it is not correct. Only in this way can we really improve from a situation where we have to rely on either survey information or register information. 


\section{Conclusions and remaining gaps, summary recommendations}

\subsection{Summary, conclusions and recommendations}

\section{Measuring educational attainment}

With respect to respondent's educational attainment, the report argued that this is probably the most important single variable in the PIAAC BQ, used as a predictor of adult skills, labour market outcomes, and control variable. Its reliability, validity and comparability is thus of crucial importance. A close look at the country-specific measurement instruments and the way they are harmonized into the ISCED-based coding scheme in PIAAC (B_Q01a) reveals both lacking measurement quality of the source items as well as inconsistencies in the way they are harmonized into B_Q01a. Furthermore, even though comparative construct validation analyses show that the B_Q01a predicts adult skills almost as well as the country-specific variables, this is partly due to the fact that countries only measured education in the exact level of detail required by B_Q01a, rather than at the level of detail that would have been most suitable for the respective national education system. For example, some countries used measurement instruments not capable of distinguishing vocational and general upper secondary education, although this distinction is highly important for both skill development and the labour market in many countries. Finally, the validation analyses show that ISCED 2011 main levels are substantially better suited for the multivariate analysis of adult skills than years of education, ISCED 1997 main levels or even 'broad' ISCED levels (low, medium, high). The report draws practical conclusions for PIAAC Cycle 2 from this research and sets out ways to improve both the quality of education measurement within countries as well as harmonization of educational attainment across countries, both in terms of an improved target variable, better guidelines for countries and a consultation processes supporting countries in realizing optimized instruments. The report also summarizes options for PIAAC to better identify and potentially directly measure foreign qualifications.

\section{Measuring non-formal and informal education}

Although formal education is the most important indicator for key skills, the relationship is not perfect and also varies between countries. Therefore, there are also other mechanisms that affect the acquisition of key skills . One of them is the participation in non-formal and informal learning activities. Individuals who engage in training activities are expected to also engage in learning opportunities which have an impact not only on specific but also on key skills. In the first PIAAC cycle, several items on non-formal training were part of the background questionnaire. However, the analyses of these variables showed that some of the items did not collect the information in a manner that was most useful. Therefore, we suggest items that should be changed. Furthermore, we suggest further items that could be included in the PIAAC background questionnaire for the second cycle in order to improve the analytical power of the variables on non-formal training. Finally, we propose several items on informal learning opportunities. 


\section{Measuring pathways}

Information on educational pathways to their highest degree is crucial to understanding how selection effects and learning effects shape individuals' human capital. For example, it should make quite a difference whether someone reached higher education through a general program in secondary education, or through a vocational track. Secondary VET programs are usually seen as stepping stones to the labour market; general programs are thought to prepare for further education. As a result, VET programmes in secondary education usually aim at transferring occupationally specific skills, whereas general programs more strongly focus on general academic ability. However, in many countries, VET programs can provide access to further education as well, and it is quite possible to finish university after having followed a vocational path through education.

Despite a lengthy and quite complicated set of questions, PIAAC Cycle 1 did not provide comprehensive data on educational pathways. The only indicators other than highest attained level concerned respondents who were in education at the time of the survey, or who had enrolled in a formal education programme at some point but left without completing it. In this report, we provide a detailed description of the opportunities and challenges when measuring pathways. The report discusses the level of detail required for analysing pathway effects. The large number of possible permutations, and the low number of cases for most of those permutations, probably render a detailed analysis of every conceivable pathway unrealistic. At a minimum, the coding of pathways should allow for creating a typology. We argue that it is relatively easy to obtain detailed information on the full list of qualifications completed during one's lifetime, by simply using a checkbox item and requesting respondents to report all qualifications completed.

In order to reconstruct pathways, listing completed qualifications is not enough. We should also gain information about the timing of key qualifications. In principle this could be asked for all completed levels, but for those respondents whose path through education has been long and perhaps complex, the resulting time burden may be unacceptably high and recall bias is an issue. We propose a pragmatic compromise, in which the timing is asked for the highest qualification and other programmes at the same broad level (low-medium-high) and the broad level below the highest level. For most respondents this only requires timing data to be provided for two to four qualifications. We also propose questions on respondents' current education, and education started but not completed, both only if applicable. We offer a number of recommendations about how to best approach this.

A key aspect of pathways involves those respondents who completed all or part of their education abroad. The PIAAC Cycle 1 instrument failed to provide good information on this. The current proposal aims to provide a fairly comprehensive overview of pathways that were partially or entirely completed abroad, and offers a way in which at least some foreign-born respondents can report their education in terms of the educational classification of their country of origin.

\section{Improving data collection by using register data}


One of the main ways in which we may improve upon the data collection from the first PIAAC cycle is by making better use of register data. The common arguments in favour of using register data are:

- Lower burden for respondent

- Lower costs of coding

- Increased accuracy of coding and increased quality of data

The first two of these arguments certainly hold true for PIAAC. Questions on education, occupation and sector, usually take up much time in the interview, especially if show cards have to be used (some 1-2 minutes for each question). This can be significantly reduced when using prefilled information from the register.

We also have indications from the countries that the quality of the data can be improved. In general, coding of education, and especially occupation and sector, is difficult and requires highly trained interviewers to extract the relevant information from the respondent as well as highly trained coders to transfer this information into a valid code. We argue that register data can be used to improve the quality of the data in the second cycle of PIAAC, especially with respect to education variables, occupation and sector of employment. However we have to acknowledge that register data are not error-free. We propose that countries that have such register data will use that to prefill the questionnaire, but should always include the possibility that respondents can adapt or change the information if it is not correct (as was done in Sweden during PIAAC Cycle 1). Only in this way can we really improve from a situation where we have to rely solely on either survey information or register information.

\subsection{Remaining gaps}

This report focused on developing an integrated conceptual framework, questionnaire module and survey implementation guidelines for formal education (including educational pathways) and non-formal training for the purposes of PIAAC Cycle 2. Some tasks regarding improvement of the PIAAC Cycle 1 instruments could however not be tackled within the framework of this contract, and we would like to draw the attention to two points where we regard further work as highly important for the success of the revised education and training module in PIAAC Cycle 2.

Firstly, within the framework of this contract, the proposed solutions could not yet be empirically tested, neither in a qualitative nor quantitative fashion. Given revisions between field test and main study will as in PIAAC Cycle 1 be very limited in Cycle 2, it is of utmost importance that the new ideas presented here are put into practice in some form of pilot study before being included in the PIAAC Cycle 2 field test. This could be achieved by e.g. fully developing the module for two or three test countries (including ex-ante harmonization, translation and technical implementation in e.g. web survey software) and cognitively testing the resulting questionnaire in these countries.

Secondly, while this report mentions that the ISCED classification for fields of education and training (FET) was revised by UNESCO in 2013, discussing the measurement of FET was not 
a task for this report. FET are an important mediator between formal education, skills and labour market outcomes, but their measurement in surveys is often not well constructed: It is neither clear whether respondents can easily classify themselves in the categories provided by the ISCED FET classification, nor whether the classification really distinguishes fields in such a way as making most sense for analysts studying the 'effects' (which may be causal or by way of selection of individuals into fields) of FET on skills and labour market outcomes. 


\section{References}

Acemoglu, D., \& Pischke, J. S. (1999). The Structure of Wages and Investment in General Training. Journal of Political Economy, 107(3), 539-572

Bartel, A. P. (1995). Training, Wage Growth, and Job Performance: Evidence from a Company Database. Journal of Labor Economics, 13(3), 401-425.

Bassanini, A., Booth, A., Brunello, G., De Paola, M., \& Leuven, E. (2005). Workplace Training in Europe. IZA Discussion Paper Series, 1640.

Becker, G. S. (1962). Investment in Human Capital: A Theoretical Analysis. The journal of Political Economy(9-49).

Bilger, F., Gnahs, D., Hartmann, J., \& Kuper, H. (Eds.). (2013). Weiterbildungsverhalten in Deutschland. Resultate des Adult Education Survey 2012. Bielefeld: Bertelsmann.

Blundell, R., Dearden, L., Meghir, C., \& Sianesi, B. (1999). Human capital investment: the returns from education and training to the individual, the firm and the economy. Fiscal studies, 20(1), 1-23.

Boateng, S. K. (2009). Significant country differences in adult learning. Eurostat: Statistics in Focus, 44(2009), 1-11. Retrieved from http://ec.europa.eu/eurostat/documents/3433488/5281333/KS-SF-09-044EN.PDF/82cd034b-a65f-47ca-8f62-6285ad593c20

Booth, A. L. (1991). Job-related formal training: Who receives it and what is it worth? Oxford Bulleting of Economics and Statistics, 53(3), 281-294

Brücker, H., Kroh, M., Bartsch, S., Goebel, J., Kühne, S., Liebau, E., Trübswetter, P., Tucci, I. and Schupp, J. (2014) 'The new IAB-SOEP Migration Sample: an introduction into the methodology and the contents', in SOEP Survey Papers Series C - Data Documentations. Berlin: DIW/SOEP.

Brunello, G. and Rocco, L. (2015) 'The Labour Market Effects of Academic and Vocational Education over the Life Cycle: Evidence from Two British Cohorts', in IZA Discussion Paper Series, Paper No. 9275, August 2015,: Bonn/IZA.

Büchel, F., \& Pannenberg, M. (2004). Berufliche Weiterbildung in West- und Ostdeutschland * Teilnehmer, Struktur und individueller Ertrag. Zeitschrift für ArbeitsmarktForschung, 37(2), 73-126.

CEDEFOP. (2008). Terminology of European education and training policy - A selection of 100 key terms. Retrieved from Luxembourg:

CEDEFOP. (2014). Terminology of European education and training policy: a selection of 130 terms. . Retrieved from Luxembourg:

Cross, K. P. (1981). Adults as Learners: Increasing Participation and Facilitating Learning. San Francisco: Jossey-Bass.

Desjardins, R. (2003). Determinants of literacy proficiency: A lifelong-lifewide learning perspective. International Journal of Educational Research, 39(3), 205-245.

Desjardins, R., Milana, M., \& Rubenson, K. (2006). Unequal chances to participate in adult learning: International perspectives. Paris: UNESCO.

Erikson, R. and Goldthorpe, J. H. (1992) The constant flux: A study of class mobility in industrial societies. Oxford: Clarendon Press.

ESS ERIC (2016) ESS7 - 2014 Documentation Report. 3.0. Bergen: European Social Survey Data Archive, NSD - Norwegian Centre for Research Data for ESS ERIC.

European Commission (2002) Council Resolution of 27 June 2002 on lifelong learning, OJ C $163,9.7 .2002$, p. $1-3$

European Commission (2007) Task force on core social variables final report, Task force on core social variables final report. Luxembourg: European Commission. 
European Commission (Ed.) (2011). Progress towards the common European objectives in education and training. Indicators and benchmarks 2010/2011 Luxembourg: Publications Office of the European Union.

European Social Survey (2010) Appendix A1 - Education, ESS5 - 2010 ed. 4.0, ESS5 Data Documentation Report. Bergen.

European Social Survey (2012) Appendix A1 - Education, ESS6 - 2012 ed. 2.0, ESS6 Data Documentation Report. Bergen. Available at:

http://www.europeansocialsurvey.org/docs/round6/survey/ESS6_appendix_a1_e02_0.pdf (Accessed: 2 August 2015).

Green, F., Ashton, D., \& Feldstead, A. (2001). Estimating the determinants of supply of computing, problem-solving, communication, social, and teamworking skills. Oxford Economic Papers, 3, 406-433. doi:10.1093/oep/53.3.406

Hansson, B. (2008). Job-Related Training and Benefits for Individuals. Retrieved from Hanushek, E. A., \& Woessmann, L. (2015). The Economic Impact of Educational Quality In P. Dixon, S. Humble, \& C. Counihan (Eds.), Handbook of International Development and Education (pp. 6-19). Cheltenham, UK: Edward Elgar Publishing.

Kuwan, H., \& Seidel, S. (2013). Informelles Lernen Erwachsener. In F. Bilger, D. Gnahs, J. Hartmann, \& H. Kuper (Eds.), Weiterbildungsverhalten in Deutschland. Resultate des Adult Education Survey 2012. Bielefeld: Bertelsmann.

Lundetræ, K., Lagerstrøm, B. O. and Gabrielsen, E. (2016) An attempt to understand Norwegian 16-24-year olds' poor literacy results in the International Assessment of Adult Competencies.

Maehler, D., Massing, N., Helmschrott, S., Rammstedt, B., Staudinger, U. M., \& Wolf, C. (2013). Grundlegende Kompetenzen in verschiedenen Bevölkerungsgruppen. In B. Rammstedt (Ed.), Grundlegende Kompetenzen Erwachsener im internationalen Vergleich. Ergebnisse von PIAAC 2012 (pp. 77-124). Münster: Waxmann.

Massing, N., \& Schneider, S. L. (2017). Degrees of competency: the relationship between educational qualifications and adult skills across countries. Large-scale Assessments in Education, 5(6).

Mulder, M., Weigel, T. and Collins, K. (2007) The concept of competence in the development of vocational education and training in selected EU member states: a critical analysis, in:

Journal of Vocational Education \& Training Vol. 59 , Iss. 1,2007.

OECD. (2003). Employment Outlook. Retrieved from Paris:

OECD. (2004). Employment Outlook. Retrieved from Paris:

OECD (2010) PIAAC Background questionnaire. MS version. Paris.

OECD (2011) PIAAC Conceptual Framework of the Background Questionnaire Main Survey Table of Contents. Paris.

OECD. (2013). OECD Skills outlook 2013: First results from the Survey of Adult Skills. Paris: OECD Publishing.

OECD and Eurostat (2014) Joint Eurostat-OECD guidelines on the measurement of educational attainment in household surveys.

Reder, S. (2009). The Development of Literacy and Numeracy in Adult Life. In S. Reder; \& J. Bynner; (Eds.), Tracking Adult Literacy and Numeracy Skills. New York: Routledge.

Rubenson, K., \& Desjardins, R. (2009). The Impact of Welfare State Regimes on Barriers to Participation in Adult Education: A Bounded Agency Model. Adult Education Quarterly, 59(3), 187-207. doi:10.1177/0741713609331548

Schneider, S. L. (2008) 'Suggestions for the cross-national measurement of educational attainment: Refining the ISCED-97 and improving data collection and coding procedures', in 
Schneider, S. L. (ed.) The International Standard Classification of Education (ISCED-97). An evaluation of content and criterion validity for 15 European countries. Mannheim: MZES, pp. 311-330. doi: 10.13140/RG.2.1.4614.9526.

Schneider, S. L. (2010) 'Nominal comparability is not enough: (In-)equivalence of construct validity of cross-national measures of educational attainment in the European Social Survey', Research in Social Stratification and Mobility. Elsevier Ltd, 28(3), pp. 343-357. doi:

10.1016/j.rssm.2010.03.001.

Thurow, L. C. (1976). Generating inequality: Macmillan London.

Wolf, A., \& Evans, K. (2011). Improving literacy at work: London: Routledge.

UNESCO Institute for Statistics (2012) International Standard Classification of Education ISCED 2011. Montreal: UNESCO Institute for Statistics.

UNESCO, OECD, Eurostat and UNESCO Institute for Statistics (2015) ISCED 2011 Operational Manual. Paris: OECD.

Wolf, C., Schneider, S. L., Behr, D. and Joye, D. (2016) 'Harmonizing survey questions between cultures and over time', in Wolf, C., Joye, D., Smith, T. W., and Fu, Y. (eds) The SAGE Handbook of Survey Methodology. Los Angeles: Sage, pp. 502-524. 


\section{Appendix}

\subsection{Detailed analyses of educational attainment variables in PIAAC Cycle 1}

\subsubsection{Inconsistencies in measurement instruments and harmonization in PIAAC Cycle 1}

In the following, examples for inconsistencies across countries in measurement of educational attainment in PIAAC Cycle 1 are provided. The list is certainly not complete but meant by way of illustrating what can go wrong.

The country-specific education measurement instruments in some countries are not capable of drawing distinctions required by the detailed ISCED variable implemented in PIAAC Cycle 1, b_q01a.

- The instrument in AUT and GBR cannot differentiate between ISCED levels 0 and 1. In AUT, all respondents in the lowest country-specific education category are coded as ISCED 1, which is thus a mix of ISCED 0 and 1 in AUT. In GBR, all respondents without qualifications are coded as ISCED 0 , which is thus a mix of ISCED 0 and 1 in GBR.

- The instrument in DEU mixes some educational qualifications corresponding to ISCED 5A medium and ISCED 5A long in one category: "Fachhochschulabschluss (Master; Diplom)". While the pre-Bologna "Diplom" is classified as ISCED 5A medium, the Master introduced by the Bologna reforms is classified as ISCED 5A long. In b_q01a, this category is coded in ISCED 5A long, overestimating educational attainment in DEU.

- The instrument in GBR cannot differentiate between ISCED 5A intermediate, medium, long and ISCED 6. This lead to an extra category in the harmonised variable specifically for the aggregation of these categories in GBR in the 'harmonised' variable b_q01a, pointing to an apparent failure of ex-ante output harmonisation.

- A large number of countries employ measurement instruments incapable of distinguishing between ISCED 3A/B and 3C.

Some countries omitted educational qualifications from their measurement instruments, leading to empty categories in b_q01a although the country has relevant classifications.

- POL and SVK have not measured qualifications corresponding to ISCED 5B.

- There are likely many examples of this happening for ISCED level 4.

In some countries, the mapping of country-specific categories to ISCED in PIAAC does not conform to ISCED criteria and official ISCED mappings. Sometimes this is due to the fact that ISCED 97 did not yet clearly differentiate between educational enrolment and attainment statistics, which ISCED 2011 does. Sometimes programme destination is undifferentiated although the measurement instrument allows the distinctions foreseen by b_q01a.

- In NZL and USA, respondents who have been enrolled in ISCED 1 without completing it are coded as ISCED 1 rather than ISCED 0. Similarly, those who were enrolled in ISCED 2 without completing it are coded as ISCED 2 rather than ISCED 1. 
- In DEU, the combination of upper secondary general education and completed vocational training is officially classified as ISCED 4A (vocational). In PIAAC data, it is coded as ISCED 4 (without distinction A-B-C) rather than ISCED 4A-B.

- In FRA, "Baccalauréat technologique" and "Baccalauréat general" are officially classified as ISCED 3A general. In PIAAC data, it is coded as ISCED 3 (without distinction A-B-C) rather than ISCED 3A-B.

- In TUR, "Lise" is officially classified as ISCED 3A. In PIAAC data, it is coded as ISCED 3 (without distinction A-B-C) rather than ISCED 3A-B.

- In CAN, both "First professional degree (medical, veterinary medicine, dental, optometry, law, divinity)" and "University certificate above the bachelor's" are officially classified as ISCED 5A long. In PIAAC data, these are coded as ISCED 5A medium rather than ISCED 5A long.

Not having obtained any formal qualification is treated differently across countries, leading to inconsistent ISCED coding specifically for ISCED levels 0 to 2.

- In AUT it leads to ISCED 1 and in GBR to ISCED 0 (see above).

- In DEU, it leads to ISCED 0 or 1 depending on whether ISCED 1 was completed or not.

\subsubsection{Empirical evaluation of the comparative validity of the PIAAC Cycle 1 ISCED-based coding scheme}

In order to find out which kind of comparative education coding scheme best represents the information contained in country-specific measures, a detailed comparative construct validation analysis following the model in Schneider (2010) was conducted using PIAAC round 1 and 2 data. For this purpose skills were regressed on various differently coded educational attainment variables. The adjusted $\mathrm{R} 2 \mathrm{~s}$ produced by the different international education variables are compared with the adjusted R2s produced by the country-specific measures, which thus serve as a benchmark.

The following education variables were included in the validation:

- ISCED variables included in PIAAC dataset "as is" (GB: levels 6-8 always aggregated):

○ B_Q01a (close to ISCED 97 coding scheme employed in the EU-LFS until 2013, but with added distinctions in tertiary education anticipating ISCED 2011)

○ ISCED11_8/EDCAT8: ISCED 2011 main levels with levels 0 and 1 aggregated

- ISCED11_7/EDCAT7: ISCED 2011 main levels with levels 0 and 1 as well as 7 and 8 aggregated

○ yearsqual: theoretical years of education, derived from country-specific education variables

- ISCED variables commonly used but not included in PIAAC dataset:

○ ISCED11_1: ISCED 2011 main levels, derived from B_Q01a

○ ISCED97_1: ISCED 1997 main levels, derived from B_Q01a

○ ISCED97_6: ISCED 1997 main levels with levels 0 and 1 aggregated 
○ ISCED97_5: ISCED 1997 main levels with levels 0 and 1 as well as 5 and 6 aggregated

○ ISCED_3: ISCED 1997 0-2, 3-4 and 5-6 aggregated ("low, medium, high") commonly used in cross-tabulations

- ES-ISCED (European Survey version of ISCED) as proposed in Schneider (2010). This variable aims to minimize loss of information through harmonization while not being more detailed than ISCED 97 main levels. Figure 5 and Table 6 show how ESISCED is constructed. Because many countries failed distinguishing vocational and general upper secondary education, a category IIIu for unspecified orientation at this level had to be added.

Figure 5: How ES-ISCED derives from ISCED 97

\begin{tabular}{|c|c|}
\hline ISCED 97 & ES-ISCED \\
\hline $\begin{array}{l}\text { ISCED } 0 \text { (less than primary) } \\
\text { ISCED } 1 \text { (primary) }\end{array}$ & $\longrightarrow$ ES-ISCED I (less than lower secondary) \\
\hline ISCED 2 (lower secondary) & $\longrightarrow$ ES-ISCED II (lower secondary) \\
\hline ISCED 3 (upper secondary) & $\Longrightarrow$ ES-ISCED IIIb (upper secondary, vocational or no access to V1) \\
\hline $\begin{array}{r}\text { ISCED } 4 \text { (post-secondary } \\
\text { non-tertiary) }\end{array}$ & $\begin{array}{l}\rightarrow \text { ES-ISCED IIIa (upper secondary, general and/or access to V1) } \\
\longrightarrow \text { ES-ISCED IV (adyanced yocational sub-deoree) }\end{array}$ \\
\hline ISCED 5 (first stage of tertiary) & 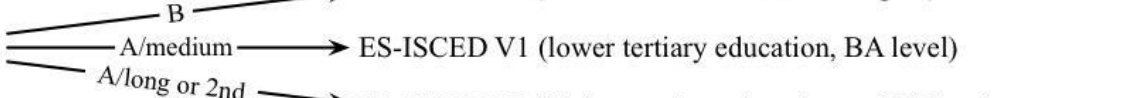 \\
\hline ISCED 6 (second stage of tertiary) & $\longrightarrow$ ES-ISCED V2 (higher tertiary education, $\geq$ MA level) \\
\hline $\begin{array}{l}\text { Note: 'A', 'B' and ' } C \text { ' are ISCE } \\
\text { than } 2 \text { years, } 3 \text { to } 4 \text { years and mo }\end{array}$ & $\begin{array}{l}97 \text { destination categories; 'short', 'medium' and 'long' stand for programmes shorter } \\
\text { in } 4 \text { years respectively; and ' } 2 \text { nd, indicates second degrees in higher education. }\end{array}$ \\
\hline
\end{tabular}

Table 6: Correspondence between PIAAC variables B_Q01a, VET and ES-ISCED:

\begin{tabular}{lll}
\hline ES-ISCED & B_Q01a or EDCAT7 and VET & ISCED 97 \\
\hline I & EDCAT7=1 & 1 or less \\
II & EDCAT7=2 & $2,3 C$ short \\
IIIb (without 3B gen but 3A voc) & B_Q01a=5 OR B_Q01a=7 OR B_Q01a=6 AND VET=1 & 3C long, 3AB \\
& & voc \\
IIIa (without 3A voc and 4A voc but 3B gen & B_Q01a=6 AND VET=0 OR B_Q01a=9 AND VET=0 & 3AB gen, 4AB \\
and 4B gen) & & gen \\
IV (without 4B gen) & B_Q01a=8 OR B_Q01a=9 AND VET=1 OR B_Q01a=10 & 4C, 4AB voc, \\
& OR B_Q01a=11 & 5B \\
V1 & EDCAT7=6 & 5A med \\
V2 & EDCAT7=7 & 5A long, 6 \\
\hline
\end{tabular}

Before interpreting the results of the comparative education variables, it is worth looking at the results concerning the country specific variables, shown in Figure 6. Some countries show very weak relationships between educational attainment and skills even when using country specific education variables. These are RUS (4\% adjusted R2), CYP and GRC (each 12\%), LTU (16\%) and EST (19\%). While the results for the Baltic states may not be entirely off, we 
should be careful interpreting the results for these countries: either the country-specific measurement instruments are of low quality already, or there are other data quality issues involved.

Other countries in contrast show very strong links between educational attainment and skills, which is closer to what one would theoretically expect: In SGP, education explains more than $50 \%$ of the variation in literacy skills, followed by NLD with $40 \%$. BFL, CHL, FRA and CFR all have 36-37\%. It is quite remarkable that SGP and CHL only have 10 and 9 education categories in the measurement instruments respectively.

Figure 6: Adjusted R2, regression of literacy skills on country specific education variables

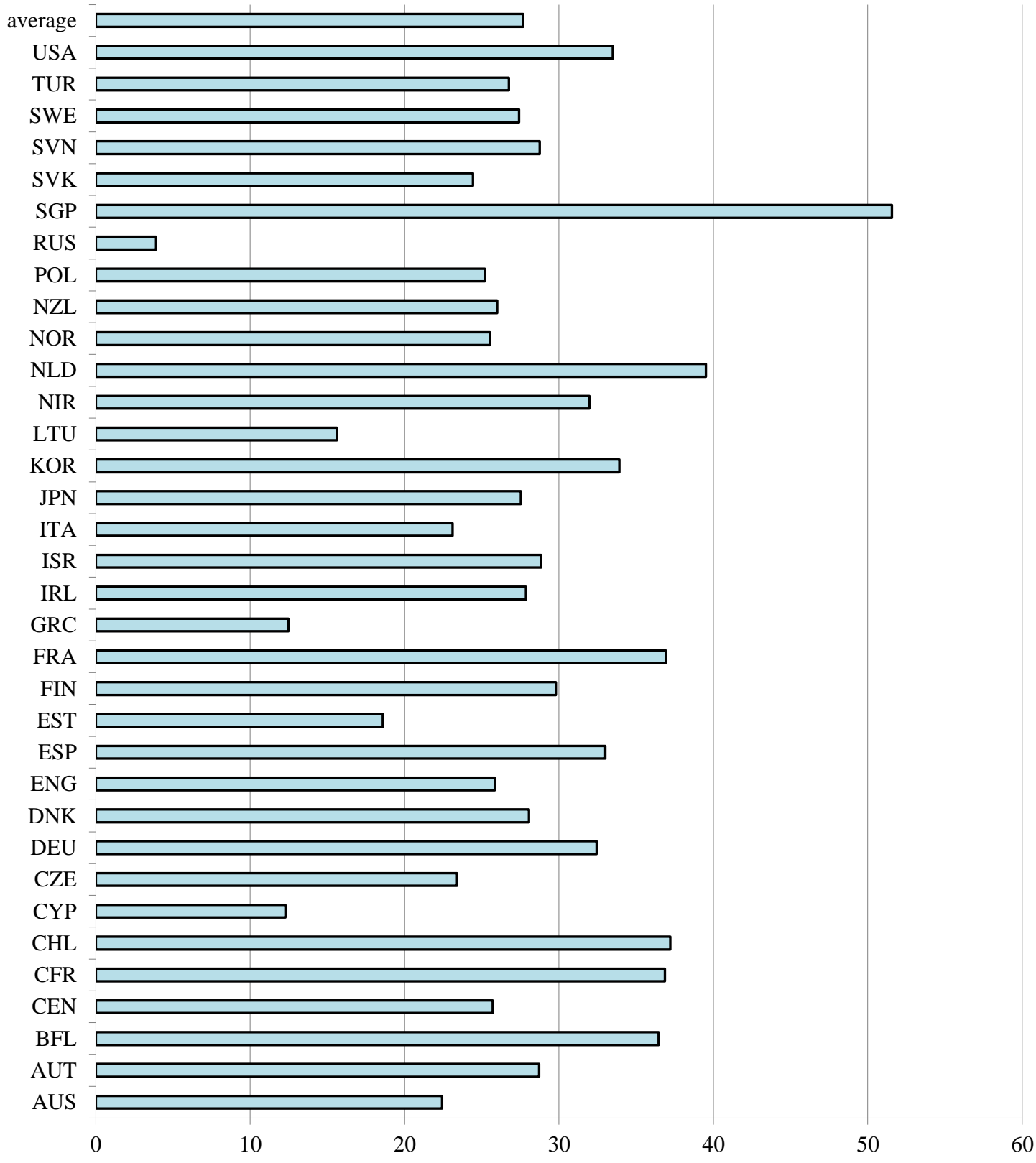


The results of the analysis comparing the performance of comparative education variables with country specific ones are shown in Figure 77. Adjusted R2s are shown relative to those reported in Figure 6, which are set to $100 \%$.

Figure 7: Relative adjusted R2 predicting literacy skills by different educational attainment measures

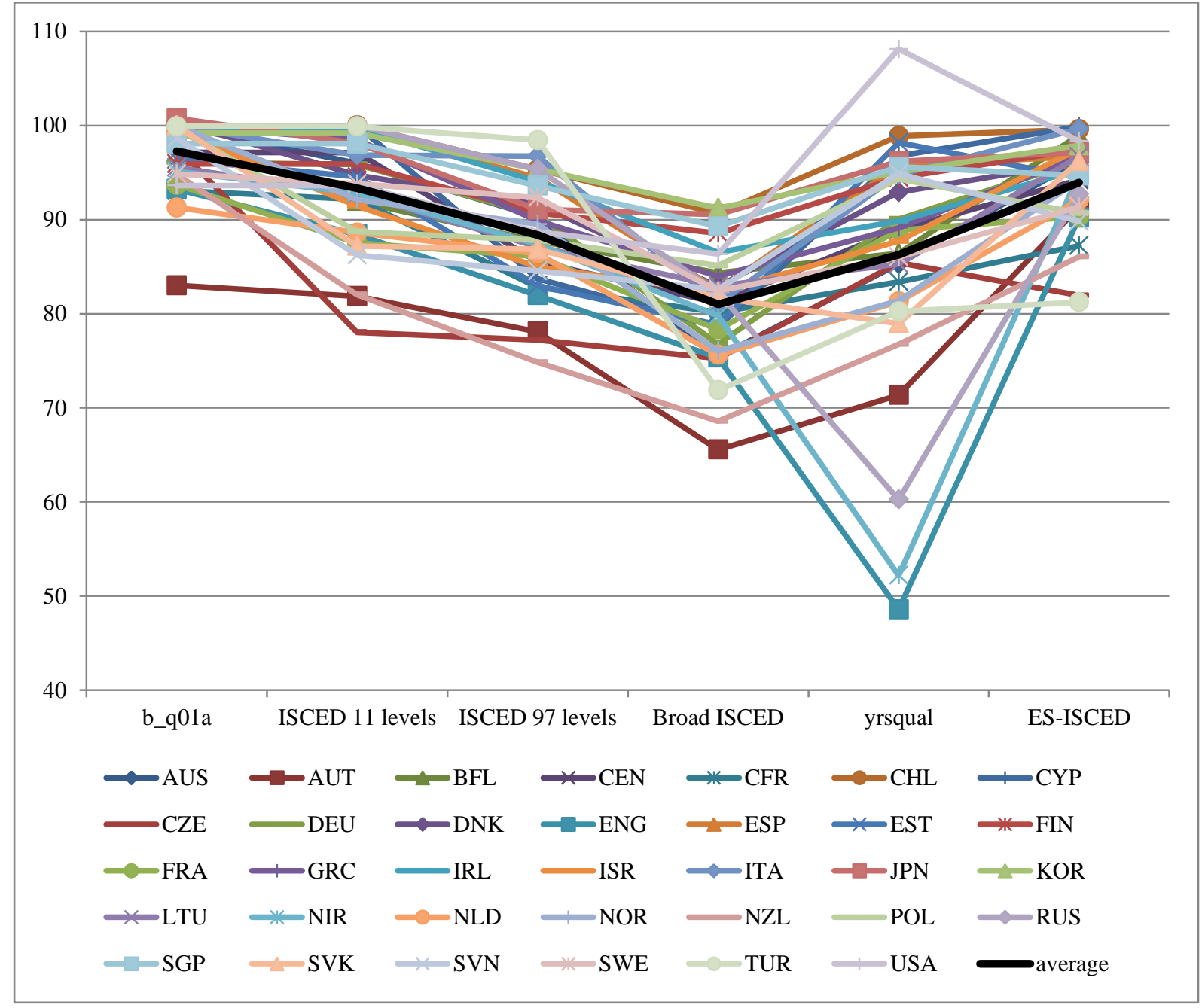

The graph shows that when you harmonize country-specific education variables into the detailed comparable education variable in PIAAC, b_q01a, we can see that the harmonization process itself does not necessitate substantial losses of information and explanatory power. Using this variable, the loss of information is $3 \%$ on average. The variation across countries in the losses is also the lowest of all variables (standard deviation=3.7). However, for AUT and NLD, the loss of information is already visible in b_q01a, with $17 \%$ in the case of AUT and $9 \%$ in the case of NLD, which is not negligible. Let us look at these two cases more closely to see what happens.

In AUT, 16 country specific categories correspond to 9 b_q01a categories, meaning a substantial amount of aggregation even for the most detailed education variable in PIAAC. Looking at the regression results of the country specific education variable, especially ISCED $3 \mathrm{~A} / \mathrm{B}$ is revealed to be a highly heterogeneous category in Austria with respect to literacy 
skills, with the lowest category "Lehre mit Berufschule" achieving substantially lower literacy scores than the middle category "Fach-oder Handelsschule: 2 Jahre und länger" (a statistically significant difference of 15 points) and even a stronger distance between the middle and the highest category, "AHS (z.B. Gymnasium)" (a statistically significant difference of 23 points). The former two are vocational qualifications, the first one dual and the second schoolbased, and the latter refers to academic upper secondary education. These distinctions are unfortunately not captured in the ISCED coding scheme employed in PIAAC. At ISCED $4 \mathrm{~A} / \mathrm{B}$, we also find a skill difference of 21 points between the two qualifications classified here, nursing school and post-secondary vocational school. In fact, the literacy skills of nursing school graduates are virtually identical to those of vocational school at ISCED level 3. Given this programme can be entered at age 16, i.e. at a lower age than the usual completion age of ISCED 3A/B, one may wonder whether the qualification is misclassified in the ISCED mappings. It gets even more extreme when looking at ISCED 5B: here, graduates of the lowest country-specific category, "Meister- und Werkmeisterprüfung,

Bauhandwerkerprüfung" (i.e. completion of the master crafts exam), achieve the same level of literacy skills as those who completed upper secondary vocational or nursing school, while those with other ISCED 5B qualifications in AUT show 18 to 37 points higher literacy scores (the high scores refer to fairly small categories though). Only the aggregation of the two country specific categories corresponding to ISCED 5A long does not pose any validity problems since both groups perform rather equally. From a national point of view, these results are entirely plausible. Had other countries differentiated different types of education within ISCED 3A/B in similar ways, their results might have looked similarly, too.

For NLD, 16 country specific education categories are also harmonised into 9 b_q01a categories. Here, already at ISCED level 2 we find 3 country specific categories with vastly different average literacy skills. The lowest category performs 48 points below the middle one, and the middle 20 points below the upper one. From a dutch point of view, it is thus important to differentiate vocational from general lower secondary education, but given the low numbers in vocational lower secondary education, it is even more important to distinguish between the two tracks in lower secondary education in NLD. Even though both are classified as 'general education' in ISCED, one track is markedly pre-vocational, selecting pupils from the lower ability spectrum and feeding them largely into vocational rather than general/academic upper secondary education. Upper secondary education in NLD is also highly stratified, with three qualifications classified as ISCED 3C $>2$ years, and 3 qualifications classified as ISCED 3A/B. While the lowest category in ISCED 3C >2 years, "leerlingwezen primair, bbl 2 jarig", shows the same literacy scores as those in pre-vocational ISCED 2, the other two ("bol/mbo 2 jarig, kmbo 2 jarig" and "leerlingwezen secundair of tertiair, bbl 3- of 4-jarig") perform substantially higher (but still below those having academic ISCED 2 as their highest attainment!). In ISCED 3A/B, the largest and only vocational category, "bol/mbo 3 of 4 jarig", performs 21 to 23 points lower than the two smaller general categories, "havo, mms" and "vwo, gymnasium, hbs". Within tertiary education, which is also tracked in NLD, we again find substantial literacy skill differences within ISCED 5A medium (Bachelor level), between graduates of vocational colleges (HBO) and universities (WO). Within ISCED 5A long, the distinction is not made in the Dutch measurement instrument. 
ISCED 2011 main levels fare slightly worse, with an average loss of information of 7\%. In 9 out of 34 countries, the education variable loses more than $10 \%$ predictive power when using main ISCED 2011 levels rather than the country-specific variable. The variation in the loss of information across countries is also substantially higher here (standard deviation=5.8). The losses are strongest for CZE (22\%), AUT (18\%) and NZL (18\%). A further 6 countries also show losses above 10\% (SVN, SVK, FRA, ENG, NLD, POL). For CZE, this is due to the fact that there are 21 points difference in literacy skills between those classified as ISCED 3C >2 years ("Vyučení bez maturity delší než 2 roky", vocational education without matura) and the largest group classified in ISCED 3A/B ("Střední odborné s maturitou", technical education with matura). Summarising ISCED 2 and $3 \mathrm{C}$ short in contrast does not pose any problems.

For NZL, merging ISCED 3C short and ISCED 2 leads to a heterogeneous ISCED level 2/3C short in the levels-only ISCED 2011 because those classified as ISCED 2 have on average 25 and 37 points lower literacy scores. However, since these latter individuals do not actually have any educational qualification, while the lowest general school-leaving qualification in NZL is classified as ISCED 3C short, one may also wonder whether the ISCED mapping for NZL is comparable with that of most other countries where the first school-leaving qualification is awarded at the end of ISCED level 2, and individuals who left school without qualifications are classified in ISCED level 1. At ISCED level 3, qualifications classified as ISCED 3C long are related to substantially lower literacy skills than qualifications classified as ISCED 3A/B (differences of up to 40 points), especially "NCEA Level 3/Bursary or Scholarship/Higher Leaving Certificate/Higher School Certificate".

Looking at the results for ISCED 97 main levels, education explains substantially less variation in literacy skills than the original country-specific education variable - on average $12 \%$. In 18 out of 34 countries, predictive power of this harmonized variable is more than $10 \%$ lower than with the country-specific variable. While the losses of information are rather large on average, the variation of these losses across countries is slightly smaller than when using ISCED 2011 levels (standard deviation=5.6).

If you further aggregate to just three education categories commonly used in statistical reporting, the average loss is even 19\%. In 31 out of 34 countries, losses of predictive power of the education variable are higher than $10 \%$. The variation across counties in the relative losses are also the highest compared to the other categorical education variables (standard deviation=6.0). This variable typically used in cross-tabulations in statistical reports is thus not very suitable for multivariate analyses.

So, while with some very plausible (and in principle avoidable) exceptions, b_q01a works rather well, this variable has a large number of categories, and some of them are empty for a substantial number of countries, which is inconvenient for statistical analysis. Aggregating to main ISCED levels (2011 or 1997) leads to further reductions of comparative construct validity and thus comparability. Therefore, two alternative simpler variables derived from b_q01a are checked here as well: ES-ISCED and years of education.

Years of education perform a little worse than ISCED 97 levels on average (average loss in $\mathrm{R} 2=14 \%$ ). The variation in the relative losses is however by far higher than with the categorical education variables though (standard deviation=12.7). Years of education only achieve half of the adjusted R2 achieved using the country-specific education variable in ENG 
and NIR, and $60 \%$ in RUS. (The Russian data appear unreliable though throughout, generating very low R2s generally.) In 19 out of 34 countries, the loss of information by using years of education is larger than $10 \%$. The USA is the only country where it explains $8 \%$ more variation than the country-specific education variable. (This should actually not be possible if the variable yrsqual was indeed derived from the country-specific variable.)

Turning to ES-ISCED, the analyses show that if you aggregate detailed education categories in a way that keeps important and drops less important distinctions, one can achieve acceptable harmonization results even with a variable containing only 8 categories. The average loss of information using this variable is $6 \%$, and the variation of losses is lower than with any other variable except b_q01a (standard deviation=4.7). The variable works least well for TUR because it drops the distinction between ISCED levels 0 and 1, which is still very relevant in less developed countries. For CZE, CFR and NZL, the losses using ES-ISCED are also above $10 \%$ (i.e. 4 out of 34 countries).

When aggregating ISCED levels 0 and 1 in variable ISCED11_8, this has very little impact across countries - with one exception: TUR (loss of $19 \%$ in relative adjusted R2). This is very plausible given the lower level of educational attainment of the Turkish population, and the consequently rather important distinction between ISCED levels 0 and 1 also in terms of literacy skills. When further aggregating ISCED 5A long and 6 in ISCED11_7, this is even less consequential. Similarly, when using ISCED 97, it does not make a large difference for this average whether ISCED 0 and 1 or ISCED 5 and 6 are aggregated or not (of course the result for TUR is replicated, results not shown). Basically, the loss of information between ISCED 2011 main levels and ISCED 97 main levels happens when aggregating ISCED 5B (level 5 in ISCED 2011) and 5A (levels 6 and 7 in ISCED 2011), not any more when aggregating 5 and 6. Aggregating ISCED 97 levels 5A long and 6 thus seems to be rather safe, and when not analysing substantially less developed countries, ISCED levels 0 and 1 can also be safely aggregated.

One problem with these analyses in general is that the country specific education variables in PIAAC are often no more detailed than the variable b_q01a - NPMs have thus implemented questionnaire items that just satisfy the requirements of the comparative PIAAC variable b_q01a, and not more (and sometimes not even that, see section 7.1). Consequently, there is a strong negative correlation of -0.5 between the number of categories in the country specific education variable and the relative adjusted R2 achieved by b_q01a when predicting literacy skills. This means that had more countries measured educational attainment in more detail, like e.g. GBR, CAN, NZL, DEU and FRA (all using several questionnaire items), or even EST, AUT, NLD, SWE and SVN (all using one questionnaire item but with 15 to 20 response categories), the results might look a little less positive for b_q01a. Indeed, average performance of b_q01a when only looking at these countries drops to $94 \%$.

Table shows the detailed results. They are pretty similar when using numeracy rather than literacy skills as validation construct. 
Table 7: Results from comparative construct validation of education variables using literacy skills

\begin{tabular}{|c|c|c|c|c|c|c|c|}
\hline & Adjusted R2 & Adjustec & $\mathrm{R} 2$ relative to $\mathrm{CSE}$ & $V$ in \% (Country-sp & cific education & ariable) & \\
\hline Country & CSEV & b_q01a & ISCED 11 levels & ISCED 97 levels & Broad ISCED & yrsqual & ES-ISCED \\
\hline AUS & 22 & 100 & 96 & 90 & 75 & 85 & 96 \\
\hline AUT & 29 & 83 & 82 & 78 & 66 & 71 & 91 \\
\hline BFL & 36 & 100 & 92 & 88 & 84 & 86 & 99 \\
\hline CEN & 26 & 97 & 97 & 86 & 81 & 89 & 94 \\
\hline CFR & 37 & 93 & 92 & 83 & 80 & 83 & 87 \\
\hline CHL & 37 & 100 & 100 & 95 & 91 & 99 & 100 \\
\hline CYP & 12 & 100 & 100 & 84 & 79 & 97 & 100 \\
\hline CZE & 23 & 98 & 78 & 77 & 75 & 85 & 82 \\
\hline DEU & 32 & 96 & 96 & 90 & 77 & 90 & 96 \\
\hline DNK & 28 & 100 & 95 & 92 & 83 & 93 & 96 \\
\hline ENG & 26 & 93 & 88 & 82 & 75 & 49 & 90 \\
\hline ESP & 33 & 100 & 100 & 94 & 83 & 96 & 97 \\
\hline EST & 19 & 96 & 95 & 83 & 79 & 98 & 94 \\
\hline FIN & 30 & 96 & 96 & 91 & 89 & 94 & 97 \\
\hline FRA & 37 & 94 & 88 & 86 & 78 & 89 & 90 \\
\hline GRC & 12 & 100 & 98 & 90 & 84 & 89 & 97 \\
\hline IRL & 28 & 100 & 100 & 94 & 87 & 90 & 95 \\
\hline ISR & 29 & 99 & 91 & 85 & 82 & 88 & 98 \\
\hline ITA & 23 & 100 & 97 & 97 & 81 & 95 & 100 \\
\hline JPN & 28 & 101 & 98 & 91 & 91 & 96 & 97 \\
\hline KOR & 34 & 99 & 99 & 95 & 91 & 95 & 98 \\
\hline LTU & 16 & 96 & 93 & 87 & 83 & 85 & 97 \\
\hline NIR & 32 & 95 & 93 & 87 & 80 & 52 & 95 \\
\hline NLD & 40 & 91 & 89 & 86 & 76 & 81 & 92 \\
\hline NOR & 26 & 100 & 92 & 90 & 76 & 81 & 94 \\
\hline NZL & 26 & 95 & 82 & 75 & 69 & 77 & 86 \\
\hline POL & 25 & 100 & 89 & 88 & 85 & 94 & 91 \\
\hline RUS & 4 & 100 & 100 & 95 & 82 & 60 & 93 \\
\hline SGP & 52 & 98 & 98 & 94 & 89 & 96 & 95 \\
\hline SVK & 24 & 100 & 87 & 87 & 82 & 79 & 96 \\
\hline SVN & 29 & 99 & 86 & 85 & 83 & 95 & 90 \\
\hline SWE & 27 & 95 & 94 & 92 & 82 & 86 & 91 \\
\hline TUR & 27 & 100 & 100 & 98 & 72 & 80 & 81 \\
\hline USA & 33 & 94 & 94 & 89 & 86 & 108 & 98 \\
\hline Average & 28 & 97 & 93 & 88 & 81 & 86 & 94 \\
\hline Min & 4 & 83 & 78 & 75 & 66 & 49 & 81 \\
\hline Q1 & 25 & 95 & 89 & 85 & 77 & 82 & 91 \\
\hline Q2 & 28 & 99 & 94 & 88 & 82 & 89 & 95 \\
\hline Q3 & 33 & 100 & 98 & 92 & 84 & 95 & 97 \\
\hline Max & 52 & 101 & 100 & 98 & 91 & 108 & 100 \\
\hline Std dev & 8.8 & 3.7 & 5.8 & 5.6 & 6.0 & 12.7 & 4.7 \\
\hline
\end{tabular}




\subsection{Descriptive results on training participation based on PIAAC, PIAAC Germany, PIAAC-LN and the Adult Education Survey 2011}

\subsubsection{General Participation}

Figure 8: PIAAC - Participation in non-formal training by country (in \%)

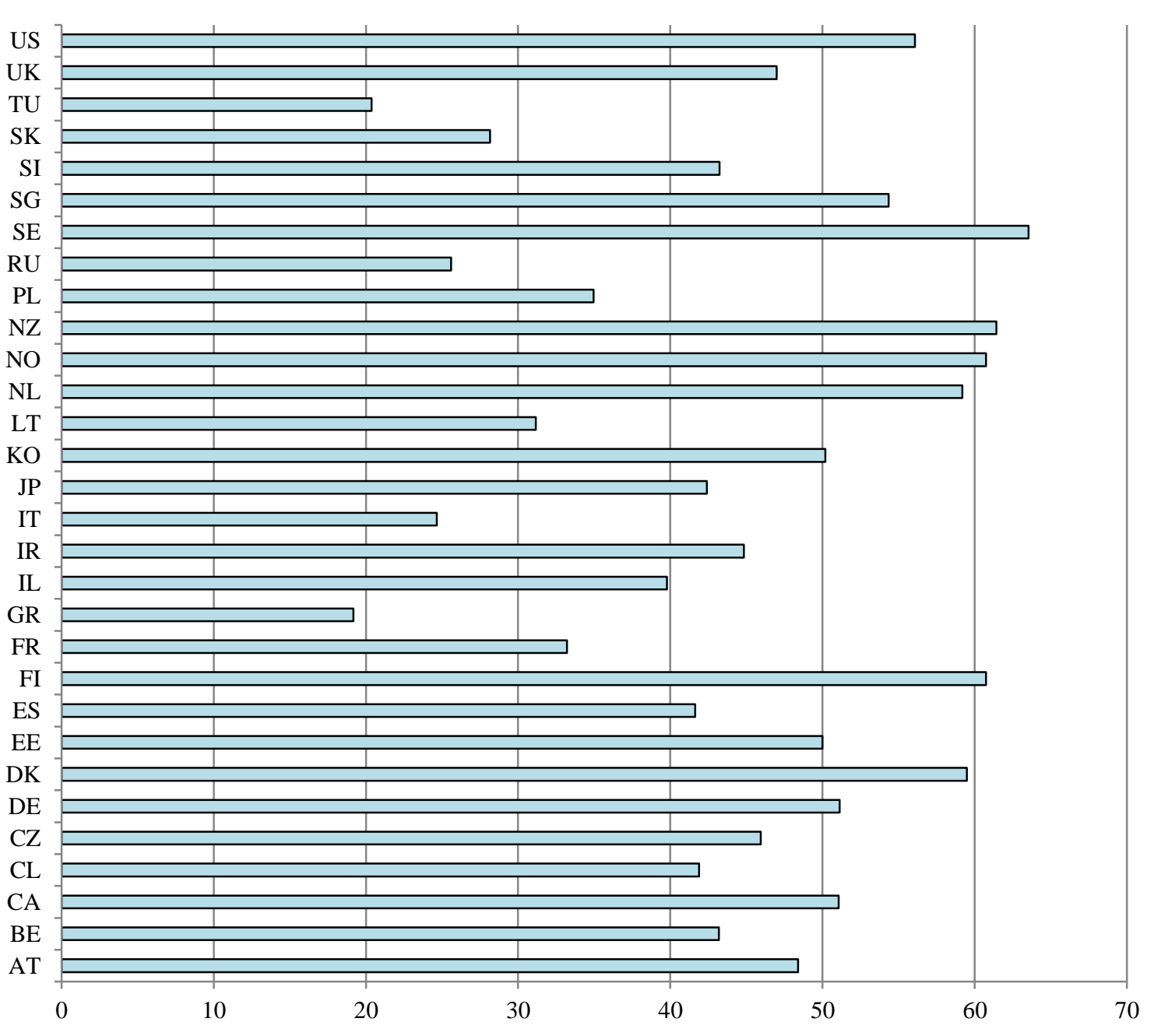

Source: PIAAC 2012 and 2014, own calculations.

Table 8a. Participation in non-formal training in Germany (PIAAC and PIAAC-L)

PIAAC 2012

PIAAC-LN

Participated in job-related NFE in past 12 months

Participated in general NFE in past 12 months

Participated in any kind of NFE

52.84

47.41

Source: PIAAC 2012 and PIAAC-LN, own calculations. 
Table 8b. Participation in non-formal training for job-related reasons

PIAAC $2012 \quad$...share of respondents who took part in NFE

Job-related reason $\quad 41.71$

...share of whole population

22.04

Not job-related

51.15

27.03

Source: PIAAC 2012, own calculations.

Table 8c. Training took place during working hours

PIAAC 2012

PIAAC-LN

Only during working hours

67.04

52.89

Mostly during working hours

10.36

13.89

Mostly outside working hours

6.21

6.49

Only outside working hours

16.38

26.73

Source: PIAAC 2012 and PIAAC-LN, own calculations. 


\subsubsection{Participation in training and gender}

Figure 9a: PIAAC - Participation in non-formal training by country and gender (percent)

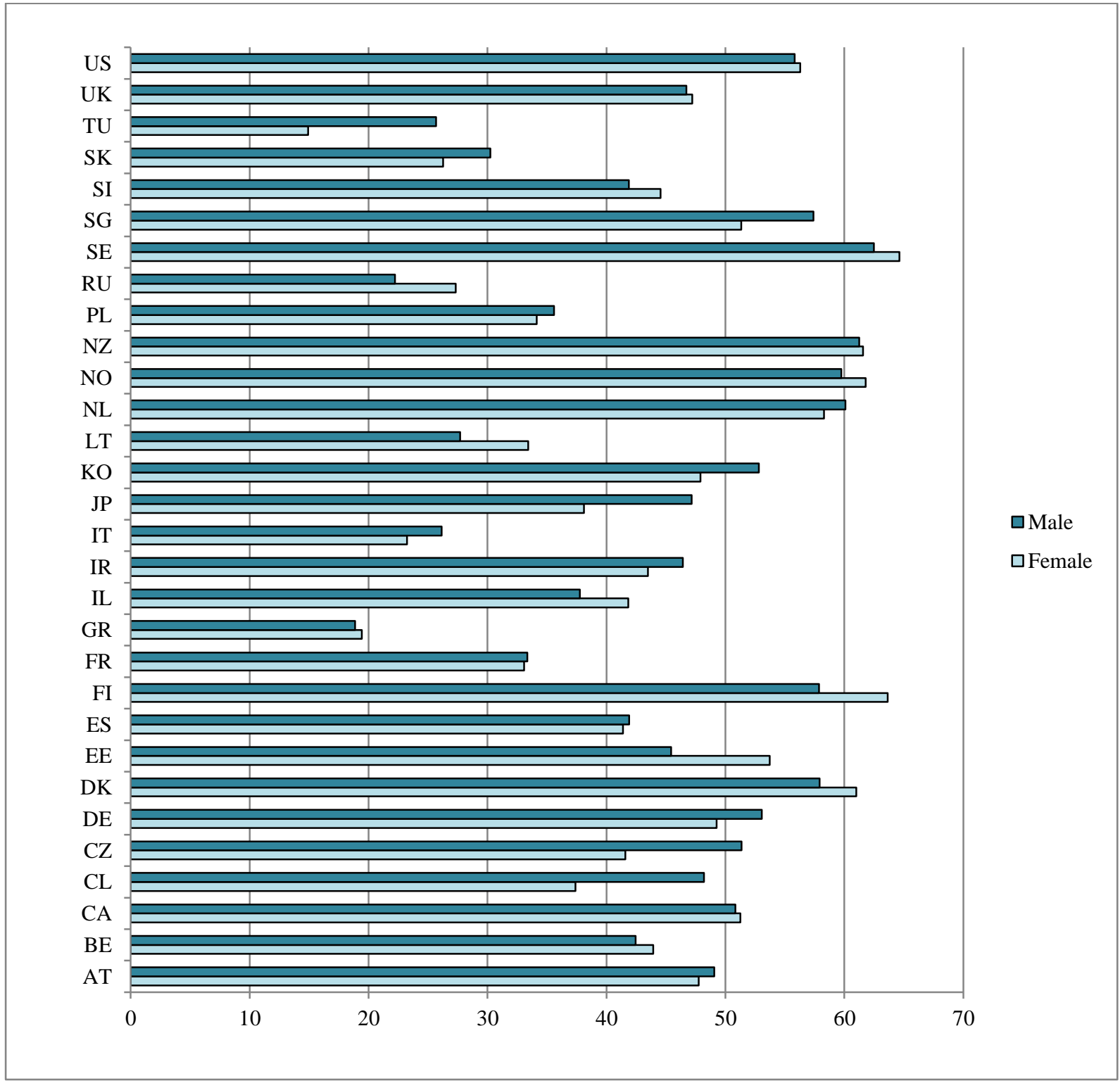

Source: PIAAC 2012 and 2014, own calculations. 
Figure 9b: PIAAC Germany and PIAAC-LN - Participation in non-formal training by country and gender (percent)

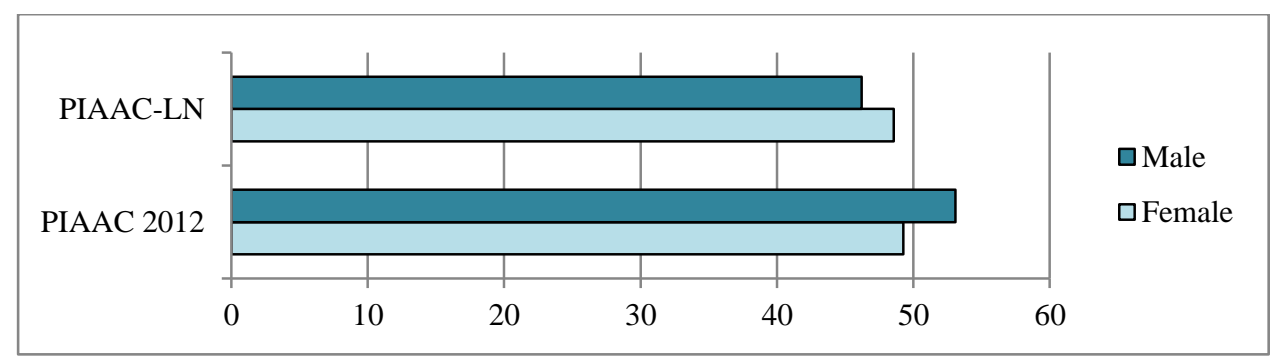

Source: PIAAC 2012 and PIAAC-LN, own calculations.

Figure 9c: AES - Participation in non-formal training by country and gender (percent)

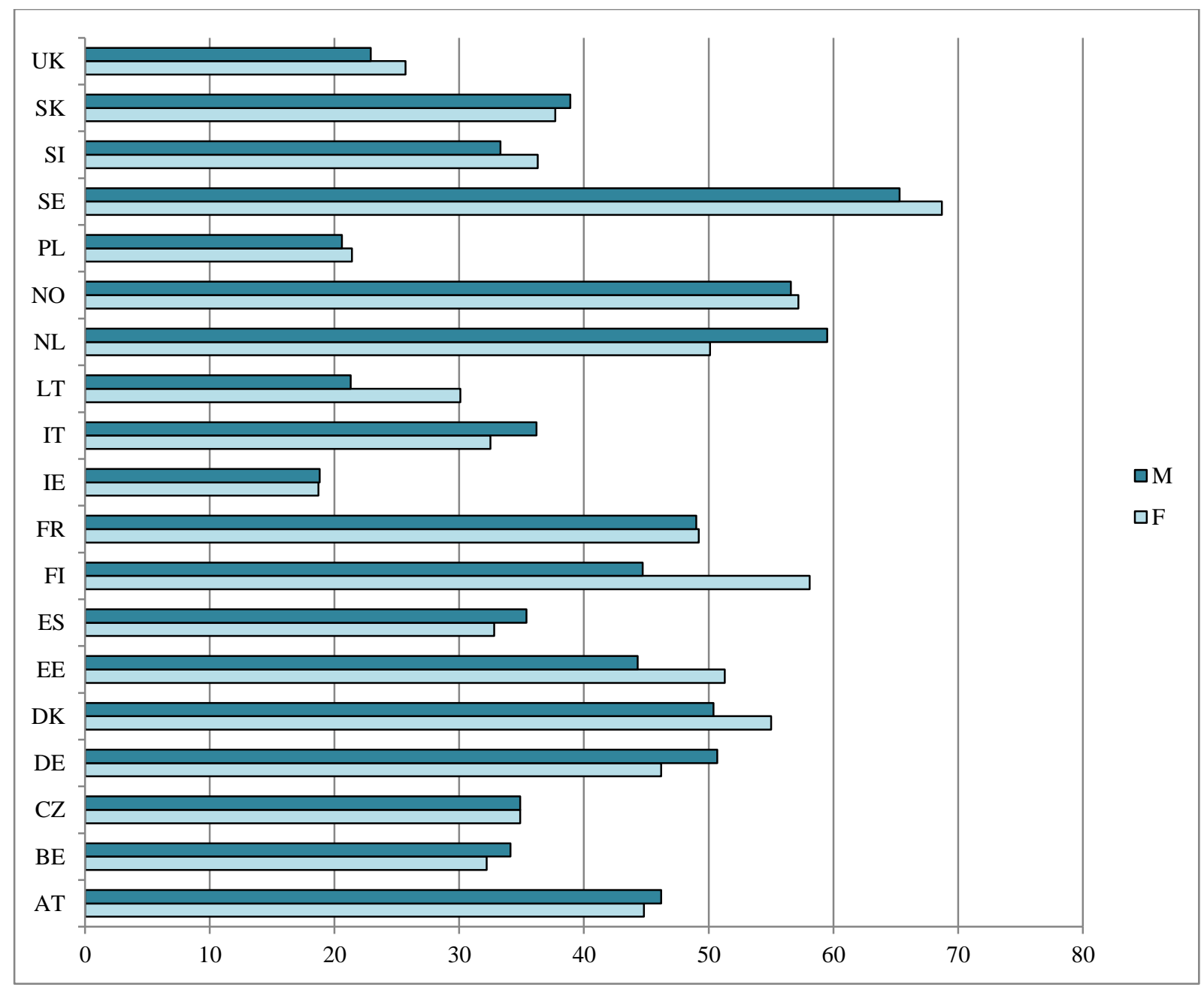

Source: AES 2011, based on data provided by Eurostat. Note: only countries which also participated in PIAAC are presented. 


\subsubsection{Participation and age}

Figure 10a: PIAAC - Participation in non-formal training by country and age

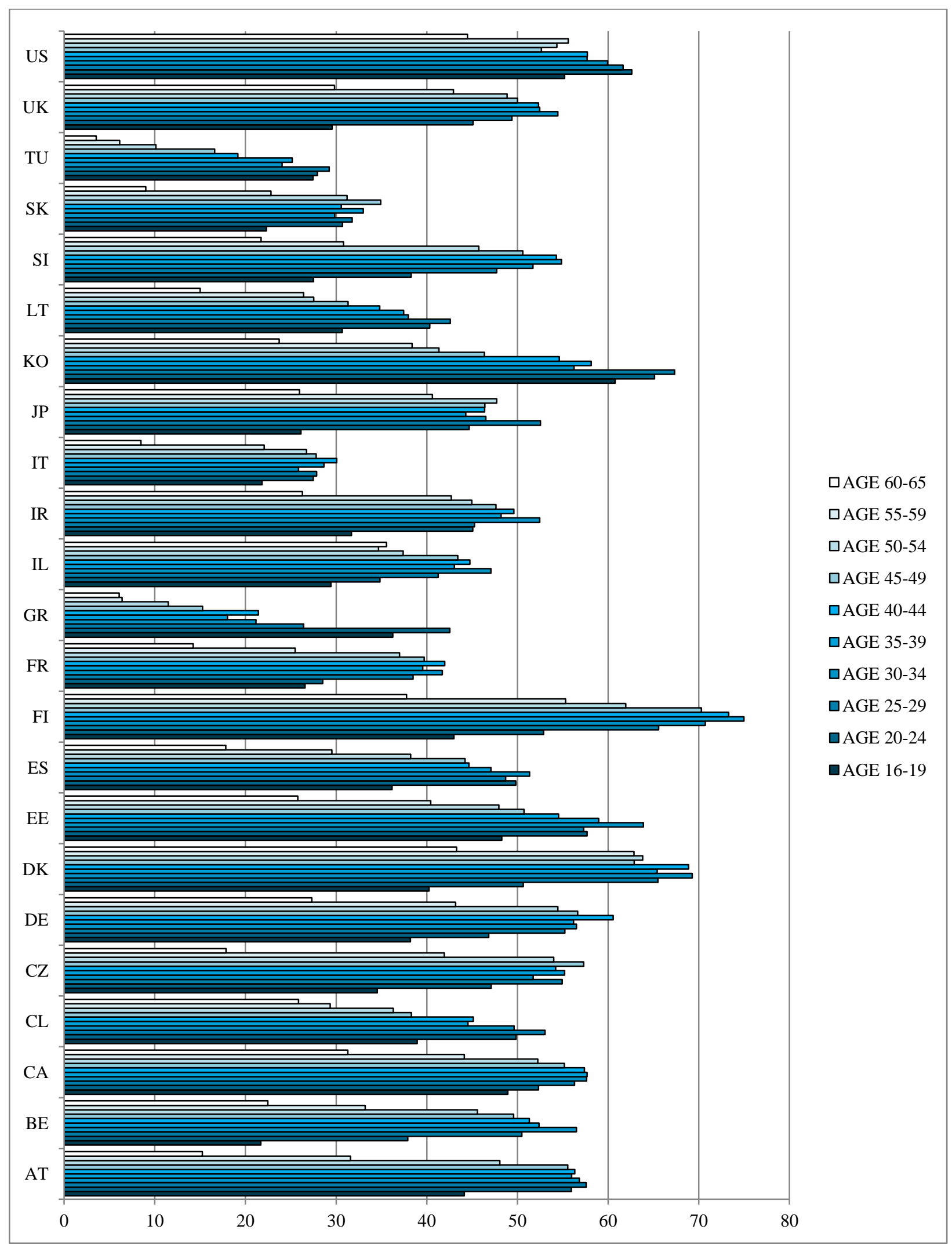

Source: PIAAC 2012 and 2014, own calculations. 
Figure 10b: PIAAC Germany and PIAAC-LN Participation in training by age

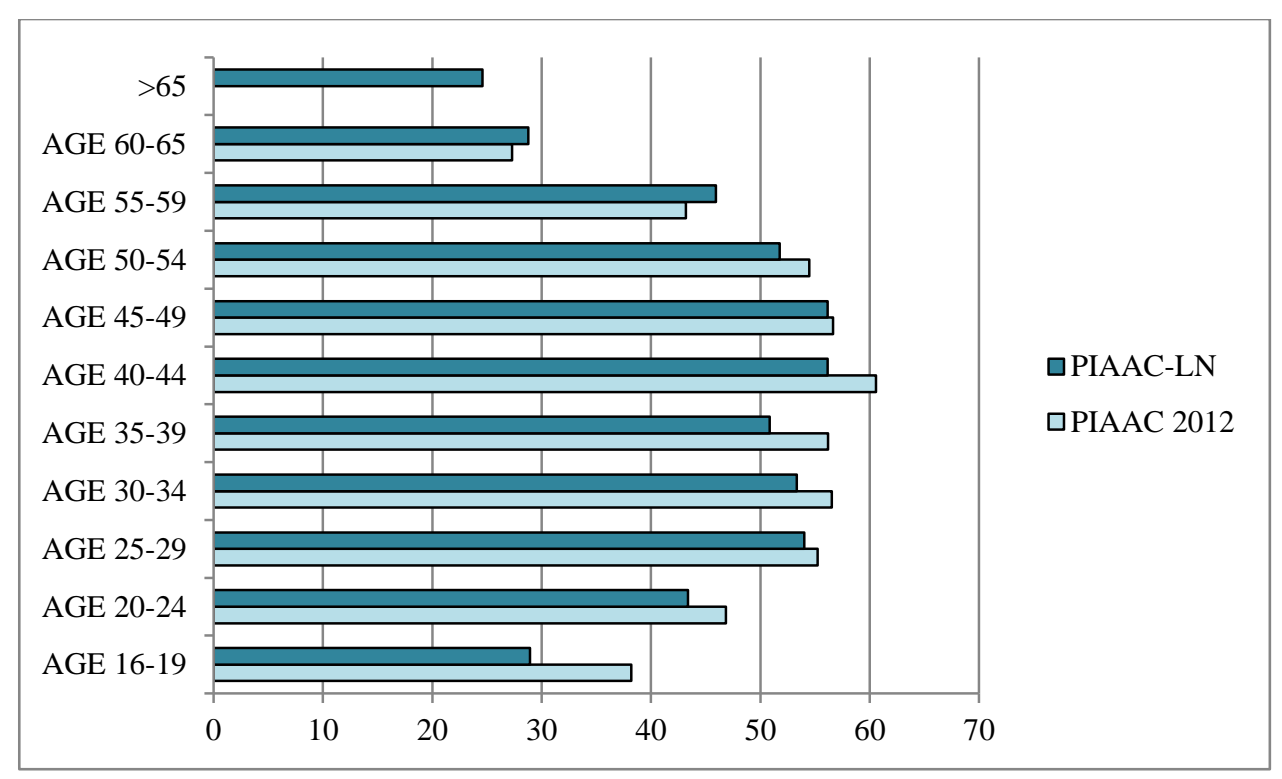

Source: PIAAC 2012 and PIAAC-LN, own calculations. 


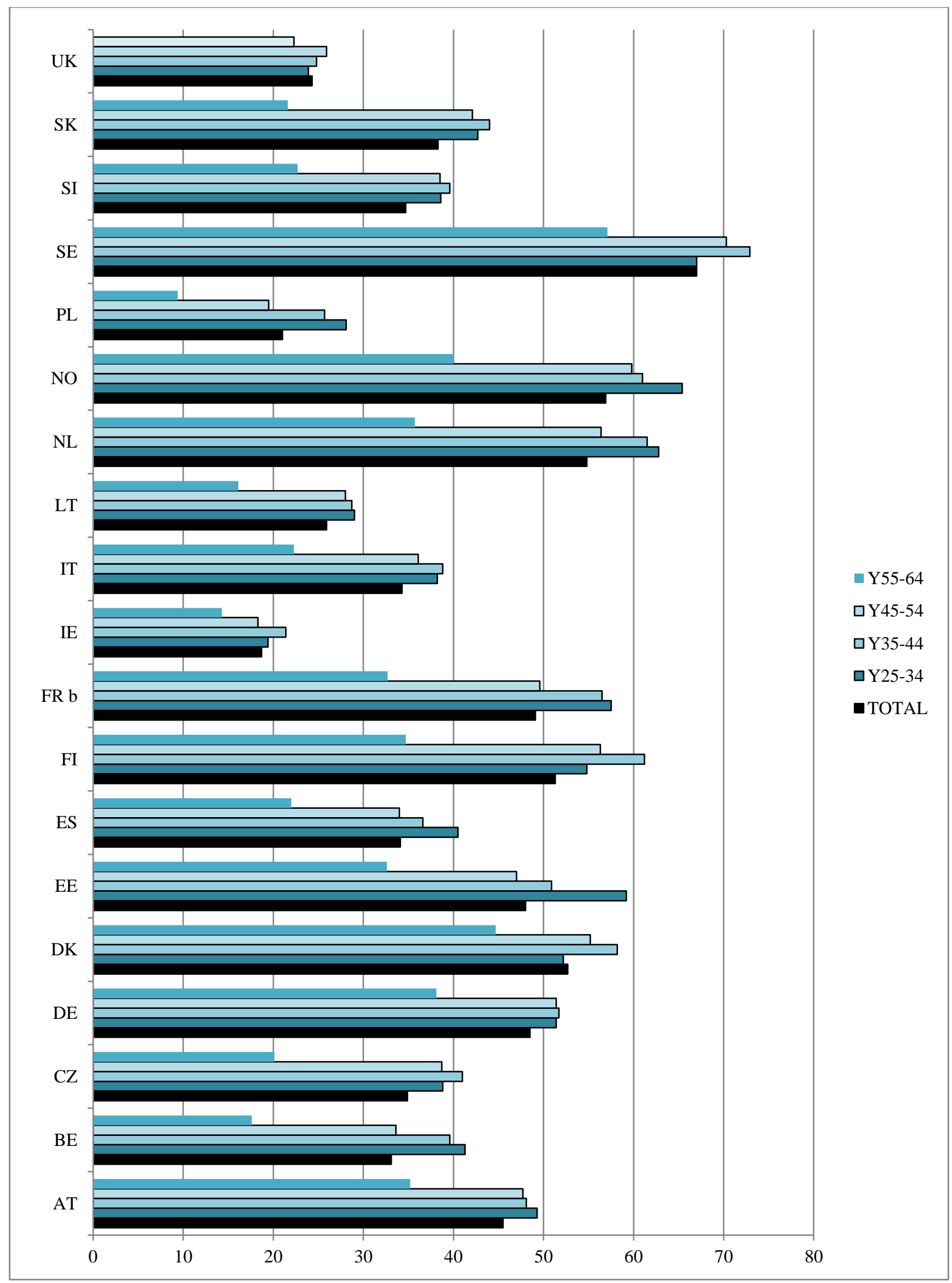

Source: AES 2011, based on data provided by Eurostat. Note: only countries which also participated in PIAAC are presented. 


\subsubsection{Participation in training and formal educational qualifications}

Figure 11a: PIAAC - Percent Participation in non-formal training by country and educational group (broad ISCED levels)

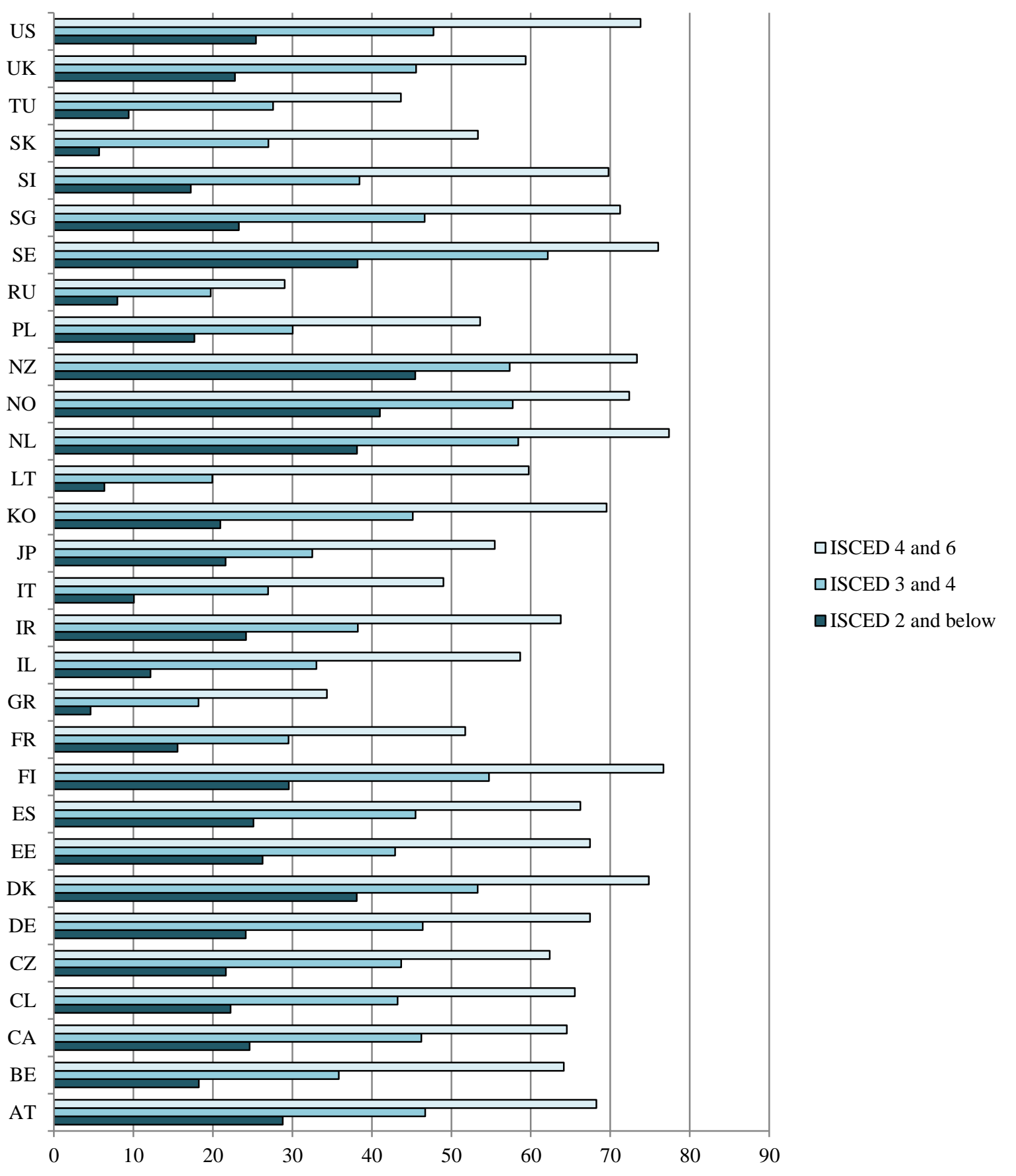

Source: PIAAC 2012 and 2014, own calculations. 
Figure 11b: PIAAC Germany and PIAAC-LN - Participation in training by educational group (broad ISCED levels)

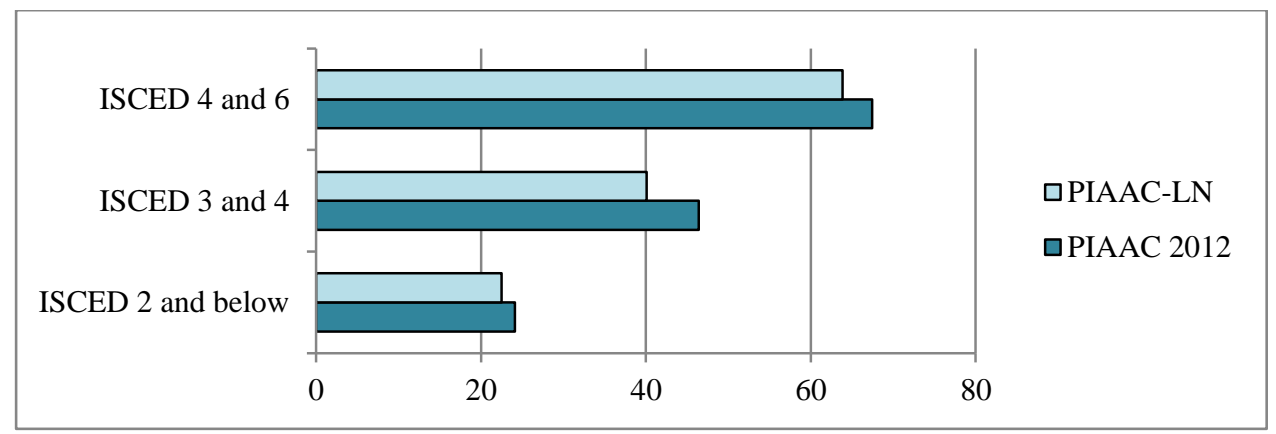

Source: PIAAC 2012 and PIAAC-LN, own calculations. 
Figure 11c: Percent Participation in non-formal training by country and educational group (broad ISCED level)

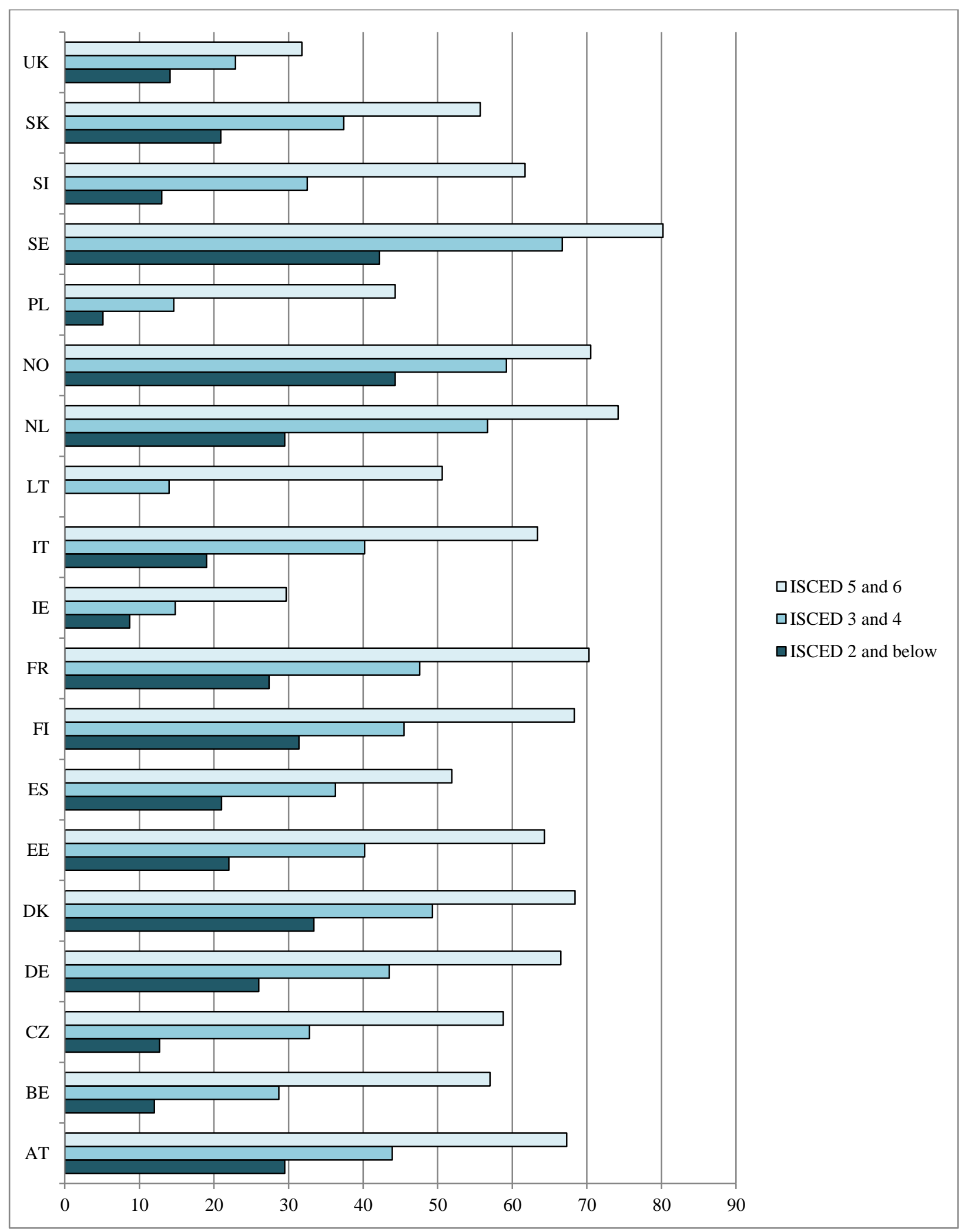

Source: AES 2011, based on data provided by Eurostat. Note: only countries which also participated in PIAAC are presented. 


\subsubsection{Participation in Training and employment status}

Figure 12a: PIAAC -Participation in non-formal training by employment status.

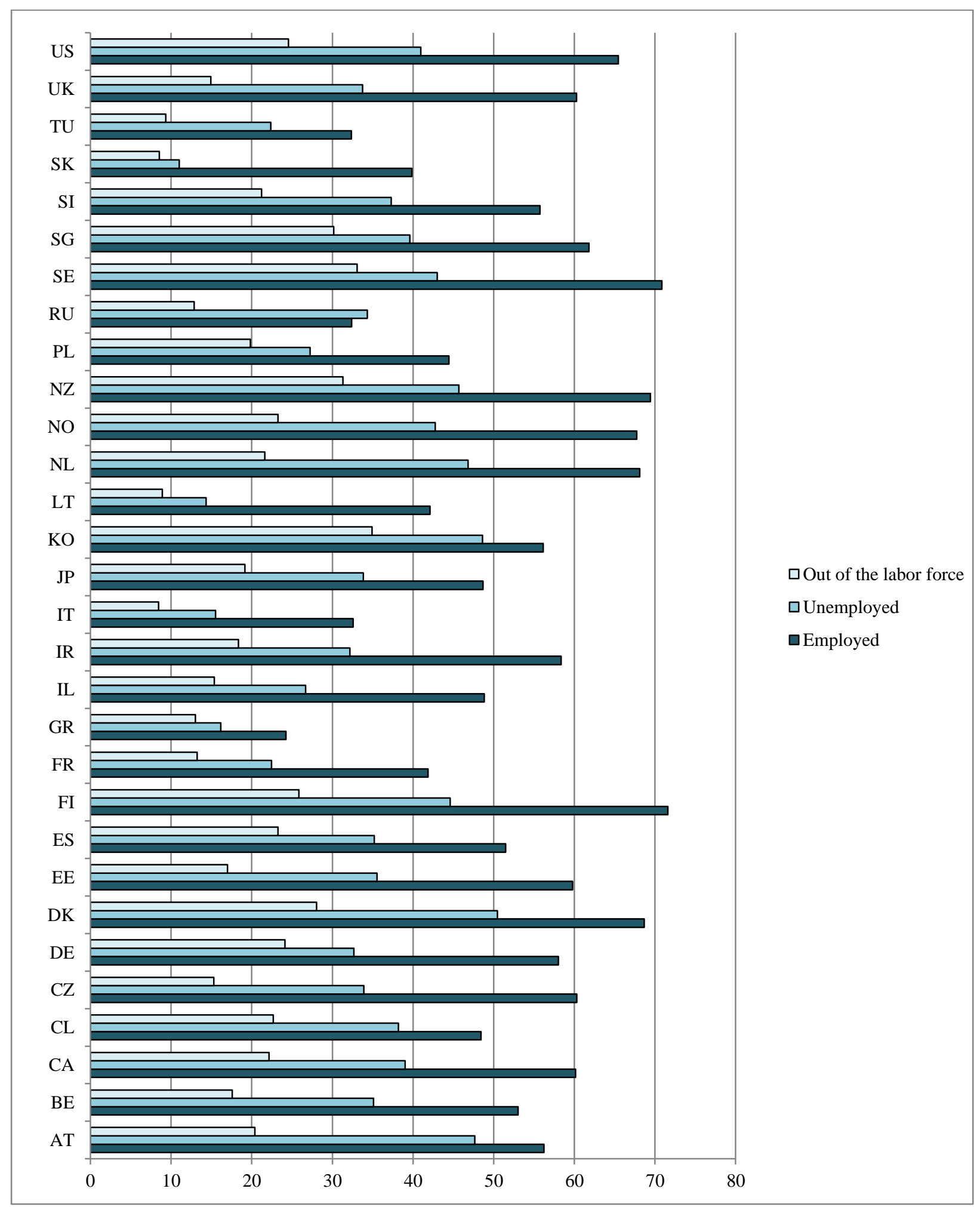

Source: PIAAC 2012 and 2014, own calculations. 
Figure 12b: PIAAC Germany and PIAAC-LN - Participation in non-formal training by employment status.

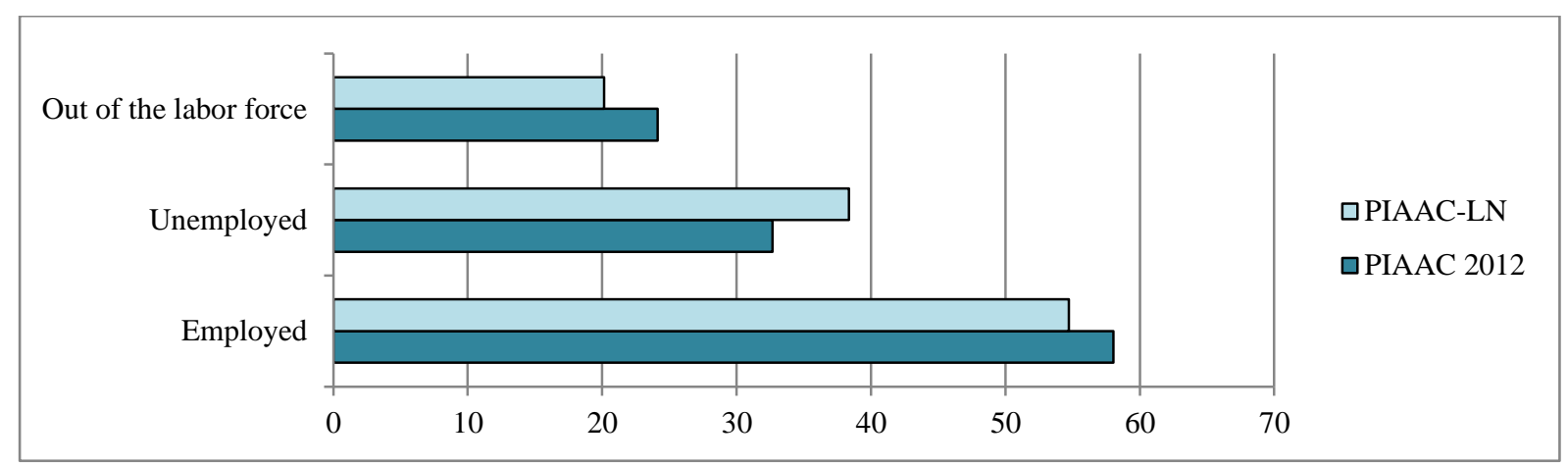

Source: PIAAC 2012 and PIAAC-LN, own calculations. 
Figure 12c: AES - Participation in non-formal training by employment status.

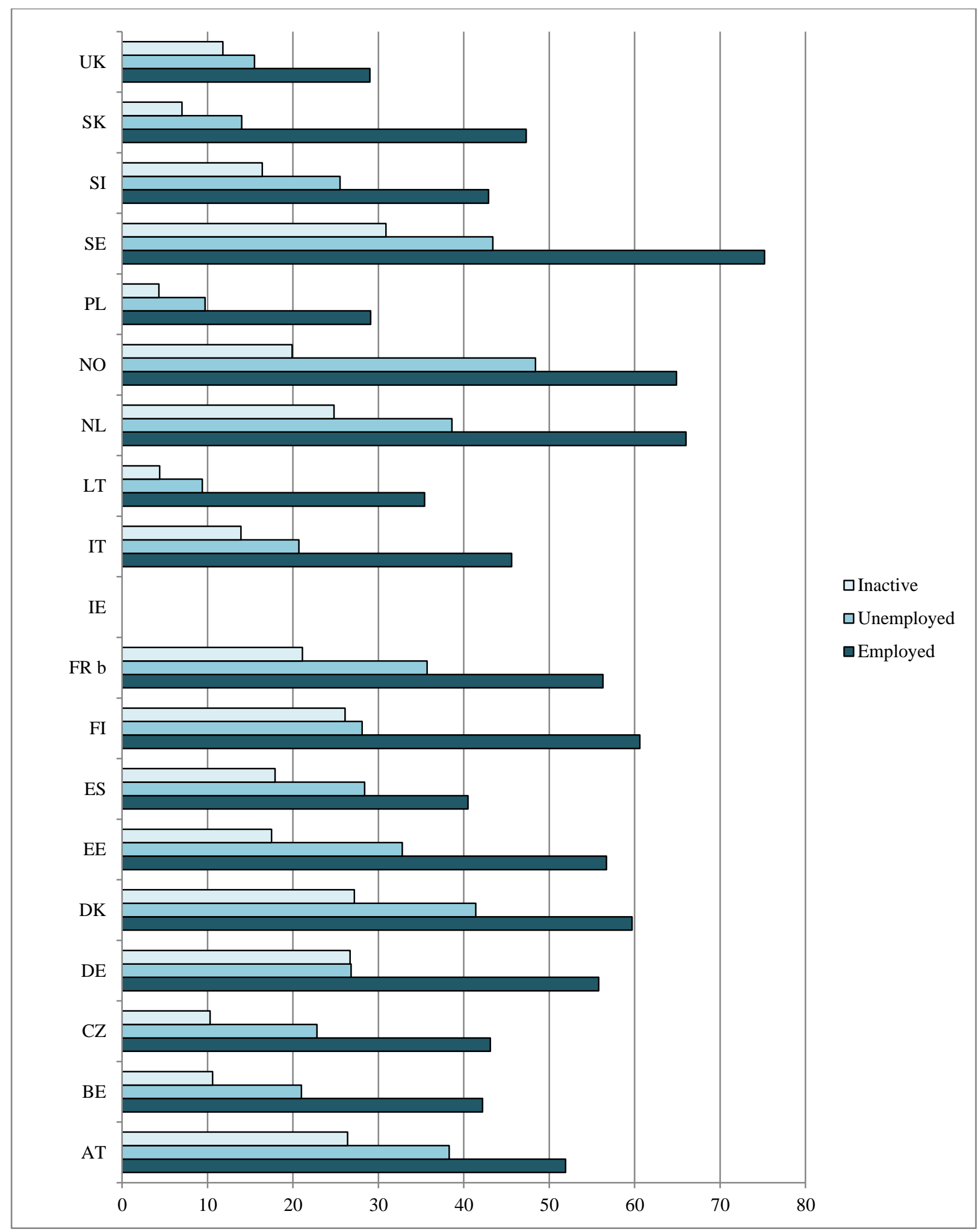

Source: AES 2011, based on data provided by Eurostat. Note: only countries which also participated in PIAAC are presented. 


\subsubsection{Average hours spent on training activities}

Figure 13a: PIAAC - Average hours spent on training participation by country.

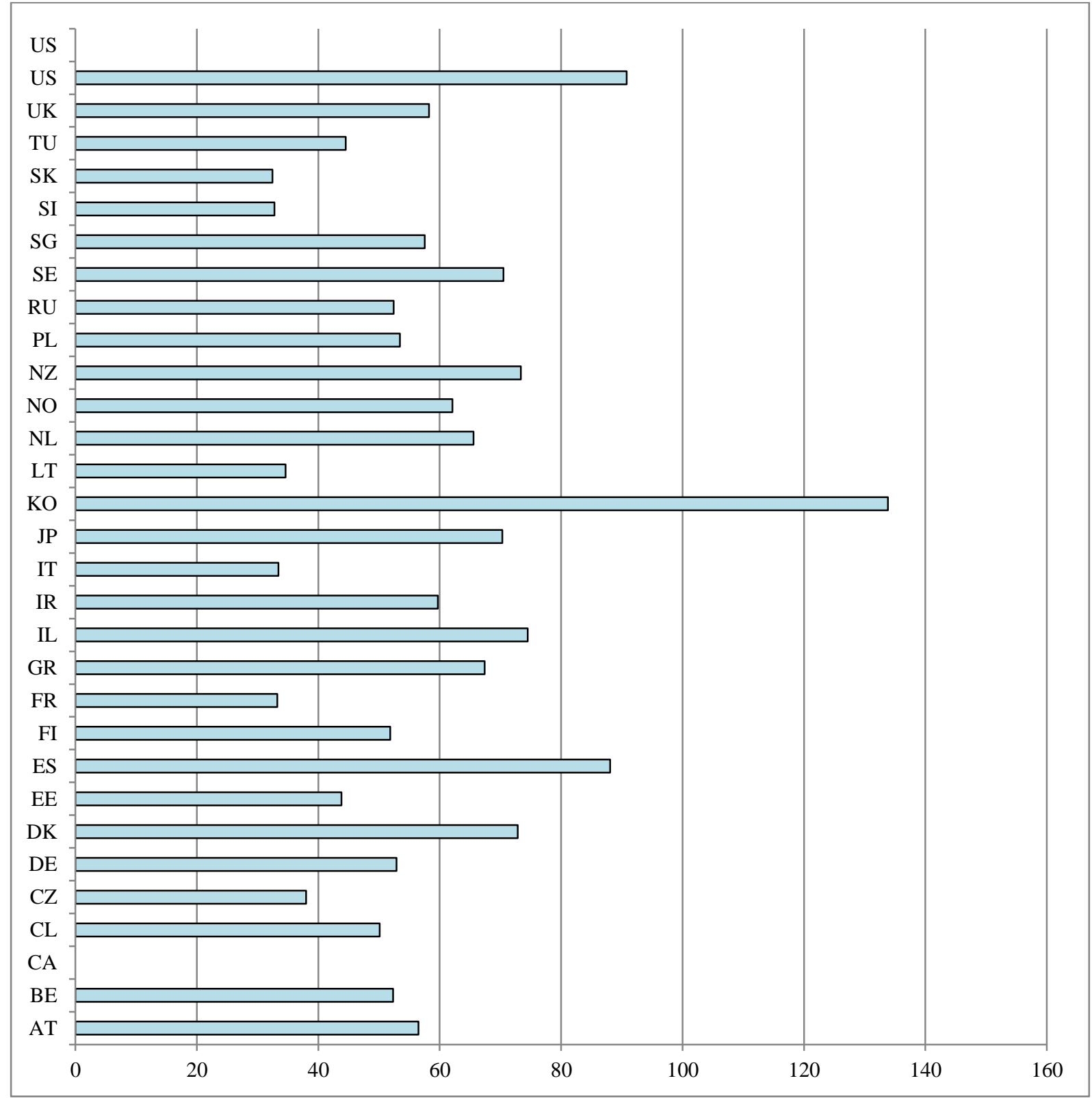

Source: PIAAC 2012 and 2014, own calculations. 
Figure 13b: AES - Average hours in non-formal training by country

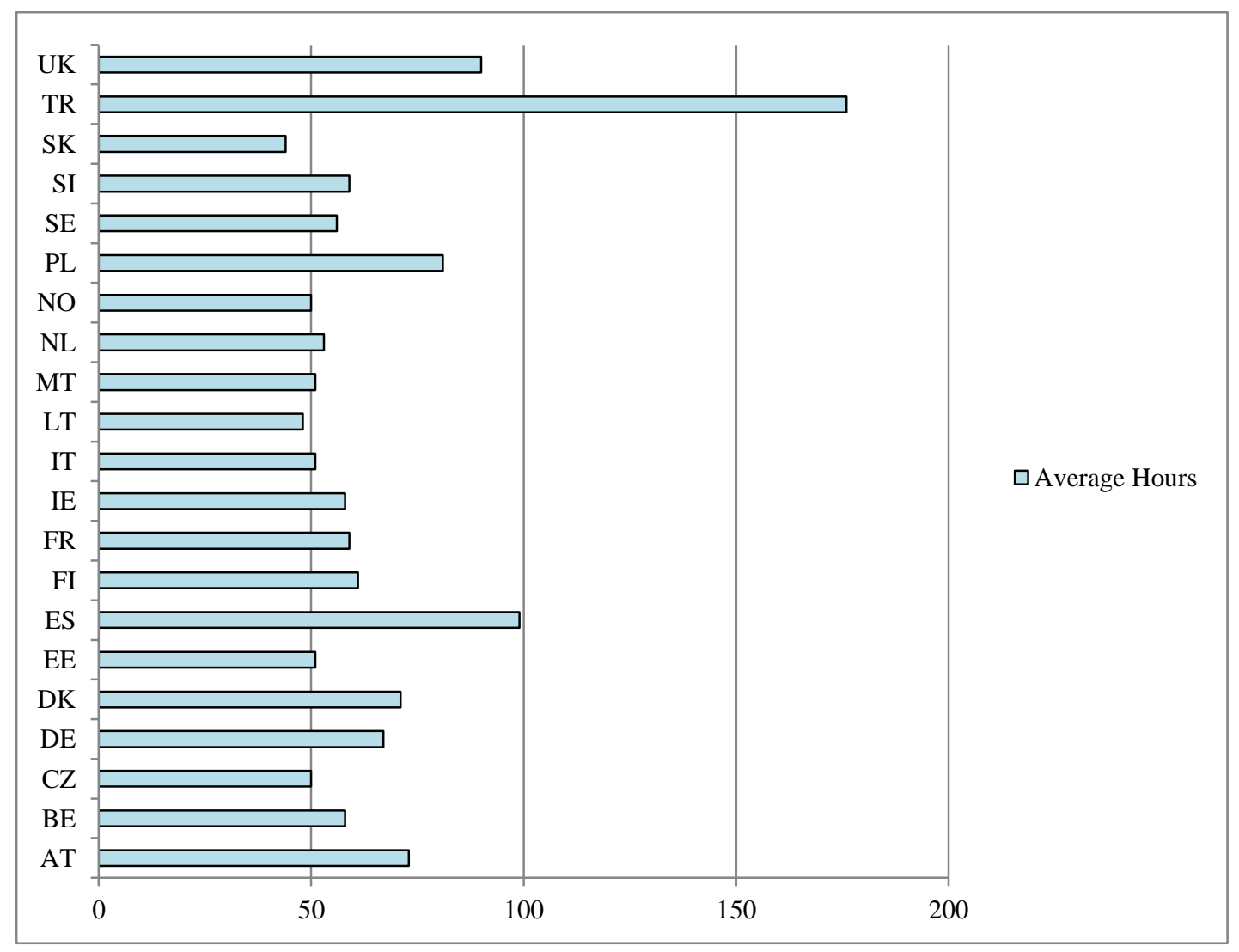

Source: AES 2011, based on data provided by Eurostat. Note: only countries which also participated in PIAAC are presented. 
7.2.7 Participation in work-related, employer-sponsored and non-job-related training Table 9a: PIAAC- Training is work related, sponsored by the employer, not sponsored or non-job related

\begin{tabular}{|c|c|c|c|c|}
\hline & Job-related NFE & $\begin{array}{l}\text { Job-related NFE } \\
\text { sponsored by employer }\end{array}$ & $\begin{array}{l}\text { Job-related NFE not } \\
\text { sponsored the } \\
\text { employer }\end{array}$ & $\begin{array}{l}\text { Only non-job-related } \\
\text { NFE }\end{array}$ \\
\hline $\mathrm{AT}$ & 72.9 & 62.8 & 23.0 & 27.1 \\
\hline $\mathrm{BE}$ & 64.9 & 56.8 & 29.8 & 35.1 \\
\hline $\mathrm{CA}$ & 70.2 & 63.2 & 26.6 & 29.8 \\
\hline $\mathrm{CL}$ & 60.1 & 30.4 & 45.4 & 39.8 \\
\hline $\mathrm{CZ}$ & 64.6 & 48.5 & 28.2 & 35.4 \\
\hline $\mathrm{DE}$ & 67.9 & 56.7 & 24.5 & 32.1 \\
\hline DK & 76.1 & 74.4 & 13.2 & 23.8 \\
\hline $\mathrm{EE}$ & 57.2 & 47.7 & 33.5 & 42.8 \\
\hline ES & 54.3 & 34.5 & 34.5 & 45.7 \\
\hline FI & 65.9 & 67.4 & 21.0 & 34.0 \\
\hline FR & 75.5 & 64.6 & 18.5 & 24.5 \\
\hline GR & 74.4 & 15.5 & 46.3 & 25.6 \\
\hline IR & 68.8 & 47.7 & 32.7 & 31.2 \\
\hline IS & 61.0 & 49.3 & 36.6 & 39.0 \\
\hline IT & 71.4 & 43.4 & 47.0 & 28.6 \\
\hline JP & 68.7 & 37.0 & 22.7 & 31.3 \\
\hline KO & 59.1 & 59.0 & 57.4 & 40.9 \\
\hline LT & 56.9 & 41.6 & 40.4 & 43.1 \\
\hline NL & 68.1 & 70.6 & 22.9 & 31.8 \\
\hline NO & 81.1 & 79.1 & 13.5 & 18.9 \\
\hline $\mathrm{NZ}$ & 75.2 & 59.3 & 25.9 & 24.8 \\
\hline $\mathrm{PO}$ & 53.3 & 31.5 & 32.3 & 46.6 \\
\hline RU & 56.6 & 0.0 & 0.0 & 43.6 \\
\hline SE & 72.5 & 61.2 & 27.9 & 27.5 \\
\hline SG & 71.4 & 64.1 & 25.3 & 28.6 \\
\hline SL & 66.1 & 56.5 & 17.9 & 33.9 \\
\hline SR & 74.1 & 48.2 & 36.5 & 25.7 \\
\hline $\mathrm{TU}$ & 65.5 & 22.6 & 42.0 & 34.5 \\
\hline UK & 71.5 & 61.9 & 27.8 & 28.5 \\
\hline US & 68.0 & 51.9 & 36.9 & 32.0 \\
\hline
\end{tabular}

Source: PIAAC 2012 and 2014, own calculations. 
Table 9b: PIAAC-Germany and PIAAC-LN - Training is work related, sponsored by the employer, not sponsored or non-job related

PIAAC 2012

PIAAC-LN

Job-related NFE

67.90

69.32

Job-related NFE sponsored by employer

56.67

64.25

Job-related NFE not sponsored the employer

24.52

28.58

Only non-job-related NFE

32.10

30.68

Source: PIAAC 2012 and PIAAC-LN, own calculations. 
Table 9c. AES - Training is work related, sponsored by the employer, not sponsored or non-job related - by gender

\begin{tabular}{|c|c|c|c|c|c|c|c|c|c|c|c|c|c|c|c|c|c|c|c|c|}
\hline & Gender & AT & $\overline{\mathrm{BE}}$ & $\mathrm{CZ}$ & $\mathrm{DE}$ & DK & $\mathrm{EE}$ & ES & FI & FR b & IE & IT & LT & NL & $\mathrm{NO}$ & PL & $\mathrm{SE}$ & SI & SK & UK \\
\hline \multirow[t]{2}{*}{ Job-related NFE } & $\mathrm{F}$ & 72.1 & 87.1 & 76.8 & 78.2 & 82.3 & 83.9 & 77.4 & 74.6 & 69.1 & 84.5 & 62.1 & 87.5 & 83.2 & 90.6 & 82.1 & 78 & 63.9 & 88.7 & 78 \\
\hline & M & 80.9 & 91.4 & 88.4 & 87.2 & 83.7 & 83.1 & 87.2 & 84.7 & 80.8 & 89 & 77.3 & 88.3 & 89.9 & 93 & 89 & 82.4 & 75.2 & 92.3 & 85.9 \\
\hline \multirow[t]{2}{*}{ Job-related NFE sponsored by employer } & $\mathrm{F}$ & 67.7 & 84.2 & 72.9 & 76.2 & 84.1 & 77.8 & 69.5 & 74.1 & 69.9 & 46.2 & 56.2 & 82.4 & 82.8 & 89.8 & 74.9 & 78.7 & 70 & 87.4 & 79.3 \\
\hline & M & 76.5 & 85.5 & 84 & 84.5 & 83.6 & 79.8 & 79.1 & 85.7 & 81.2 & 47.2 & 75 & 86.2 & 89.5 & 92.6 & 84.5 & 81.9 & 77 & 88.7 & 79.8 \\
\hline \multirow[t]{2}{*}{ Job-related NFE not sponsored by employer } & $\mathrm{F}$ & 14.2 & 9.4 & 12 & 11 & 5.8 & 10.9 & 18.1 & 7.1 & 6.7 & 44.2 & 15.2 & 9 & 5.2 & 4.1 & 13.7 & 5.2 & 6.4 & 6.3 & 9.7 \\
\hline & M & 10.4 & 10.2 & 6.5 & 6.9 & 4.4 & 9.7 & 14.2 & 5.3 & 5.4 & 47.7 & 11.4 & 11.1 & 5 & 2.8 & 9.4 & 4.6 & 5.8 & 5.6 & 11.8 \\
\hline \multirow[t]{2}{*}{ Only non-job-related NFE } & $\mathrm{F}$ & 26.2 & 12.9 & 23.1 & 21.5 & 15.1 & 15.7 & 22.4 & 24.3 & 30.2 & 15.5 & 37.9 & 12.3 & 16.4 & 4 & 17.9 & 21.8 & 36.1 & 11.3 & 19.4 \\
\hline & M & 18.5 & 8.6 & 11.5 & 12.6 & 12.4 & 16.9 & 12.5 & 14.2 & 17.4 & 11 & 22.7 & 11.7 & 9.6 & 2.3 & 11 & 17.2 & 24.8 & 7.7 & 11.4 \\
\hline \multirow[t]{2}{*}{ No answer } & $\mathrm{F}$ & & & & & 2.6 & & & 1 & 0.7 & & & & & 5.4 & & & & & 2.6 \\
\hline & $\mathrm{M}$ & & & & & 3.9 & & & & 1.8 & & & & & 4.6 & & & & & \\
\hline
\end{tabular}

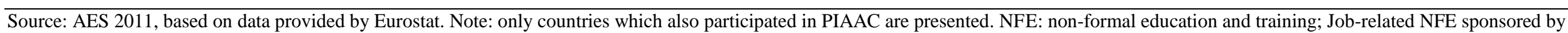
employer only includes employees 
7.2.8 Barriers to training participation by gender

Table 10a: PIAAC - Barriers to education and training by gender and country

\begin{tabular}{|c|c|c|c|c|c|c|c|c|}
\hline & & $\begin{array}{l}\text { I did not have the } \\
\text { prerequisites }\end{array}$ & & $\begin{array}{l}\text { Education or training was } \\
\text { too expensive/I could not } \\
\text { afford it }\end{array}$ & Lack of employer's support & I was too busy at work & $\begin{array}{l}\text { The course or programme } \\
\text { was offered at an } \\
\text { inconvenient time or place }\end{array}$ & $\begin{array}{l}\text { Something unexpected } \\
\text { came up that prevented me } \\
\text { from taking education or } \\
\text { training }\end{array}$ \\
\hline \multirow[t]{2}{*}{ AT } & Male & & 2.08 & 11.28 & 5.04 & 51.63 & 20.18 & 9.79 \\
\hline & Female & & 3.15 & 17.32 & 3.15 & 44.88 & 22.31 & 9.19 \\
\hline \multirow[t]{2}{*}{$\mathrm{BE}$} & Male & & 1.5 & 6.77 & 8.65 & 46.99 & 30.83 & 5.26 \\
\hline & Female & & 4.17 & 9.47 & 7.95 & 44.32 & 28.41 & 5.68 \\
\hline $\mathrm{CA}$ & $\begin{array}{l}\text { Male } \\
\text { Female }\end{array}$ & & & & & & & \\
\hline \multirow[t]{2}{*}{ CL } & Male & & 7.82 & 20.48 & 11.36 & 35.57 & 17.32 & 7.45 \\
\hline & Female & & 9.44 & 29.6 & 6.08 & 28 & 16.64 & 10.08 \\
\hline \multirow[t]{2}{*}{$\mathrm{CZ}$} & Male & & 4.89 & 14.37 & 10.34 & 50.57 & 13.22 & 6.32 \\
\hline & Female & & 6.97 & 26.97 & 11.01 & 29.89 & 13.93 & 11.24 \\
\hline \multirow[t]{2}{*}{$\mathrm{DE}$} & Male & & 3.3 & 10.1 & 12.82 & 53.01 & 17.86 & 2.91 \\
\hline & Female & & 2.09 & 18.41 & 14.8 & 35.67 & 24.67 & 4.36 \\
\hline \multirow[t]{2}{*}{ DK } & Male & & 4.23 & 15.32 & 14.93 & 44.91 & 15.19 & 5.28 \\
\hline & Female & & 3.37 & 20.55 & 23.32 & 29.21 & 15.75 & 7.69 \\
\hline \multirow[t]{2}{*}{$\mathrm{EE}$} & Male & & 5.98 & 18.75 & 8.11 & 43.35 & 19.15 & 4.65 \\
\hline & Female & & 4.04 & 29.26 & 8.87 & 30.25 & 24.24 & 3.35 \\
\hline \multirow[t]{2}{*}{ ES } & Male & & 10.11 & 14.5 & 5.53 & 50.76 & 15.08 & 3.82 \\
\hline & Female & & 9.8 & 20.59 & 2.75 & 43.92 & 18.82 & 4.12 \\
\hline \multirow[t]{2}{*}{ FI } & Male & & 4.39 & 5.65 & 11.51 & 44.77 & 29.5 & 4.18 \\
\hline & Female & & 3.77 & 11.16 & 13.05 & 34.59 & 32.55 & 4.72 \\
\hline \multirow[t]{2}{*}{ FR } & Male & & 4.25 & 22.75 & 24 & 39.75 & 4.75 & 4.5 \\
\hline & Female & & 4.95 & 28.77 & 26.89 & 26.89 & 6.6 & 5.9 \\
\hline \multirow[t]{2}{*}{ GR } & Male & & 8.63 & 26.9 & 4.57 & 34.01 & 19.29 & 6.6 \\
\hline & Female & & 4.85 & 50.61 & 0.91 & 15.76 & 22.12 & 5.76 \\
\hline \multirow[t]{2}{*}{ IL } & Male & & 2.55 & 28.54 & 4.41 & 45.24 & 17.17 & 2.09 \\
\hline & Female & & 5.73 & 39.91 & 5.5 & 28.9 & 16.97 & 2.98 \\
\hline \multirow[t]{2}{*}{ IR } & Male & & 7.55 & 27.36 & 7.92 & 36.42 & 16.04 & 4.72 \\
\hline & Female & & 4.65 & 34.88 & 5.58 & 28.53 & 18.29 & 8.06 \\
\hline \multirow[t]{2}{*}{ IT } & Male & & 1.62 & 16.19 & 3.24 & 65.99 & 8.1 & 4.86 \\
\hline & Female & & 3.91 & 26.33 & 5.69 & 50.89 & 8.19 & 4.98 \\
\hline JP & Male & & 4.91 & 8.53 & 1.03 & 51.94 & 32.56 & 1.03 \\
\hline
\end{tabular}




\begin{tabular}{|c|c|c|c|c|c|c|c|}
\hline & & $\begin{array}{l}\text { I did not have the } \\
\text { prerequisites }\end{array}$ & $\begin{array}{l}\text { Education or training was } \\
\text { too expensive/I could not } \\
\text { afford it }\end{array}$ & Lack of employer's support & I was too busy at work & $\begin{array}{l}\text { The course or programme } \\
\text { was offered at an } \\
\text { inconvenient time or place }\end{array}$ & $\begin{array}{l}\text { Something unexpected } \\
\text { came up that prevented me } \\
\text { from taking education or } \\
\text { training }\end{array}$ \\
\hline & Female & 4.85 & 15.63 & 0.54 & 42.05 & 34.77 & 2.16 \\
\hline \multirow{2}{*}{ KO } & Male & 4.26 & 9.05 & 1.46 & 65.91 & 17.31 & 2 \\
\hline & Female & 2.6 & 21.33 & 0.68 & 44.58 & 25.96 & 4.85 \\
\hline \multirow[t]{2}{*}{ LT } & Male & 3.02 & 20.6 & 12.06 & 46.73 & 11.56 & 6.03 \\
\hline & Female & 0.87 & 32.47 & 7.14 & 35.28 & 18.83 & 5.41 \\
\hline \multirow[t]{2}{*}{ NL } & Male & 2.08 & 16.41 & 11.46 & 51.56 & 10.42 & 8.07 \\
\hline & Female & 1.74 & 20.06 & 14.24 & 35.47 & 16.86 & 11.63 \\
\hline \multirow[t]{2}{*}{ NO } & Male & 4.47 & 9.62 & 12.75 & 51.01 & 14.99 & 7.16 \\
\hline & Female & 4.08 & 15.05 & 20.66 & 35.97 & 15.56 & 8.67 \\
\hline \multirow[t]{2}{*}{ NZ } & Male & 3.73 & 17.83 & 10.86 & 44.57 & 15.88 & 6.97 \\
\hline & Female & 3.71 & 25.26 & 8.92 & 38.82 & 16.57 & 6.72 \\
\hline \multirow[t]{2}{*}{ PL } & Male & 8.13 & 24.15 & 8.35 & 20.77 & 28.44 & 10.16 \\
\hline & Female & 7.16 & 35.39 & 6.96 & 10.93 & 31.01 & 8.55 \\
\hline \multirow[t]{2}{*}{ RU } & Male & 4.27 & 23.93 & 3.42 & 26.5 & 35.9 & 5.98 \\
\hline & Female & 3.23 & 29.03 & 7.53 & 33.33 & 20.79 & 6.09 \\
\hline \multirow[t]{2}{*}{ SE } & Male & 5.84 & 14.72 & 9.09 & 44.16 & 19.26 & 6.93 \\
\hline & Female & 5.8 & 19.64 & 14.96 & 34.6 & 18.08 & 6.7 \\
\hline \multirow[t]{2}{*}{ SG } & Male & 2.76 & 17.87 & 7.75 & 53.48 & 13.53 & 4.6 \\
\hline & Female & 3.52 & 21.56 & 7.95 & 41.13 & 19.27 & 6.57 \\
\hline \multirow[t]{2}{*}{ SI } & Male & 11.8 & 21.97 & 10.49 & 24.59 & 23.28 & 7.87 \\
\hline & Female & 12.22 & 37.78 & 8.6 & 15.38 & 19.46 & 6.56 \\
\hline \multirow[t]{2}{*}{ SK } & Male & 2.34 & 16.37 & 12.87 & 48.54 & 14.04 & 5.85 \\
\hline & Female & 4.35 & 24.15 & 14.49 & 35.27 & 15.46 & 6.28 \\
\hline \multirow[t]{2}{*}{ TU } & Male & 4.98 & 12.44 & 5.47 & 48.26 & 25.37 & 3.48 \\
\hline & Female & 6.02 & 21.05 & 3.76 & 27.07 & 32.33 & 9.77 \\
\hline \multirow[t]{2}{*}{ UK } & Male & 2.13 & 22.62 & 11.48 & 45.25 & 13.61 & 4.92 \\
\hline & Female & 3.04 & 31.08 & 10.71 & 32.54 & 16.67 & 5.95 \\
\hline \multirow[t]{2}{*}{ US } & Male & 3.25 & 27.85 & 5.79 & 38.7 & 18.99 & 5.24 \\
\hline & Female & 2.74 & 36.39 & 5.34 & 30.92 & 16.01 & 8.62 \\
\hline
\end{tabular}




\begin{tabular}{|c|c|c|}
\hline & Male & Female \\
\hline There was no suitable training available & 22.34 & 18.17 \\
\hline The course or programme was offered at an inconvenient time or place & 2.59 & 2.35 \\
\hline My work responsibilites did not leave time for training & 14.99 & 6.8 \\
\hline My family reponsibilites did not leave time for training & 1.36 & 10.85 \\
\hline Lack of employer's support & 5.31 & 4.97 \\
\hline Training would not have increased employment opportunities & 6.27 & 6.41 \\
\hline Training would have meant costs/pay cuts & 1.77 & 2.48 \\
\hline Lack of confidence & 0.41 & 0.26 \\
\hline I did not have the prerequisites & 2.86 & 2.48 \\
\hline At my age training is not worthwhile & 5.18 & 4.71 \\
\hline I did not know enough about training opportunities & 1.63 & 1.83 \\
\hline I was not interested in training & 17.98 & 19.61 \\
\hline Another reason & 17.3 & 19.08 \\
\hline
\end{tabular}


Table 11: AES - Barriers to non-formal training by gender

\begin{tabular}{|c|c|c|c|c|c|c|c|c|c|c|c|c|c|c|c|}
\hline \multirow[b]{3}{*}{ Belgium } & \multicolumn{3}{|c|}{$\begin{array}{l}\text { Training takes place at a too } \\
\text { distant place }\end{array}$} & \multicolumn{3}{|c|}{$\begin{array}{l}\text { Health problems or age not } \\
\text { adequate for the training }\end{array}$} & \multicolumn{3}{|c|}{$\begin{array}{l}\text { No suitable education or } \\
\text { training activity (offer) }\end{array}$} & \multicolumn{3}{|c|}{ Other personal reasons } & \multicolumn{3}{|c|}{$\begin{array}{l}\text { No access to a computer or } \\
\text { internet (for distance learning) }\end{array}$} \\
\hline & Total & Female & Male & Total & Female & Male & Total & Female & Male & Total & Female & Male & Total & Female & Male \\
\hline & 3.6 & 4.2 & 3.0 & 6.4 & 7.6 & 5.2 & 2.9 & 2.8 & 3.1 & 3.9 & 4.3 & 3.4 & 0.5 & : & : \\
\hline Czech Republic & 3.7 & 4.1 & 3.4 & 7.1 & 8.0 & 6.3 & 7.9 & 6.9 & 8.9 & 16.3 & 15.2 & 17.4 & 1.2 & 1.2 & 1.1 \\
\hline Denmark & 2.2 & 2.9 & 1.5 & 7.0 & 8.9 & 5.2 & 13.0 & 12.7 & 13.3 & 5.5 & 6.0 & 5.0 & $:$ & : & $:$ \\
\hline Germany & 5.6 & 6.8 & 4.3 & 12.1 & 13.2 & 11.0 & 10.0 & 10.4 & 9.6 & 19.0 & 20.4 & 17.6 & 1.8 & 1.8 & 1.8 \\
\hline Estonia & 14.0 & 14.0 & 14.0 & 16.3 & 15.9 & 16.8 & 15.4 & 14.3 & 16.6 & 15.9 & 14.3 & 17.7 & 2.8 & 2.4 & 3.4 \\
\hline Ireland & 2.4 & 2.5 & 2.3 & 3.1 & 2.6 & 3.7 & 2.7 & 2.0 & 3.5 & 4.8 & 4.6 & 5.0 & 0.8 & 0.7 & 0.9 \\
\hline Spain & 2.3 & 2.3 & 2.4 & 5.6 & 6.2 & 5.0 & 4.7 & 4.5 & 5.0 & 21.6 & 20.0 & 23.1 & 0.6 & 0.5 & 0.8 \\
\hline France & 6.3 & 7.7 & 4.8 & 5.1 & 6.3 & 3.9 & 9.8 & 10.3 & 9.2 & 5.8 & 6.8 & 4.8 & 1.9 & 2.0 & 1.8 \\
\hline Italy & 10.3 & 12.0 & 8.6 & 8.7 & 10.2 & 7.2 & 13.9 & 13.2 & 14.7 & 17.0 & 17.7 & 16.3 & 3.0 & 3.2 & 2.9 \\
\hline Lithuania & 3.9 & 4.5 & 3.3 & 14.3 & 15.1 & 13.3 & 2.8 & 2.6 & 3.0 & 16.4 & 18.3 & 14.3 & 1.3 & 1.0 & 1.5 \\
\hline Netherlands & 11.7 & 13.0 & 10.3 & 16.2 & 18.8 & 13.6 & 15.7 & 16.1 & 15.3 & 19.9 & 22.8 & 17.0 & 2.6 & 3.4 & $:$ \\
\hline Austria & 8.0 & 8.7 & 7.2 & 5.2 & 5.6 & 4.8 & 5.3 & 5.5 & 5.1 & 4.9 & 5.6 & 4.3 & 1.6 & 1.7 & 1.4 \\
\hline Poland & 2.9 & 3.3 & 2.4 & 11.6 & 12.4 & 10.9 & 5.7 & 5.2 & 6.2 & 13.6 & 14.3 & 12.8 & 0.6 & 0.6 & 0.5 \\
\hline Slovenia & 4.2 & 4.6 & 3.9 & 6.9 & 7.2 & 6.6 & 6.8 & 6.4 & 7.3 & 27.4 & 28.8 & 26.2 & : & : & $:$ \\
\hline Slovakia & 1.4 & 1.4 & 1.4 & 6.2 & 6.2 & 6.2 & 2.0 & 2.3 & 1.6 & 4.6 & 4.4 & 4.7 & 0.5 & : & $:$ \\
\hline Finland & 15.9 & 18.3 & 13.5 & 12.8 & 14.3 & 11.3 & 13.5 & 14.4 & 12.6 & 12.1 & 13.5 & 10.6 & 1.8 & 2.2 & 1.5 \\
\hline Sweden & 7.9 & 9.3 & 6.5 & 8.1 & 10.9 & 5.4 & 9.2 & 8.9 & 9.6 & 26.0 & 28.1 & 24.0 & $:$ & $:$ & $:$ \\
\hline United Kingdom & : & : & : & : & : & : & $:$ & $:$ & : & : & $:$ & : & : & : & $:$ \\
\hline Norway & 9.0 & 10.4 & 7.8 & 6.7 & 8.9 & 4.6 & 8.1 & 9.1 & 7.1 & 6.1 & 6.9 & 5.3 & 2.2 & 2.7 & 1.7 \\
\hline
\end{tabular}

Source: AES 2011, based on data provided by Eurostat. Note: only countries which also participated in PIAAC are presented. 
Table 11: AES - Barriers to non-formal training by gender - continued

\begin{tabular}{|c|c|c|c|c|c|c|c|c|c|c|c|c|c|c|c|c|c|c|}
\hline & \multicolumn{3}{|c|}{$\begin{array}{l}\text { No need for (further) } \\
\text { education and training }\end{array}$} & \multicolumn{3}{|c|}{ Lack of prerequisites } & \multicolumn{3}{|c|}{ Cost too high } & \multicolumn{3}{|c|}{$\begin{array}{l}\text { Lack of employer's support } \\
\text { or public services support }\end{array}$} & \multicolumn{3}{|c|}{$\begin{array}{l}\text { Conflict with work schedule } \\
\text { or training organised at } \\
\text { inconvenient time }\end{array}$} & \multicolumn{3}{|c|}{ Family responsibilities } \\
\hline & Total & Female & Male & Total & Female & Male & Total & Female & Male & Total & Female & Male & Total & Female & Male & Total & Female & Male \\
\hline $\begin{array}{l}\text { Belgium } \\
\text { Czech }\end{array}$ & 43.7 & 41.6 & 45.9 & 2.6 & 2.5 & 2.7 & 4.7 & 5.0 & 4.5 & 4.0 & 3.2 & 4.8 & 13.0 & 12.1 & 13.9 & 10.3 & 13.7 & 6.8 \\
\hline Republic & 41.6 & 37.1 & 45.9 & 2.1 & 1.9 & 2.3 & 7.6 & 8.7 & 6.5 & 4.9 & 4.5 & 5.2 & 11.1 & 9.7 & 12.5 & 22.1 & 31.0 & 13.3 \\
\hline Denmark & 100.0 & 100.0 & 100.0 & 2.0 & 1.6 & 2.4 & 14.4 & 17.4 & 11.4 & 10.7 & 11.1 & 10.2 & 16.8 & 16.7 & 17.0 & 12.0 & 12.6 & 11.5 \\
\hline Germany & 76.4 & 77.0 & 75.7 & 7.0 & 8.0 & 5.9 & 13.3 & 14.6 & 11.9 & 10.6 & 10.1 & 11.2 & 21.2 & 17.9 & 24.5 & 23.0 & 30.9 & 15.3 \\
\hline Estonia & $:$ & : & $:$ & 1.4 & : & 1.7 & 22.0 & 27.1 & 16.4 & 4.8 & 4.9 & 4.7 & 24.0 & 23.3 & 24.9 & 14.6 & 18.5 & 10.3 \\
\hline Ireland & 6.0 & 4.3 & 7.9 & 3.1 & 2.2 & 4.0 & 8.8 & 8.7 & 8.9 & 2.0 & 1.4 & 2.6 & 6.7 & 5.4 & 8.0 & 28.4 & 37.4 & 18.8 \\
\hline Spain & 11.5 & 8.5 & 14.3 & 3.2 & 3.0 & 3.3 & 6.6 & 7.2 & 6.0 & 7.5 & 7.0 & 7.9 & 20.5 & 17.7 & 23.3 & 30.7 & 39.4 & 22.1 \\
\hline France & 78.6 & 77.1 & 80.1 & 4.5 & 5.1 & 3.9 & 11.6 & 13.3 & 9.9 & 14.1 & 14.6 & 13.6 & 15.7 & 16.2 & 15.2 & 6.5 & 9.6 & 3.3 \\
\hline Italy & 14.8 & 12.2 & 17.2 & 5.1 & 5.4 & 4.8 & 22.2 & 24.9 & 19.4 & 4.8 & 3.7 & 6.0 & 25.0 & 20.0 & 30.1 & 31.8 & 41.3 & 22.0 \\
\hline Lithuania & 68.4 & 62.1 & 74.7 & 4.3 & 3.3 & 5.5 & 19.0 & 22.0 & 15.8 & 2.0 & 2.5 & 1.5 & 20.0 & 21.1 & 18.8 & 9.4 & 13.2 & 5.2 \\
\hline Netherlands & 51.9 & 48.9 & 54.8 & 4.3 & 4.9 & 3.6 & 19.5 & 24.4 & 14.7 & 12.0 & 11.7 & 12.3 & 28.4 & 28.3 & 28.5 & 37.3 & 46.8 & 27.8 \\
\hline Austria & $:$ & $:$ & : & 3.0 & 3.3 & 2.7 & 7.4 & 8.3 & 6.5 & 5.1 & 5.0 & 5.1 & 12.2 & 12.9 & 11.5 & 13.2 & 17.9 & 8.5 \\
\hline Poland & 60.1 & 56.1 & 63.8 & 1.8 & 1.6 & 2.0 & 15.5 & 17.3 & 13.6 & 5.2 & 4.5 & 5.8 & 11.8 & 10.3 & 13.3 & 21.6 & 28.7 & 14.4 \\
\hline Slovenia & 61.8 & 56.2 & 66.5 & 1.4 & 1.3 & 1.4 & 12.6 & 15.2 & 10.2 & 3.0 & 3.2 & 2.9 & 13.0 & 12.8 & 13.3 & 16.1 & 19.9 & 12.6 \\
\hline Slovakia & 30.0 & 27.0 & 33.1 & 0.7 & : & : & 4.7 & 5.0 & 4.4 & 1.8 & 1.6 & 1.9 & 4.9 & 4.3 & 5.5 & 6.0 & 8.1 & 3.9 \\
\hline Finland & 39.8 & 36.6 & 42.6 & 4.7 & 5.2 & 4.3 & 11.1 & 14.1 & 8.1 & 10.6 & 11.4 & 9.7 & 31.1 & 31.6 & 30.6 & 21.7 & 26.7 & 16.6 \\
\hline $\begin{array}{l}\text { Sweden } \\
\text { United }\end{array}$ & 63.3 & 57.8 & 68.1 & 4.2 & 4.8 & 3.6 & 10.2 & 12.1 & 8.3 & 8.6 & 10.1 & 7.2 & 16.6 & 16.9 & 16.3 & 18.4 & 22.3 & 14.5 \\
\hline Kingdom & : & $:$ & $:$ & & : & $:$ & & : & $:$ & & : & : & : & : & $:$ & & & : \\
\hline Norway & 34.5 & 30.3 & 38.5 & 6.8 & 6.9 & 6.8 & 9.4 & 11.4 & 7.6 & 9.6 & 11.1 & 8.3 & 17.1 & 16.8 & 17.4 & 14.2 & 17.3 & 11.3 \\
\hline
\end{tabular}

Source: AES 2011, based on data provided by Eurostat. Note: only countries which also participated in PIAAC are presented. 


\subsubsection{Looking for information on training activities}

Table 12a: PIAAC-LN - Looking for information about training activities

Did not look for information on learning possibilities
Looked for and found information on learning possibilities
Looked for but did not find any information on learning possibilities

\begin{tabular}{rrrr}
\hline 81.9 & 15.5 & 2.6 \\
\hline Source: PIAAC-LN, & 15.5 calculations.
\end{tabular}

Source: PIAAC-LN, own calculations.

Table 12b: AES - Looking for information about training activities by country

\begin{tabular}{|c|c|c|c|}
\hline & $\begin{array}{l}\text { Did not look for information on } \\
\text { learning possibilities }\end{array}$ & $\begin{array}{l}\text { Looked for and found information on } \\
\text { learning possibilities }\end{array}$ & $\begin{array}{l}\text { Looked for but did not find any } \\
\text { information on learning possibilities }\end{array}$ \\
\hline Austria & 77.4 & 21.0 & 1.6 \\
\hline Belgium & 81.2 & 17.2 & 1.6 \\
\hline Czech Republic & 80.4 & 18.6 & 1.0 \\
\hline Germany & 77.2 & 19.8 & 3.0 \\
\hline Denmark & 54.8 & 43.1 & 2.1 \\
\hline Estonia & 77.4 & 19.4 & 3.2 \\
\hline Spain & 74.4 & 21.3 & 4.3 \\
\hline Finland & 57.9 & 37.5 & 4.5 \\
\hline France & 73.2 & 24.6 & 2.2 \\
\hline Ireland & 78.5 & 19.7 & 1.8 \\
\hline Italy & 83.0 & 15.1 & 1.9 \\
\hline Lithuania & 87.5 & 11.2 & 1.3 \\
\hline Netherlands & 66.4 & 30.8 & 2.8 \\
\hline Norway & 74.3 & 23.9 & 1.8 \\
\hline Poland & 85.7 & 13.4 & 0.9 \\
\hline Sweden & 67.3 & 29.7 & 3.0 \\
\hline Slovenia & 79.2 & 19.3 & 1.5 \\
\hline Slovakia & 75.8 & 23.9 & : \\
\hline United Kingdom & 29.1 & 61.8 & 9.1 \\
\hline
\end{tabular}

Source: AES 2011, based on data provided by Eurostat. Note: only countries which also participated in PIAAC are presented.

Table 13a: PIAAC-LN - Sources of information for information search

Internet

Member of the family, neighbour, work colleague

Employer

Career guidance provider (including employment service office)

In program by training providers

An education or training institution (school, college, centre, university)

In other media (e.g. TV, radio, newspaper)

Other

Source: PIAAC-LN, own calculations. 
Table 13b: AES - Sources of information for information search

\begin{tabular}{|c|c|c|c|c|c|c|c|c|c|c|c|c|c|c|c|c|c|c|c|}
\hline & $\mathrm{AT}$ & $\mathrm{BE}$ & $\mathrm{CZ}$ & $\mathrm{DE}$ & DK & $\mathrm{EE}$ & ES & FI & FR & IE & IT & LT & $\mathrm{NL}$ & NO & PL & SE & SI & SK & UK \\
\hline Books & 13.8 & 3.9 & 22.3 & 23.1 & & & 9.3 & 3.2 & 5 & 16.1 & 3.7 & 15.9 & 3.6 & & 10 & 18.1 & 9.6 & 29.3 & 4.5 \\
\hline Employer & 34.9 & 23.1 & 26.3 & 35.3 & 36.6 & 8.4 & 5.5 & 29.3 & 46.9 & 6.7 & 7.9 & 9.9 & 26.3 & 17.8 & 16.4 & 20.8 & 24.6 & 30.5 & 41.2 \\
\hline $\begin{array}{l}\text { Member of the family, neighbour, } \\
\text { work colleague }\end{array}$ & 25.4 & 15.4 & 27.4 & 16.2 & 9.3 & 12.7 & 17.6 & 26.8 & 17 & 7.8 & 30.3 & 15.1 & 10.8 & 8.9 & 18.6 & 25.6 & 22.3 & 35.7 & 28.3 \\
\hline $\begin{array}{l}\text { Career guidance provider } \\
\text { (including employment service } \\
\text { office) }\end{array}$ & 25.8 & 14.5 & 7.9 & 4.0 & 18 & 4.6 & 12.4 & 8.1 & 17.8 & 13.4 & 11.3 & & 4.0 & 5.3 & 11.2 & 3.4 & 6.5 & 4.1 & 8.4 \\
\hline Internet & 66.3 & 69 & 79.2 & 68.8 & 59 & 84.3 & 81.8 & 89 & 56.4 & 79.6 & 71.1 & 90.4 & 78 & 80.4 & 82.3 & 88.6 & 68 & 80.5 & 18.8 \\
\hline $\begin{array}{l}\text { An education or training } \\
\text { institution (school, college, centre, } \\
\text { university) }\end{array}$ & 39.2 & 28 & 26.4 & 38.1 & 20 & 14.7 & 17.2 & 32.1 & 17.3 & 23.6 & 5.4 & 7.6 & 15.8 & 15 & 25.3 & 33.6 & 27.8 & 27.1 & 31.7 \\
\hline $\begin{array}{l}\text { Mass media (TV, radio, } \\
\text { newspaper, poster) }\end{array}$ & 16.5 & 8.5 & 24.2 & 8.3 & 3.9 & 9.0 & 6.6 & 29.3 & 4.3 & 16.8 & 11.1 & 10.5 & 7 & & 13 & 9.1 & 17.5 & 29.6 & 15.1 \\
\hline
\end{tabular}

Source: AES 2011, based on data provided by Eurostat. Note: only countries which also participated in PIAAC are presented. 


\subsection{Comprehensive educational pathways module}

$\begin{array}{ll}\text { B_Q01a } & \text { Are you currently working towards any kind of formal qualification? } \\ & 1 \text { Yes } \\ & 2 \text { No } \\ & \text { DK } \\ & \text { RF } \\ & \text { ROUTING: If }\left(B_{-} \text {Q01a }=1\right) \text {, go to B_Q01b else go to B_Q01e }\end{array}$

B_Q01b What is the level of the qualification you are currently studying for?

90

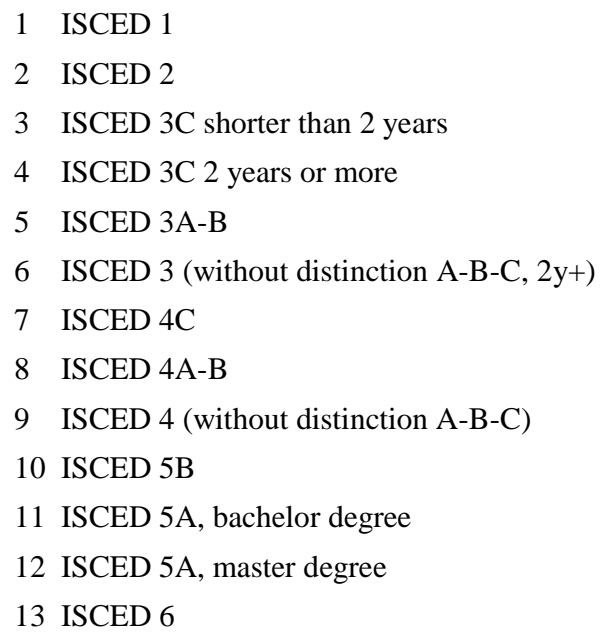

DK

$\mathrm{RF}$

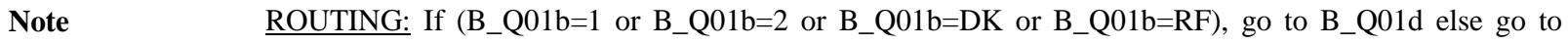


B_Q01c What is the area of study, emphasis or major for this qualification? If there is more than one, please

30

1 General programmes

2 Teacher training and education science

3 Humanities, languages and arts

4 Social sciences, business and law

5 Science, mathematics and

6 Engineering, manufacturing and construction

7 Agriculture and veterinary

8 Health and welfare

9 Services

DK

RF

Explanation May be adapted to the new classification, if applicable

B_Q01d In what year did you first start studying towards this qualification?

30

Year.... (4 digits)

DK

$\mathrm{RF}$

format Integer

Note (min:1962)(max:2022)

Note ROUTING: Go to B_Q01f

Explanation We don't necessarily need to ask this, but it may be useful in reconstructing educational pathways

B_Q01e In what year were you last enrolled in some form of formal education?

30

Year.... (4 digits)

DK

RF

format Integer

Note $\quad(\min : 1962)(\max : 2022)$ 
B_Q01f Looking at all the qualifications you have completed in your life, were all of these completed in \#CountryName?

15 Yes

2 No, some were obtained abroad

3 No, all were obtained abroad

DK

$\mathrm{RF}$

Note ROUTING: If $\left(B_{-}\right.$Q01f $=1$ or B_Q01f=DK or B_Q01f=RF), goto B_Q02a0,

Else goto B O01g

Explanation $\quad$ For the majority of respondents the entire educational pathway will have been followed in the target country. This simple question identifies respondents who have followed all or part of their education abroad. This allows a more tailored approach to educational pathways for these respondents.

\section{B_Q01g Were all your foreign qualifications completed in a single country?}

15 Yes

2 No, I completed qualifications in multiple foreign countries

DK

RF

Explanation For respondents who have followed all of their educational pathway in a single foreign country,

B_D01g Derived variable: ${ }^{\wedge}$ ForeignQual

If (B_Q01g=1 then ^ForeignQual='foreign qualifications'

Else if B_Q01g=2 or B_Q01g=DK or B_Q01g=RF then ${ }^{\wedge}$ ForeignQual='highest completed foreign qualification'

Else ${ }^{\wedge}$ ForeignQual='highest completed foreign qualification'

Explanation This dynamic text allows us to tailor the formulation of B_Q01h to the type of foreign pathways followed. 
4 \#Country 4

5 \#Country 5

6 \#Country 6

7 \#Country 7

8 \#Country 8

9 \#Country 9

10 \#Country 10

11 Other country

DK

RF

Note

ROUTING: If B_Q01h=11, go to B_S01h, else go to B_C01h

Explanation

This list should contain at least the countries for which an alternative educational classification option is provided. Using the timing data below we can determine the point at which the respondent entered the domestic education system. If required we could ask ALL countries in which foreign qualifications were obtained, for those who indicated that they completed qualifications in multiple foreign countries. It is however unclear what added value this would provide, if any.

B_S01h What country was that?

15

DK

$\mathrm{RF}$

Format String

Note (250 spaces) 
Else if (^B_Q01h="1") THEN goto B_Q02a1

Else if (^B_Q01h="2") THEN goto B_Q02a2

Else if (^B_Q01h="3") THEN goto B_Q02a3

Else if (^B_Q01h="4") THEN goto B_Q02a4

Else if (^B_Q01h="5") THEN goto B_Q02a5

Else if ( ${ }^{\wedge} B \_Q 01 h=" 6$ ") THEN goto B_Q02a6

Else if (^B_Q01h="7”) THEN goto B_Q02a7

Else if (^B_Q01h="8") THEN goto B_Q02a8

Else if (^B_Q01h="9") THEN goto B_Q02a9

Else if (^B_Q01h="10") THEN goto B_Q02a10

Else goto B_Q02a0

Explanation This routes respondents to the relevant version of the educational classification. Those who are currently in education, those who completed at least some of their education in the survey country, and those who completed all of their education in a foreign country for which no pre-adapted classification scheme and show card is available, are routed to the standard classification scheme and handed the standard show card. Only those who completed all of their education in a single one of the designated countries will be routed to an alternative classification scheme and handed the corresponding alternative show card.

B_Q02a(0-10) Which educational qualifications have you ever obtained? Please use this card. Please name all qualifications you have ever obtained.

180

1 No formal qualification or below ISCED 1

2 ISCED 1

3 ISCED 2

4 ISCED 3C shorter than 2 years

5 ISCED 3C 2 years or more

6 ISCED 3A-B

7 ISCED 3 (without distinction A-B-C, 2y+) )

8 ISCED 4C

9 ISCED 4A-B

10 ISCED 4 (without distinction A-B-C)

11 ISCED 5B

12 ISCED 5A, bachelor degree

13 ISCED 5A, master degree

14 ISCED 6

DK

RF

Explanation With this simple checkbox item we capture the entire education history in terms of qualifications obtained. Combined with timing data (below) we can derive a relatively complete picture of the educational pathway. NB: alternative versions of the response categories (B_Q02a1 through B_Q02a10) will be presented for those respondents who completed all of their education in a single designated foreign country. These respondents will be handed the corresponding alternative show card. All other respondents will be routed to the standard classification B_Q01a0, with corresponding standard show card. 
B_D02a1 Derived variable: Highest level of education

<Derivation collapses the multiple levels reported in B_Q02a into a single highest reported level>

1 No formal qualification or below ISCED 1

2 ISCED 1

3 ISCED 2

4 ISCED 3C shorter than 2 years

5 ISCED 3C 2 years or more

6 ISCED 3A-B

7 ISCED 3 (without distinction A-B-C, 2y+)

8 ISCED 4C

9 ISCED 4A-B

10 ISCED 4 (without distinction A-B-C)

11 ISCED 5B

12 ISCED 5A, bachelor degree

13 ISCED 5A, master degree

14 ISCED 6

DK

RF

Explanation By deriving this from the multiple answer item we remove the respondent's subjective perception from the measure. Countries will perhaps require some support in determining the ordering when multiple national qualifications nominally correspond to the same ISCED levels. For respondents who made use of the designated foreign classifications, conversion schemes will be provided by the consortium.

\section{B_D02a2 Derived variable: Highest level of education in three levels}

If (^B_D02a1="1" OR ^B_D02a1="2" OR ^B_D02a1="3" OR ^B_D02a1="4"), ^EDLEVEL3="1"

Explanation For respondents who made use of the designated foreign classifications, conversion schemes will be provided by the consortium. 
B_Q02b Which of your qualifications were completed in \#CountryName? Please mark all that apply.

\begin{tabular}{|c|c|}
\hline 60 & 1 None, all were completed abroad \\
\hline & 2 ISCED 1 \\
\hline & 3 ISCED 2 \\
\hline & 4 ISCED 3C shorter than 2 years ) \\
\hline & 5 ISCED 3 C 2 years or more \\
\hline & 6 ISCED 3A-B \\
\hline & 7 ISCED 3 (without distinction A-B-C, 2y+) \\
\hline & 8 ISCED 4C \\
\hline & 9 ISCED 4A-B \\
\hline & 10 ISCED 4 (without distinction A-B-C) \\
\hline & 11 ISCED 5B \\
\hline & 12 ISCED 5A, bachelor degree \\
\hline & 13 ISCED 5A, master degree \\
\hline & 14 ISCED 6 \\
\hline & DK \\
\hline & RF \\
\hline Explanation & $\begin{array}{l}\text { If possible, this checkbox item should be limited to responses checked in B_Q02a. This is only asked in } \\
\text { the case that some but not all qualifications were completed in a foreign country. Only the classification } \\
\text { for the target country is needed here. }\end{array}$ \\
\hline B_C02b & ROUTING: If (^B_D02a1= “2” or ${ }^{\wedge} B$ BD02a1= “3”) THEN goto ${ }^{\wedge} B \_Q 02 d$ \\
\hline & Else goto B_Q02c \\
\hline
\end{tabular}


B_Q02c

30

Note
What was the area of study, emphasis or major for your ${ }^{\wedge}$ HighestQual qualification? If there was more than one, please choose the one you consider most important.

If ${ }^{\wedge} \mathrm{B} \_$D $02 \mathrm{a} 1=2$ then ${ }^{\wedge}$ HighestQual='ISCED 1'

Else if ${ }^{\wedge}$ B_D02a1 $=3$ then ${ }^{\wedge}$ HighestQual='ISCED 2'

Else if ${ }^{\wedge}$ B_D02a1 $=4$ then ${ }^{\wedge}$ HighestQual='ISCED 3C shorter than 2 years'

Else if ${ }^{\wedge}$ B_D02a1 $=5$ then ${ }^{\wedge}$ HighestQual='ISCED 3C 2 years or more'

Else if ${ }^{\wedge}$ B_D02a1 $=6$ then ${ }^{\wedge}$ HighestQual='ISCED 3A-B'

Else if ${ }^{\wedge} \mathrm{B} \_$D02a1 $=7$ then ${ }^{\wedge}$ HighestQual='ISCED 3 (without distinction A-B-C, $2 \mathrm{y}^{+}$)'

Else if ${ }^{\wedge} \mathrm{B} \_$D02a1 $=8$ then ${ }^{\wedge}$ HighestQual='ISCED 4C'

Else if ${ }^{\wedge}$ B_D02a1 $=9$ then ${ }^{\wedge}$ HighestQual='ISCED 4A-B'

Else if ${ }^{\wedge}$ B_D02a1=10 then ${ }^{\wedge}$ HighestQual='ISCED 4 (without distinction A-B-C)'

Else if ${ }^{\wedge}$ B_D02a1=11 then ${ }^{\wedge}$ HighestQual='ISCED 5B'

Else if ${ }^{\wedge} \mathrm{B} \_\mathrm{D} 02 \mathrm{a} 1=12$ then ${ }^{\wedge}$ HighestQual='ISCED 5A, bachelor degree'

Else if ${ }^{\wedge}$ B_D02a1=13 then ^HighestQual='ISCED 5A, master degree'

Else if ${ }^{\wedge}$ B_D02a1=14 then ${ }^{\wedge}$ HighestQual='ISCED 6'

1 General programmes

2 Teacher training and education science

3 Humanities, languages and arts

4 Social sciences, business and law

5 Science, mathematics and

6 Engineering, manufacturing and construction

7 Agriculture and veterinary

8 Health and welfare

9 Services

DK

RF

B_Q02d I will now ask some questions about the time at which you completed different qualifications. What is the easiest way for you to report on this? Would it be ...

30

1 The year in which you completed each qualification

2 Your age at the time

DK

RF

Explanation If necessary we can use the same procedure as in cycle 1, i.e. asking "In what year or at what age ..." for each qualification. However, given the larger number of dates to be reported it is probably preferable to impose a simple choice in advance, similar to that used for reporting incomes. Interviewers should be trained to assist if necessary. 


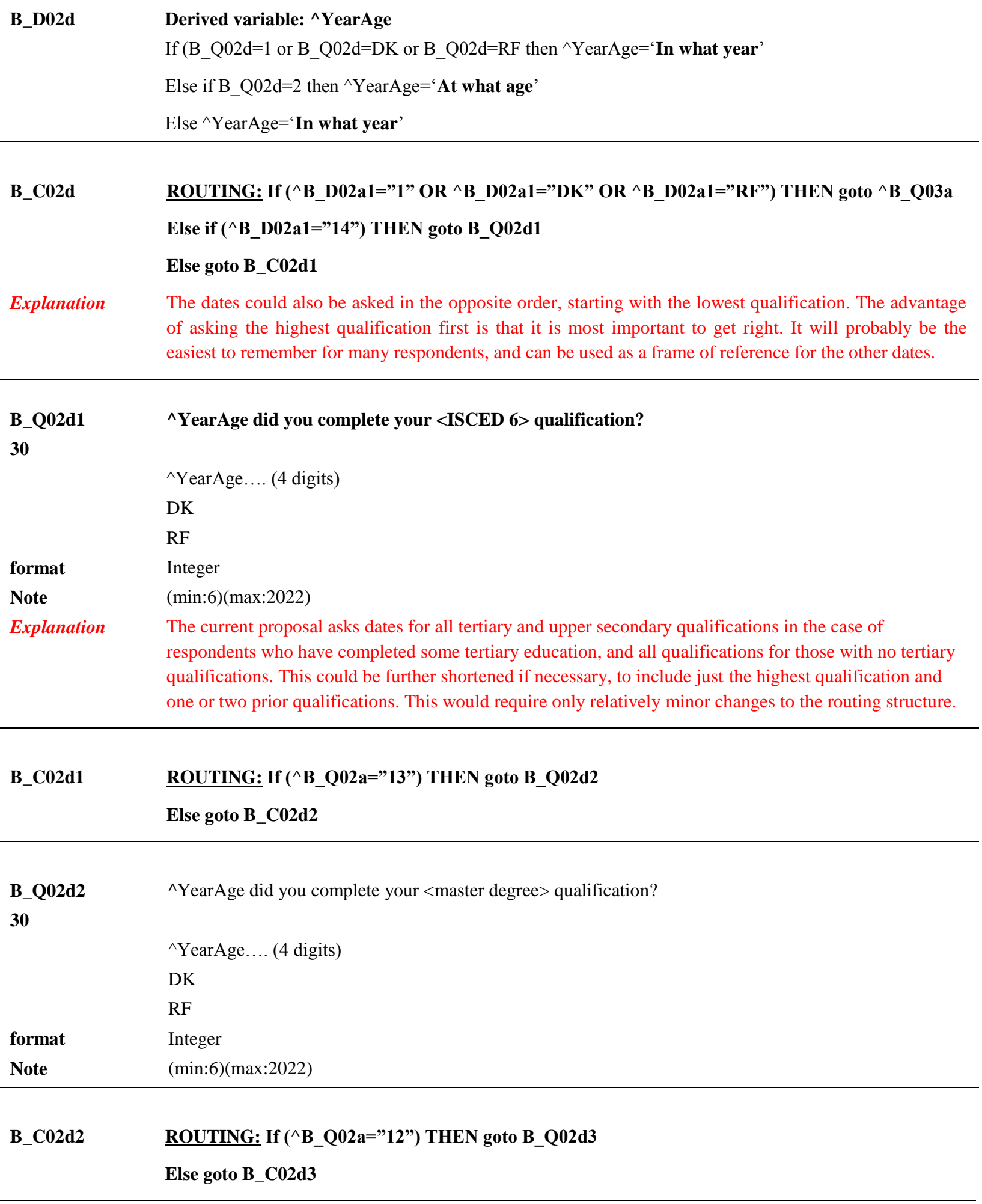


B_Q02d3 $\wedge$ YearAge did you complete your <bachelor degree> qualification?

30

${ }^{\wedge}$ YearAge.... (4 digits)

DK

$\mathrm{RF}$

format Integer

Note (min:6)(max:2022)

B_C02d3 ROUTING: If (^B_Q02a="11") THEN goto B_Q02d4

Else goto B_C02d4

B_Q02d4 $\wedge$ YearAge did you complete your <ISCED 5B > qualification?

30

$\wedge^{\wedge}$ YearAge.... (4 digits)

DK

$\begin{array}{ll} & \mathrm{RF} \\ \text { format } & \text { Integer }\end{array}$

Note $\quad(\min : 6)(\max : 2022)$

B_C02d4

Else goto B_C02d5

B_Q02d5 $\wedge$ YearAge did you complete your <ISCED 4 (without distinction A-B-C) > qualification?

30

$\wedge$ YearAge.... (4 digits)

DK

RF

format Integer

Note $\quad(\min : 6)(\max : 2022)$

B_C02d5 ROUTING: If (^B_Q02a="9") THEN goto B_Q02d6

Else goto B_C02d6

B_Q02d6 $\quad$ Y YearAge did you complete your $<$ ISCED 4A-B > qualification?

30

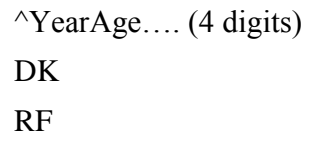




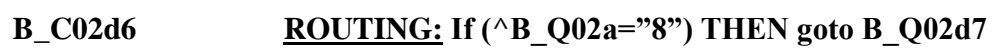

Else goto B_C02d7

B_Q02d7 $\wedge$ YearAge did you complete your <ISCED 4C> qualification?

30

${ }^{\wedge}$ YearAge.... (4 digits)

DK

RF

format Integer

Note $\quad(\min : 6)(\max : 2022)$

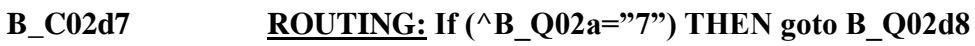

Else goto B_C02d8

B_Q02d8 $\wedge$ YearAge did you complete your <ISCED 3 (without distinction A-B-C, 2y+)> qualification?

$30 \quad \wedge$ YearAge.... (4 digits)

DK

RF

format Integer

Note $\quad(\min : 6)(\max : 2022)$

B_C02d8 ROUTING: If $\left({ }^{\wedge} B \_Q 02 a=" 6 "\right)$ THEN goto B_Q02d9

Else goto B_C02d9

B_Q02d9 $\wedge$ YearAge did you complete your $<$ ISCED 3A-B $>$ qualification?

30

${ }^{\wedge}$ YearAge.... (4 digits)

DK

RF

format Integer

Note (min:6)(max:2022)

B_C02d9 ROUTING: If (^B_Q02a="5") THEN goto B_Q02d10

Else goto B_C02d10 
B_Q02d10 $\wedge$ YearAge did you complete your <ISCED 3C 2 years or more > qualification?

30

${ }^{\wedge}$ YearAge.... (4 digits)

DK

RF

format Integer

Note $\quad(\min : 6)(\max : 2022)$

B_C02d10 $\underline{\text { ROUTING: If ( }}$ (B_Q02a="4") and B_D02a2 $=<2$ THEN goto B_Q02d11

Else goto B_C02d11

Explanation Completion dates for qualifications below upper secondary only asked for respondents who did not complete any tertiary education

B_Q02d11 $\wedge$ YearAge did you complete your <ISCED 3C shorter than 2 years $>$ qualification?

30

${ }^{\wedge}$ YearAge.... (4 digits)

DK

RF

format Integer

Note $\quad(\min : 6)(\max : 2022)$

B_C02d11 ROUTING: If (^B_Q02a="3") and B_D02a2 $=<2$ THEN goto B_Q02d12

Else goto B_C02d12

B_Q02d12 $\wedge$ YearAge did you complete your <ISCED 2> qualification?

30

${ }^{\wedge}$ YearAge.... (4 digits)

DK

RF

format Integer

Note $\quad(\min : 6)(\max : 2022)$

B_C02d12 ROUTING: If (^B_Q02a="2") and B_D02a2 $=<2$ THEN goto B_Q02d13

Else goto B_D02d13a

B_Q02d13 $\wedge$ YearAge did you complete your <ISCED 1> qualification?

30

${ }^{\wedge}$ YearAge.... (4 digits)

DK

RF

format Integer

Note (min:6)(max:2022) 
B_D02d13a Derived variable: Derived year of last completed education

${ }^{\wedge}$ YearCompl = Max(B_Q02d1, B_Q02d2, B_Q02d3, B_Q02d4, B_Q02d5, B_Q02d6, B_Q02d7, B_Q02d8, B_Q02d9, B_Q02d10, B_Q02d11, B_Q02d12, B_Q02d13)

B_D02d13b Derived variable: Derived level of last completed education

If ${ }^{\wedge} \mathrm{B} \_\mathrm{Q} 02 \mathrm{~d} 1=^{\wedge}$ YearCompl then ${ }^{\wedge}$ LevelCompl='ISCED 6 degree'

Else if ${ }^{\wedge}$ B_Q02d $2={ }^{\wedge}$ YearCompl then ${ }^{\wedge}$ LevelCompl='ISCED 5A, master degree'

Else if ${ }^{\wedge} \mathrm{B} \_\mathrm{Q} 02 \mathrm{~d} 3={ }^{\wedge}$ YearCompl then ${ }^{\wedge}$ LevelCompl='ISCED 5A, bachelor degree'

Else if ${ }^{\wedge} \mathrm{B} \_\mathrm{Q} 02 \mathrm{~d} 4={ }^{\wedge}$ YearCompl then ${ }^{\wedge}$ LevelCompl='ISCED 5B degree'

Else if ${ }^{\wedge} \mathrm{B} \_\mathrm{Q} 02 \mathrm{~d} 5={ }^{\wedge}$ YearCompl then ${ }^{\wedge}$ LevelCompl='ISCED 4 (without distinction A-B-C) degree'

Else if ${ }^{\wedge}$ B_Q02d6 $={ }^{\wedge}$ YearCompl then ${ }^{\wedge}$ LevelCompl='ISCED 4A-B degree'

Else if ${ }^{\wedge} \mathrm{B} \_\mathrm{Q} 02 \mathrm{~d} 7={ }^{\wedge}$ YearCompl then ${ }^{\wedge}$ LevelCompl='ISCED 4C degree'

Else if ${ }^{\wedge} \mathrm{B} \_\mathrm{Q} 02 \mathrm{~d} 8={ }^{\wedge}$ YearCompl then ${ }^{\wedge}$ LevelCompl='ISCED 3 (without distinction A-B-C, 2y+) degree'

Else if ${ }^{\wedge}$ B_Q02d9 $={ }^{\wedge}$ YearCompl then ${ }^{\wedge}$ LevelCompl='ISCED 3A-B degree'

Else if ${ }^{\wedge} \mathrm{B} \_\mathrm{Q} 02 \mathrm{~d} 10={ }^{\wedge}$ YearCompl then ${ }^{\wedge}$ LevelCompl='ISCED $3 \mathrm{C} 2$ years or more degree'

Else if ${ }^{\wedge} \mathrm{B} \_\mathrm{Q} 02 \mathrm{~d} 11=^{\wedge}$ YearCompl then ${ }^{\wedge}$ LevelCompl='ISCED 3C shorter than 2 years degree'

Else if ${ }^{\wedge} \mathrm{B} \_\mathrm{Q} 02 \mathrm{~d} 12={ }^{\wedge}$ YearCompl then ${ }^{\wedge}$ LevelCompl='ISCED 2 degree'

Else if ${ }^{\wedge} \mathrm{B} \_\mathrm{Q} 02 \mathrm{~d} 13={ }^{\wedge}$ YearCompl then ${ }^{\wedge}$ LevelCompl='ISCED 1 degree'

Explanation: $\quad$ The derived variable ${ }^{\wedge}$ LevelCompl needs to be formulated in such a way as to make sense when inserted into B_Q02e.

B_C02d13 ROUTING: If ${ }^{\wedge}$ YearCompl $<\wedge$ B_Q01e THEN goto B_Q02e

Else goto B_Q03a

Explanation: If the derived year of last completed education is earlier than that directly reported in B_Q01e, the respondent can be asked whether another qualification

\section{B_Q02e Was your ${ }^{\wedge}$ LevelCompl your last completed formal qualification?}

15

1 Yes

2 No

DK 


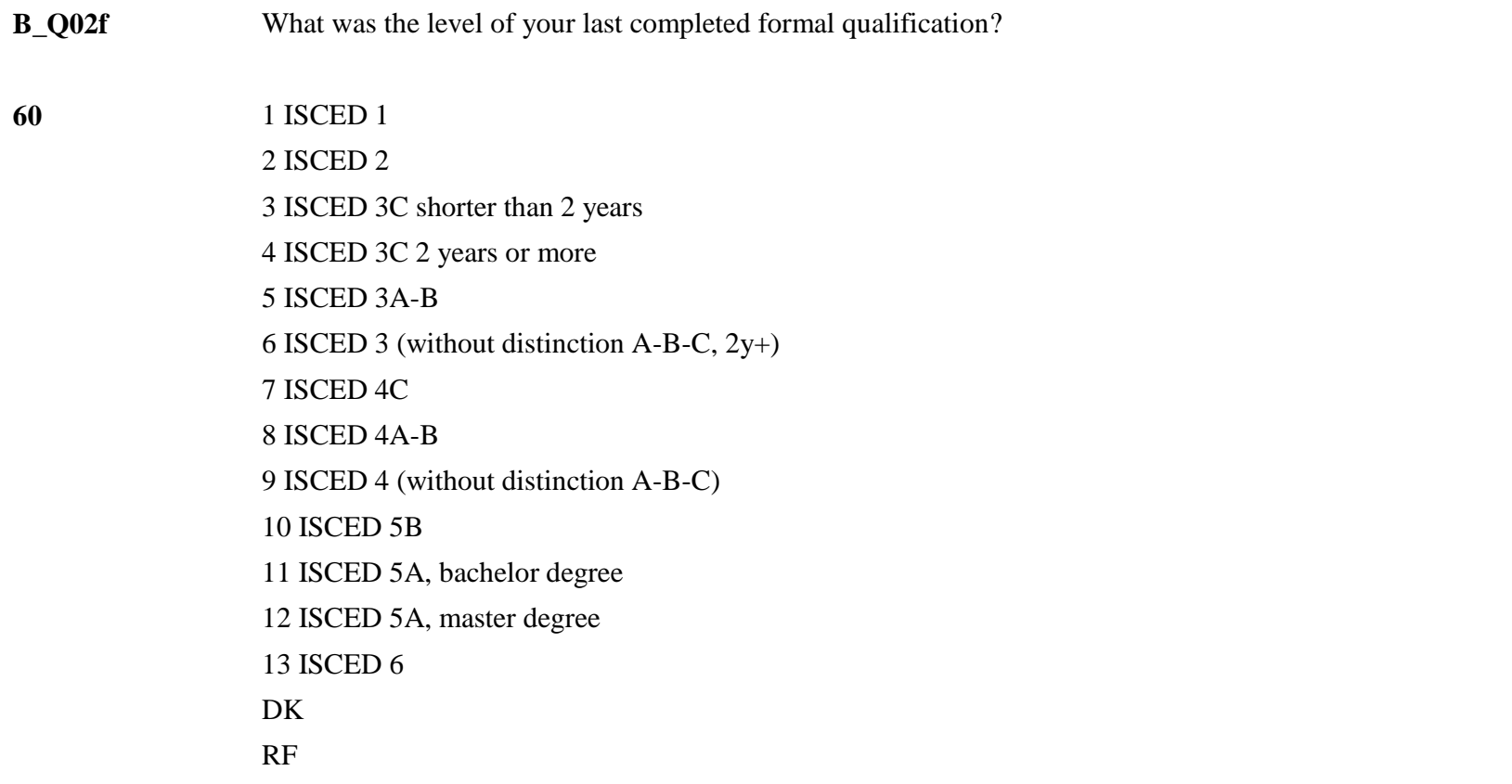

B_Q03a Did you ever start studying for any formal qualification, but leave before completing it?

$15 \quad 1$ Yes

2 No

DK

RF

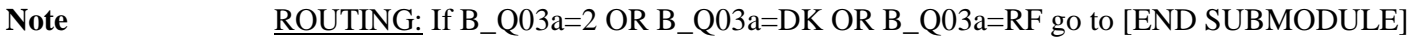


15

1 Yes

2 No

DK

RF

Note

ROUTING: If B_Q03b eq 1 THEN goto ${ }^{\wedge} \mathrm{B} \_\mathrm{Q} 03 \mathrm{c} 0$

Else if (^B_Q01h="1") THEN goto B_Q03c1

Else if (^B_Q01h=”2”) THEN goto B_Q03c2

Else if (^B_Q01h=”3”) THEN goto B_Q03c3

Else if (^B_Q01h=”4”) THEN goto B_Q03c4

Else if (^B_Q01h=”5") THEN goto B_Q03c5

Else if (^B_Q01h="6") THEN goto B_Q03c6

Else if (^B_Q01h=”7”) THEN goto B_Q03c7

Else if (^B_Q01h=" 8 ") THEN goto B_Q03c8

Else if (^B_Q01h="9”) THEN goto B_Q03c9

Else if (^B_Q01h="10”) THEN goto B_Q03c10

Else goto B_Q03c0

Explanation Respondents who have followed their entire educational pathway in one of the countries with a designated alternative foreign classification and show card will be asked to use this classification to report uncompleted education. Uncompleted education followed in the target country should however always be reported in terms of the standard classification for that country, even if the rest of the pathway was followed abroad.

B_Q03c(0-10) What was the level of the qualification you started studying for? If there was more than one, please report the one with the highest level.

\section{0}

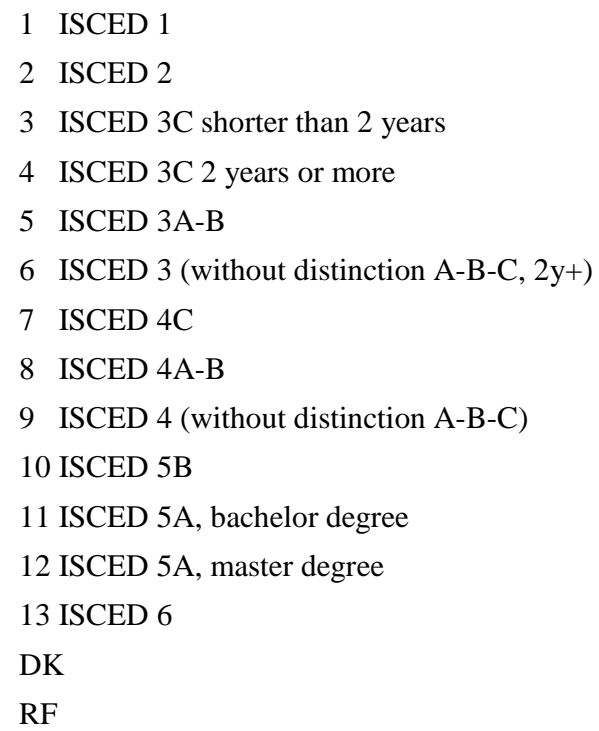

Explanation It would be possible to ask multiple uncompleted qualifications using the same checkbox approach as in B_Q02a, but the added value is expected to be minimal in that case. 
B_Q03d

15

${ }^{\wedge}$ YearAge.... (4 digits)

DK

RF

format

Integer

Note

(min:6)(max:2022) $\wedge$ YearAge did you stop studying for this qualification? 